\title{
Dissemination in Psychotherapy: The Case of Progress Monitoring Measures
}

\author{
Megan Knoll \\ Department of Educational and Counselling Psychology \\ McGill University, Montreal
}

May 2020

A thesis submitted to McGill University in partial fulfillment of the requirements of the degree of Doctor of Philosophy in Counselling Psychology

(C) Megan Knoll, 2020 


\section{Table of Contents}

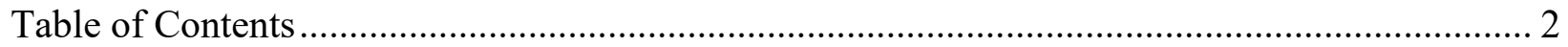

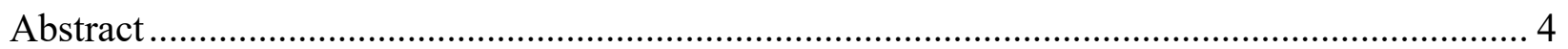

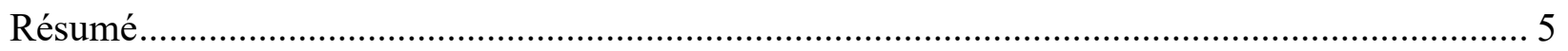

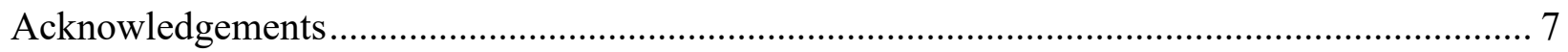

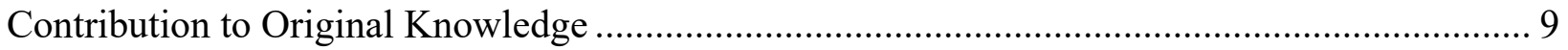

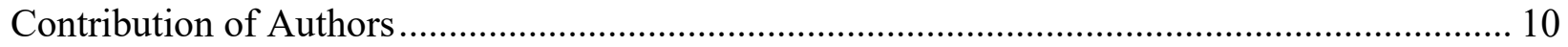

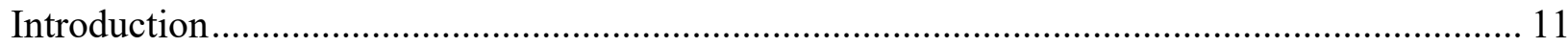

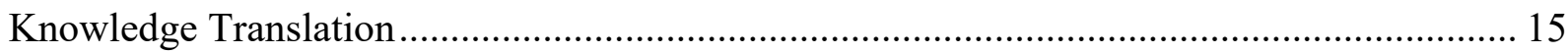

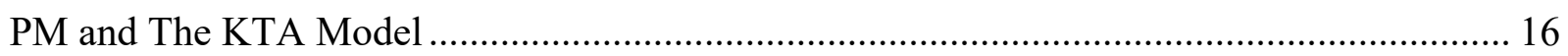

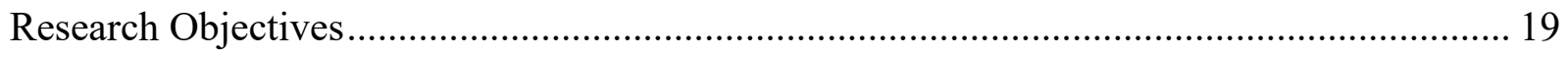

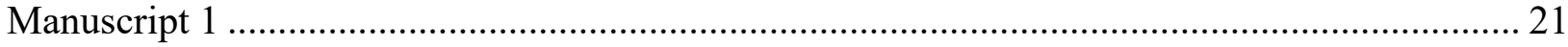

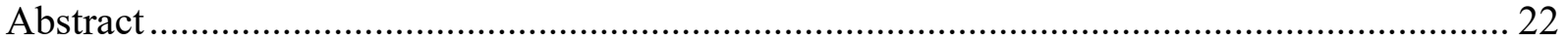

Dissemination in Psychotherapy: The Case of Progress Monitoring Measures ..................... 23

Innovation-Decision in Psychotherapy ........................................................................... 29

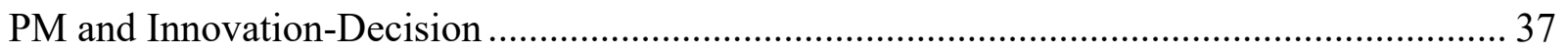

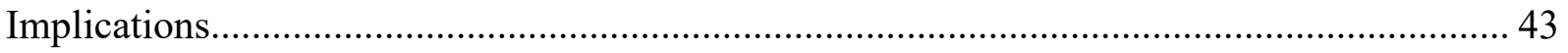

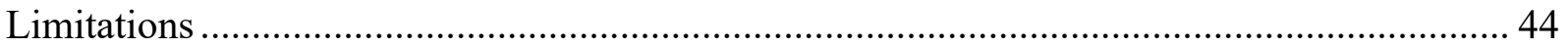

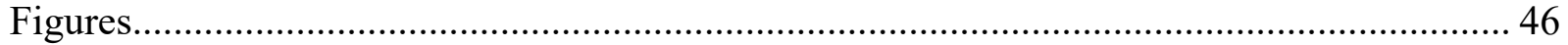

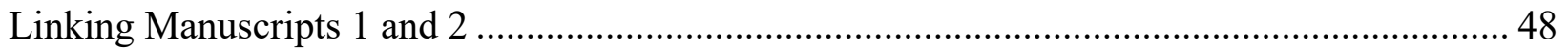

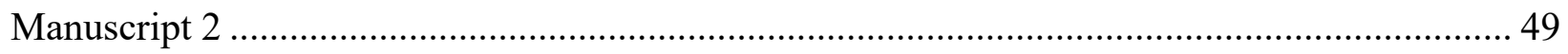

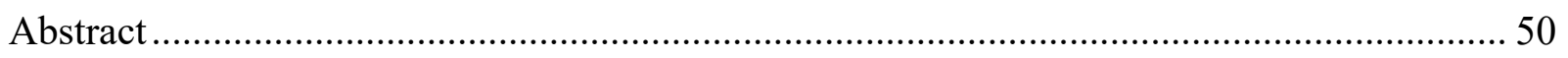

Closing the Practice-Research Gap: Development of the Innovation-Decision Scale ............ 51

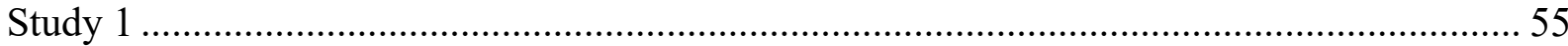

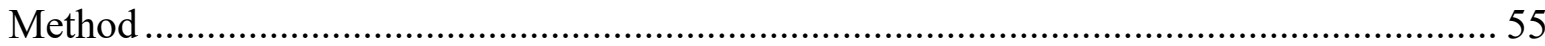

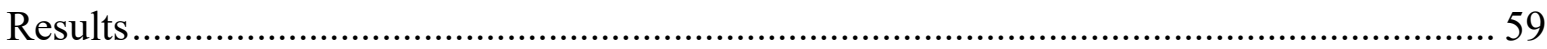

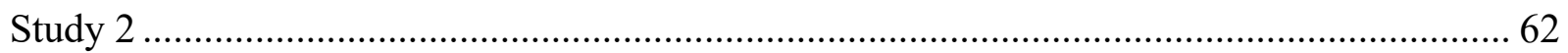

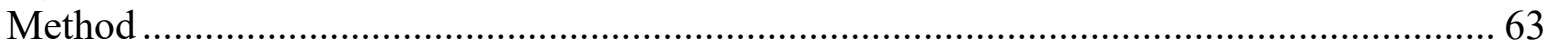

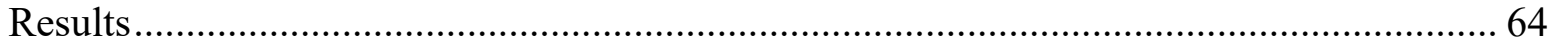

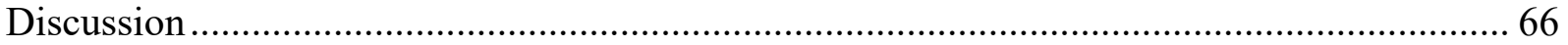

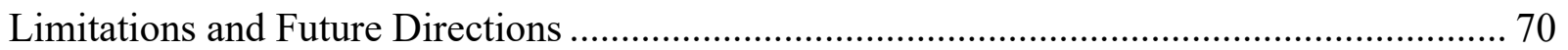

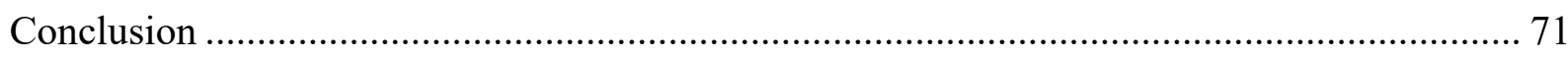

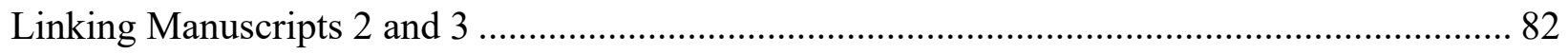




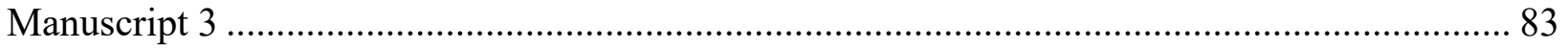

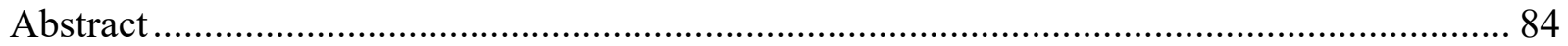

PsySuccess: Evaluation of a Dissemination Intervention ................................................... 85

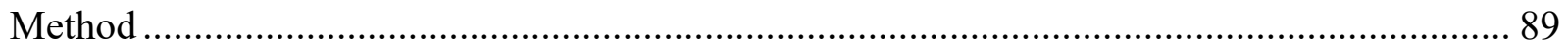

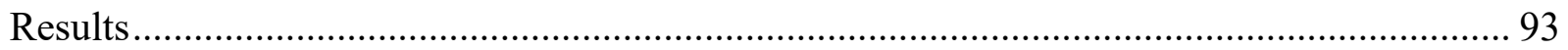

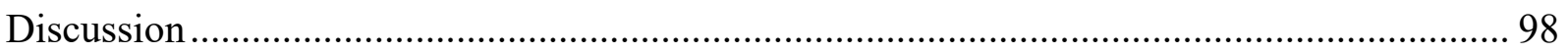

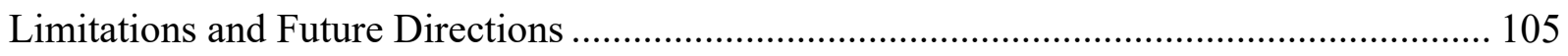

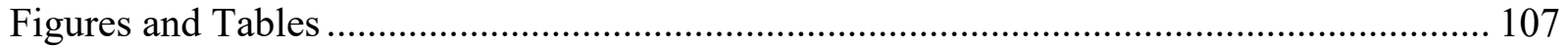

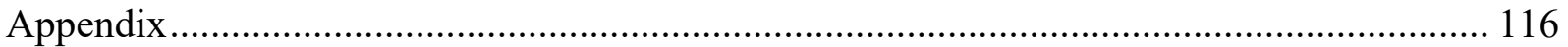

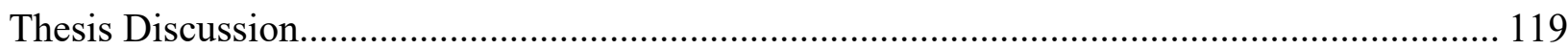

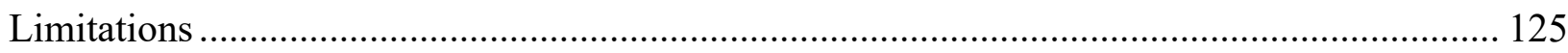

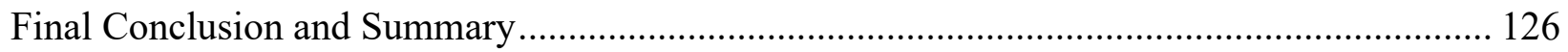

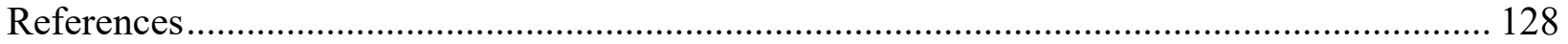




\begin{abstract}
The practice-research gap in psychotherapy limits the efficacy of practice and utility of research. The poor uptake of Progress Monitoring (PM) measures exemplifies this gap: despite PM's strong evidence base, most psychologists do not use the measures. In this thesis, the Knowledge-to-Action model was used to determine the next steps in bridging this gap. In doing so, a need for improved PM dissemination was identified.
\end{abstract}

Three questions were posed to improve PM dissemination: (1) what are the means by which innovations are disseminated in psychotherapy? (2) how can we measure the impact of a dissemination intervention? And (3) what makes a dissemination intervention effective? The answers to these questions were pursued through three manuscripts.

In Manuscript 1, the psychotherapy literature was reviewed and the strategies, facilitators and processes that may assist in the dissemination of an innovation were identified. In Manuscript 2, an instrument to assess dissemination interventions was developed and validated. In Manuscript 3, an intervention employing multiple dissemination strategies was evaluated and effective strategies were identified.

Overall, this thesis drew several conclusions regarding the process of dissemination. Firstly, low clinician engagement is as an important barrier to dissemination in psychotherapy and time effective interventions are proposed as a possible means of overcoming this barrier. Once clinicians are engaged, research that is succinct and digestible helps them to learn about PM. Certain forms of practical information are also useful; however, these resources may prove more effective when paired with experience. When it comes to improving attitudes and an intent to use PM, anecdotal information appears to be more useful. Implications of these results for the dissemination of PM and other psychotherapy innovations are discussed. 


\section{Résumé}

L'écart entre la recherche et la pratique clinique dans le domaine de la psychothérapie réduit l'efficacité de la pratique clinique et l'utilité de la recherche. La faible utilisation des mesures de suivi de progrès illustre cet écart : malgré la preuve à l'appui, la plupart des psychologues ne s'en servent pas. Dans cette thèse, le modèle « Knowledge-to-Action» a été employé pour déterminer les prochaines étapes pour combler l'écart entre la recherche et la pratique clinique. Ce faisant, un besoin pour une meilleure diffusion de ces mesures a été identifié.

Trois questions ont été posées pour améliorer la diffusion de ces mesures : (1) Quels sont les moyens par lesquels les innovations sont diffusées en psychothérapie? (2) Comment mesuret-on l'impact d'une intervention de diffusion? et (3) Qu'est-ce qui rend une intervention de diffusion efficace? Les réponses à ces questions ont été poursuivies en trois études.

Dans la première étude, la recherche a été examinée et les stratégies, les facilitateurs, et les processus qui peuvent assister dans la diffusion d'une innovation ont été identifiés. Dans la deuxième étude, un outil pour évaluer des interventions de diffusion a été développé et confirmé. Dans la troisième étude, une intervention qui emploie plusieurs stratégies de diffusion a été évaluée et des stratégies efficaces ont été identifiées.

Cette thèse contribue à une meilleure compréhension du processus de diffusion. La faible participation des cliniciens est un obstacle important de la diffusion dans le domaine de la psychothérapie et des interventions rapides sont proposées comme un moyen possible de surmonter cet obstacle. Un fois impliqués, la recherche qui est succincte, créative, et compréhensible aide les cliniciens à apprendre à propos des mesures pour suivre les progrès. Certains types d'informations pratiques sont aussi utiles : cependant, ces ressources peuvent 
s'avérer plus utiles lorsqu'elles sont soutenues par l'expérience clinique. Toutefois, l'information anecdotique s'avère plus importante pour l'amélioration des attitudes envers ces mesures, ainsi que pour l'augmentation de l'intention d'un clinicien de s'en servir. Les implications de ces résultats pour la diffusion de ces mesures et d'autres innovations dans le domaine de la psychothérapie sont discutées. 


\section{Acknowledgements}

Firstly, I would like to express my gratitude to Marilyn Fitzpatrick, my primary supervisor, in making this journey possible. She has paved the way for me to develop into a researcher and clinician. Her intellect, authenticity, and wit have marked my development professionally and personally. Marilyn's unwavering confidence in myself and this process has gifted me a sense of self-competence and pride that I will forever appreciate.

I am grateful for the unmeasurable support of my co-supervisor, Chiaki Konishi. Her contributions, both intellectual and emotional, cannot be understated. Her impeccable attention to detail and tolerance for endless revisions has made for a piece of work I am proud of. More significantly, her warmth, kindness, and genuine enthusiasm for myself and this project has ignited inspiration when difficulties emerged.

I am thankful for the support and advice of Shawna Atkins, who helped lay the foundations of my clinical knowledge and also served as an irreplaceable member of my internal research committee. She has been reliable, thorough, and whole-hearted in her support of my clinical and research development.

A thank-you is owed to my family. While they may not remember what it is that I have been studying for the past 7 years, they have always demonstrated a resolute enthusiasm in my reaching the finish line. Even as an adult, my parents continue to provide me with a soft place to land between semesters. While they have impressed me in their ability to adapt and evolve, they are consistent in their boundless dedication to improving the lives of their children. There is no thank-you that will suffice, but we are deeply appreciative. I am grateful for my brother Brock, who we can always rely on for the necessary moments of lightness and humor, often at his own 
expense. I am grateful for my brother Xavier, who has redefined my understanding of perseverance in manner that is worldview-shifting and admirable.

This work would not have been possible without my friends and colleagues, Isabelle, Bryan, Tina, and Robin. I am appreciative of every conversation in the basement of the Education Building contributing to my ever-evolving thoughts about research, therapy, and life. To my best friend and fellow therapist, Molly, I am indebted to you for the countless phone calls, invaluable support, and endless laughs you so effortlessly provide me. To my lab-partner, counselling comrade, and dear friend, Andrea, I am impossibly lucky to have taken every step of this journey with you. Your wit, kindness, generosity and inability to be irritated by anyone or anything has given me a direction for which I hope to evolve. I am thrilled to have become your friend and cannot wait for a lifetime of continued professional and personal development together.

Finally, I am endlessly grateful to Marc: my partner, therapist, sommelier, teacher of the French language, taxes, and excel. Having you as a witness and emotional consultant to this thesis has been the greatest gift. Your calming words, brilliant advice, and consistent willingness to discuss Progress Monitoring over a glass of wine on a Friday night has kept me anchored and inspired. Thank-you. 


\section{Contribution to Original Knowledge}

This thesis is comprised of three manuscripts: (1) Dissemination in psychotherapy: the case of Progress Monitoring measures, (2) Closing the practice-research gap: development of the Innovation-Decision scale, and (3) PsySuccess: evaluation of a dissemination intervention. Manuscript 1 has been published in Canadian Psychology and Manuscript 2 is currently under review for publication. All three manuscripts are original scholarship and provide distinct contributions to knowledge. 


\section{Contribution of Authors}

As first author, I reviewed the literature and determined research questions. Studies were designed in collaboration with previous graduate students and my primary supervisor. I collected all data and performed analyses in consultation with my co-supervisor. I wrote the first manuscript in consultation with my primary supervisor and the second and third manuscript in consultation with both my primary and co-supervisor. I also designed and developed the dissemination intervention evaluated in the third manuscript.

My primary supervisor, Marilyn Fitzpatrick, provided guidance in determining appropriate research questions and designing the studies. She contributed significantly to the editing of all three manuscripts.

My co-supervisor, Chiaki Konishi, provided guidance in determining appropriate research questions and designing the studies for the second and third manuscripts. She consulted in data analyses and edited the second and third manuscripts.

Shawna Atkins, the clinical contributor to my internal committee, provided guidance in determining appropriate research questions and designing all three studies. She also assisted in editing the final thesis.

Déborah Finkler provided support in editing and formatting the first manuscript. 


\section{Introduction}

Psychotherapy is effective for a variety of mental health conditions (Hunsley, Elliott, \& Therrien, 2014); however, significant portions of clients do not benefit. A review of naturalistic data found that between $3 \%$ and $14 \%$ of patients deteriorate and $46 \%$ to $61 \%$ demonstrate no change (Hansen, Lambert, \& Forman, 2002). In addition, clinicians systematically fail to attend to client deterioration, even when reminded to look for it (Hannan et al., 2005).

Part of the problem is that clinicians tend to overestimate their efficacy. On average, clinicians perceive their skills to be in the $80^{\text {th }}$ percentile and no clinicians perceive their skill to be below average (Walfish, McAlister, O'Donnell, \& Lambert, 2012). Clinicians are typical in this regard: people tend to hold overly favourable views of themselves (Alicke, 1985; Kruger \& Dunning, 1999). While this may serve to protect clinician self-esteem, it has potentially detrimental effects for clients. Professional self-doubt actually contributes to therapist efficacy. A humble and open stance may help clinicians to recognize and respond to important therapeutic issues (Nissen-Lie, Havik, Hoglend, Monsen, \& Ronnestad, 2013; Nissen-Lie et al., 2017). While a self-serving bias may be protective of clinicians' mental health, it comes at the cost of the client (de Jong, 2016).

The use of Progress Monitoring (PM) measures can help clinicians address these challenges. PM measures provide clinicians with regular, systematic feedback on client progress. Their use has been associated with improved outcomes across treatment type and patient populations (Anker, Duncan, \& Sparks, 2009; Bickman, Kelley, Breda, de Andrade, \& Riemer, 2011; Connolly Gibbons et al., 2015; Dyer, Hooke, \& Page, 2016; Gondek, Edbrooke-Childs, Fink, Deighton, \& Wolpert, 2016; Goodman, McKay, \& DePhilippis, 2013; Reese, Norsworthy, \& Rowlands, 2009; Schuman, Slone, Reese, \& Duncan, 2015; Simon et al., 2013; Slone, Reese, 
Mathews-Duvall, \& Kodet, 2015). PM is in fact most useful when clients are not responding to treatment (Crits-Christoph et al., 2012; Lambert, Harmon, Slade, Whipple, \& Hawkins, 2005; Newnham, Hooke, \& Page, 2010). When used in clinical training, students who use PM improve more over the course of an academic semester than those who do not (Reese, Usher, et al., 2009). In addition to improving outcomes for individual clients, PM can be used for documenting the efficacy of services, benchmarking, and improving our overall understanding and practice of psychotherapy (Boswell, 2019).

This is not to say that PM is a panacea. While some have found that the efficiency of services is improved: allowing not-on-track clients to receive more sessions and on-track clients to receive fewer (Harmon et al., 2007; Lambert et al., 2001; Whipple et al., 2003), these findings have not always been replicated. A review by Gondek et. al., (2016) found that most studies demonstrated that there was no impact on treatment efficiency and while two showed an improvement with PM feedback, two others showed a deterioration in efficiency with feedback. It seems that when it comes to treatment efficiency, there is more to understand.

Furthermore, while meta-analysis and systematic reviews have supported the use of PM for both adults (Gondek et al., 2016; Lambert \& Shimokawa, 2011; Lambert, Whipple, \& Kleinstauber, 2018; Shimokawa, Lambert, \& Smart, 2010) and youth (Tam \& Ronan, 2017), Cochrane reviews have determined that there is insufficient evidence to reach firm conclusions (Bergman et al., 2018; Kendrick et al., 2016). A high risk of bias due to inadequate masking and attrition have been noted as problems in the current PM literature (Bergman et al., 2018; Kendrick et al., 2016). While masking is generally important, it may be less appropriate in assessing PM as some of the anticipated effects of the measures are hypothesized to be due to the process of measurement itself (Finn \& Tonsager, 1992). Additionally, Kenrick et al.’s (2016) 
review excluded studies which used PM to enhance quality of care. Given that this is a primary purpose of PM, some have argued that these studies should have been included (Lewis et al., 2019). Regardless, higher quality PM studies continue to be needed.

Moreover, PM does not appear to be effective for all patient populations. Adverse effects has been recorded in the treatment of patients with personality disorders (de Jong, 2016) and mixed results have been found in the treatment of patients with eating disorders (Davidsen et al., 2017; Simon et al., 2013). By identifying instances where PM is not effective, however, possible mechanisms of action have been proposed. Findings from the aforementioned studies have indicated that PM may take its effect via the patient being able to witness their progress and the clinician being able to flexibly respond to feedback (Davidsen et al., 2017; de Jong, 2016). Other studies demonstrating variable efficacy have indicated that the measures need to be implemented properly (Bickman et al., 2016) and clinicians need to use the feedback and have high selfefficacy (de Jong, Van Sluis, Nugter, Heiser, \& Spinhoven, 2012).

Nonetheless, the majority of the research supports the use of PM (Knaup, Koesters, Schoefer, Becker, \& Puschner, 2009; Krägeloh, Czuba, Billington, Kersten, \& Siegert, 2015; Lambert \& Shimokawa, 2011). The measures have been shown to improve outcomes for a variety of conditions ranging from depression (Connolly Gibbons et al., 2015) to substance abuse (Crits-Christoph et al., 2012; Schuman et al., 2015). Their use has also been shown to be effective across treatment type, including for group (Schuman et al., 2015; Slone et al., 2015) and couple therapy (Anker et al., 2009; Reese, Toland, Slone, \& Norsworthy, 2010). While more remains to be understand with regard to certain populations (Davidsen et al., 2017; de Jong, 2016), PM appears to improve practice for the majority of client populations. 
The measures have several possible mechanisms of action. Clinicians do not necessarily improve with time and experience; in fact, slight but significant decreases in efficacy over time have been reported (Goldberg et al., 2016). Sapyta, Riemer, and Bickman (2005) use the analogy of an archer with a blindfold who cannot see where each arrow is landing. They argue that in the absence of corrective feedback, we cannot expect an improvement in skill (Sapyta, Riemer, \& Bickman, 2005). One important aspect of this feedback relates to the alliance. Mediation analyses have indicated that the measures work, in part, via improving the therapeutic alliance (Brattland et al., 2019). While it remains important to understand how clinicians integrate the feedback, PM measures provide information that can continue to improve clinical practice (Riemer, Rosof-Williams, \& Bickman, 2005).

PM measures may also take effect via the client. Clients have said that the measures allow them to express themselves and see their progress in therapy (Alves, Sales, \& Ashworth, 2016; Hall, Taylor, et al., 2014; Kilbride et al., 2013; Stedman et al., 2000; Steinfeld, Franklin, Mercer, Fraynt, \& Simon, 2016; Sundet, 2014; Unsworth, Cowie, \& Green, 2012). Soliciting feedback may also demonstrate a clinicians' general orientation towards to the client (Macdonald \& Mellor-Clark, 2015), improving alliance and hence outcomes (Wampold \& Imel, 2001). The act of assessing may also be inherently therapeutic (Finn \& Tonsager, 1992). Individuals want to be accurately understood by others, even if that understanding highlights things that are negative (Swarm Jr, 1983). PM may be impacting client outcomes, in part, by helping clients feel accurately heard and seen, a crucial component of the therapeutic alliance (Duncan et al., 2003).

Despite the evidence supporting PM, most North American clinicians are not using the measures (Hatfield \& Ogles, 2004; Ionita \& Fitzpatrick, 2014; Jensen-Doss et al., 2016). In a large survey of Canadian psychologists, only $12 \%$ reported to be using a PM measure (Ionita \& 
Fitzpatrick, 2014). This appears to be mainly a function of a lack of awareness: $67 \%$ of psychologists did not know that the measures existed. Among those who were aware of PM, barriers to use included insufficient knowledge and training as well as concerns that the measures took too much time or burdened clients. Clinicians reported that a brief training, positive client testimonials, and a low time investment might facilitate use. Interestingly, brief PM training is available (e.g., Duncan, 2017), clients have reported positive experiences (Kilbride et al., 2013; Solstad, Castonguay, \& Moltu, 2017; Steinfeld et al., 2016; Unsworth et al., 2012), and many measures take less than 2 minutes to complete. The general lack of PM knowledge suggests a failure of Knowledge Translation (KT).

\section{Knowledge Translation}

KT has been defined by the Canadian Institute of Health Research (CIHR) as a process that includes the synthesis, dissemination, exchange, and ethically-sound application of knowledge to improve practice (Canadian Institute of Health Research, 2016). CIHR has adopted the extensively cited Knowledge-to-Action (KTA) framework to guide their KT efforts. The KTA model consists of two phases: Knowledge Creation and the Action Cycle (Graham et al., 2006) (Figure 1, Manuscript 1). Both phases consist of several stages described below.

Knowledge Creation. Knowledge is first generated in knowledge inquiry. It is then aggregated, often in the form of meta analyses or systematic reviews, in knowledge synthesis. Finally, it is presented in a clear, concise, user-friendly format as a knowledge tool or product.

Action Cycle. In the Action Cycle, a knowledge-practice gap is first identified (identify problem); knowledge is tailored for individual users (adapt knowledge to the local context); impediments and facilitators to use are identified (assess barriers to knowledge use); and diffusion, dissemination, or implementation interventions are executed (select, tailor, and 
implement interventions). Once interventions have been implemented, changes in knowledge, attitudes, and behaviour are monitored (monitor knowledge use); impact is measured (evaluate outcomes); and finally, changes are maintained (sustain knowledge use) (Graham et al., 2006) (Figure 1).

\section{PM and The KTA Model}

Using the KTA model, the next steps in the KT of PM can be considered. Beginning with Knowledge Creation, PM has a strong evidence base (Anker et al., 2009; Bickman et al., 2011; Connolly Gibbons et al., 2015; Dyer et al., 2016; Gondek et al., 2016; Goodman et al., 2013; Reese, Norsworthy, et al., 2009; Schuman et al., 2015; Simon et al., 2013; Slone et al., 2015). The evidence has been synthesized in meta-analyses (Lambert \& Shimokawa, 2011; Lambert, Whipple, \& Kleinstauber, 2018; Shimokawa et al., 2010) and systematic reviews (Gondek et al., 2016). Narrative reviews have been published to support implementation (Lewis et al., 2019) and the Canadian Psychological Association (CPA) has published practice guidelines supporting the monitoring and evaluating of psychotherapy practice (Canadian Psychological Association, 2001). Additionally, a CPA Task Force on Outcome and Progress Monitoring in Psychotherapy recommends widespread implementation (Tasca et al., 2019). Thus, Knowledge Creation with respect to PM appears well developed.

Turning now to the Action Cycle, a substantial practice-research gap has been identified (Hatfield \& Ogles, 2004; Ionita \& Fitzpatrick, 2014; Jensen-Doss et al., 2016; Mours, Campbell, \& Peterson, 2009; Overington, Fitzpatrick, Hunsley, \& Drapeau, 2016). Regarding adapting knowledge to the local context, there is some evidence that users are adapting measures to better suit their needs. For example, some clinicians have reported reducing their frequency of use to facilitate adherence (Ionita, 2015). PM developers have also formally adapted some of the 
measures which now exist in a variety of formats (e.g., paper and pencil, computer, smartphone applications) and have variations that are tailored to specific client populations (e.g., child, youth, adult) and treatment modalities (e.g., individual, group).

Barriers to uptake have been identified among clinicians (Hatfield \& Ogles, 2004; Ionita, 2015) and internship training directors (Mours et al., 2009; Overington et al., 2016). A lack of awareness, insufficient knowledge, insufficient training, and resource constraints have all been highlighted. Interventions aimed at addressing these barriers and increasing uptake have also been initiated. PM training programs have been developed and demonstrated to have a positive impact on attitudes (Edbrooke-Childs, Wolpert, \& Deighton, 2016; Willis, Deane, \& Coombs, 2009), uptake, and sustained use (Persons, Koerner, Eidelman, Thomas, \& Liu, 2016; Steinfeld et al., 2016). Additionally, implementation programs have been rolled out, contributing to an improved understanding of the elements required for effective uptake at the organizational level (e.g., initial and ongoing training, fostering a culture of feedback, technological support, etc.) (Bickman et al., 2016; Brattland et al., 2018; Gleacher et al., 2016). However, a significant portion of clinicians work in private practice, where dissemination appears to be particularly difficult (Cook, Biyanova, \& Coyne, 2009). Private practitioners hold more negative attitudes about the PM and they use the measures less (Jensen-Doss et al., 2016). In Canada, over three quarters of clinicians work privately at least some of the time and over one third work privately most of the time (Hunsley, Ronson, \& Cohen, 2013). Thus, in addition to organization-based implementation efforts and training programs, dissemination programs need to be developed and tailored for individual clinicians. To monitor use and evaluate the impact of future dissemination interventions, recent awareness and usage statistics (Ionita \& Fitzpatrick, 2014; Mours et al., 2009; Overington et al., 2016) can be used as benchmarks. Finally, qualitative research has 
pointed to factors which may help clinicians sustain use of the measures (Knoll, Ionita, Tomaro, Chen, \& Fitzpatrick, 2016); however, large scale studies are needed to replicate these findings.

Next Steps. With respect to PM, KTA appears to be slowed at the select, tailor, and implement interventions stage of the Action cycle. Poor uptake and a low desire to use the measures (Ionita \& Fitzpatrick, 2014; Jensen-Doss et al., 2016) imply that current efforts aimed at improving uptake may not be enough. While some implementation efforts at the organizational level have proved effective (Bickman et al., 2016; Brattland et al., 2018), many clinicians work privately and require different kinds of dissemination programs. At present, more effective interventions tailored to individual clinicians are needed to promote the dissemination of PM.

The impact of such interventions on clinicians and eventually clients will also need to be monitored. Barac et al., (2014) performed a scoping review of health-related toolkits; toolkits are a specific type of dissemination intervention which bundle a variety of resources into a single package, in either a hard-copy or online format. While some of these interventions were found to instil an intention to change practice; $63 \%$ had no evaluation component, impeding conclusions regarding their efficacy (Barac, Stein, Bruce, \& Barwick, 2014). In addition, when interventions are evaluated, assessment instruments generally lack psychometric validation and are used only once, limiting cross study comparisons (Martinez, Lewis, \& Weiner, 2014). A lack of systematic evaluation constitutes a major issue in the field of implementation science. It hinders an examination of the methods which may promote the uptake of research findings and other evidence-based practices (EBP) into routine practice (Eccles \& Mittman, 2006). The field needs psychometrically sound assessment tools that can be used to measure the effectiveness of dissemination interventions. Overall, to bridge the practice-research gap with regard to PM, a 
dissemination intervention needs to be developed and evaluated using a validated and reusable measure.

\section{Research Objectives}

In order to execute the next steps indicated by the KTA model, several questions about dissemination need to be answered. These questions were the basis of the three manuscripts that comprise this thesis.

Manuscript 1 aimed to answer the question, what are the means by which we can disseminate a psychotherapy innovation, such as PM? To answer this question, the psychotherapy literature was reviewed and considered through the lens of a stage wise model of dissemination. The findings were summarized in a model of dissemination specific to psychotherapy. The model proposes how various strategies, facilitators, and processes may assist in the process of dissemination. The findings can be used to guide the development of a psychotherapy related dissemination intervention.

Manuscript 2 addressed the question, how can we measure the impact of a dissemination intervention? The stage-wise model used in Manuscript 1 was used to develop a scale assessing where clinicians fall on a continuum of innovation uptake. This scale was piloted on a group of Canadian clinicians and analyzed using an exploratory and confirmatory factor analysis. The results of the factor analysis have implications for our understanding of dissemination in psychotherapy. The manuscript provides a validated measure which can be used to assess the impact of dissemination interventions.

Manuscript 3 addressed the question, what makes a dissemination intervention effective? The findings of Manuscript 1 were used to the create a PM dissemination intervention employing multiple dissemination strategies. The scale developed in Manuscript 2 was used to evaluate the 
impact of the intervention on individual clinician participants. Additional analyses were conducted to determine which strategies facilitated specific stages of the stage-wise model used in both Manuscripts 1 and 2. These analyses determined the overall efficacy of the intervention as well as identified the specific strategies which may have contributed to its overall efficacy. 


\title{
Manuscript 1
}

Dissemination in Psychotherapy: The Case of Progress Monitoring Measures

\author{
Megan Knoll ${ }^{1}$ and Marilyn Fitzpatrick ${ }^{1}$ \\ ${ }^{1}$ Department of Educational and Counselling Psychology, McGill University
}




\begin{abstract}
The limited use of Progress Monitoring (PM) measures exemplifies the gap between practice and research in psychotherapy. Despite a strong evidence-base, most clinicians do not use or have adequate knowledge of the measures. This manuscript uses the Knowledge-to-Action model to determine the next steps in the knowledge translation of PM. Using this model, a need for PM dissemination interventions is identified. A review of the psychotherapy practice literature identifies the strategies, facilitators and processes that may assist in the dissemination of a psychotherapy innovation. The review is organized according to Rogers' (2003) Diffusion of Innovations theory to characterize how these strategies, facilitators, and processes may impact the process of dissemination. The review is then summarized in a model of dissemination specific to psychotherapy and applied to the current state of PM. Implications and limitations for improving the dissemination of PM are discussed.
\end{abstract}


Dissemination in Psychotherapy: The Case of Progress Monitoring Measures

\section{The Psychotherapy Practice-Research Gap}

The practice-research gap has been widely acknowledged in the field of psychotherapy (Kazdin, 2008). The disconnect between clinicians and researchers hinders the efficacy of practice as well as the relevance and utility of research. Knowledge Translation (KT), defined by the Canadian Institute of Health Research as the synthesis, dissemination, exchange and ethical implementation of knowledge (Canadian Institute of Health Research, 2016), has emerged to address this issue.

\section{Progress Monitoring}

One example of the practice-research gap in psychotherapy is in the application of Progress Monitoring (PM). PM involves the use of routine outcome measures that provide clinicians with systematic feedback on client progress. Integrating these measures into practice has been shown to improve outcomes across treatment type and client populations (Connolly Gibbons et al., 2015; Dyer et al., 2016; Gondek et al., 2016; Goodman et al., 2013; Lambert et al., 2005; Lambert \& Shimokawa, 2011; Reese, Norsworthy, et al., 2009). Despite this strong evidence-base, the majority of clinicians do not use the measures (Ionita \& Fitzpatrick, 2014; Jensen-Doss et al., 2016). In a large survey of Canadian psychologists, only $12 \%$ identified as PM users (Ionita \& Fitzpatrick, 2014). The largest barrier to use was a lack of knowledge; 67\% of psychologists were unaware that these measures existed. Among those who were aware of, but not using PM, barriers included insufficient knowledge, insufficient training, and concerns that the measures took too much time or that they burdened clients.

When asked about barriers to adoption, psychologists indicated that receiving a brief training, hearing positive client testimonials, and measures that take less than 5 minutes to 
complete were needed. Interestingly, brief PM training is available (Duncan, 2019), clients report positive experiences (Kilbride et al., 2013; Solstad et al., 2017; Steinfeld et al., 2016; Unsworth et al., 2012), and several measures require less than 5 minutes to complete. The gap between the state of the field and clinician awareness of PM indicates the inadequacy of KT in this area. This manuscript comprises several steps towards mitigating this inadequacy. First, Graham's (2006) Knowledge-to-Action model is used to direct current knowledge translation efforts with respect to PM. In using this model, a need for PM dissemination interventions is identified. A review of the psychotherapy practice literature identifies the strategies, processes, and facilitators which may assist in the dissemination of a psychotherapy innovation. The review is organized according to Rogers' (2003) Diffusion of Innovations theory to characterize how these elements may impact the process of dissemination. The findings are then summarized in a model of dissemination specific to psychotherapy. Finally, the model's applications to PM in particular are discussed.

\section{PM and Knowledge Translation}

The Canadian Institute of Health Research uses the Knowledge-to-Action (KTA) model to define and guide knowledge translation in Canadian healthcare. It can be used to identify the areas in which the translation of knowledge about PM is lacking. The KTA model divides KT into two major phases: Knowledge Creation and the Action Cycle (Graham et al., 2006) (Figure 1). What follows is a description of these phases and an evaluation of the current state of PM relative to each.

Knowledge Creation. Knowledge is first generated in a stage referred to as knowledge inquiry. It is then aggregated, often in the form of meta-analyses or systematic reviews, in 
knowledge synthesis. Finally, it is presented in clear, concise, user-friendly formats, also known as the knowledge tool or product (Figure 1).

With respect to knowledge inquiry, the current state of the literature makes a solid case for the need for PM. Approximately 5-10\% of clients deteriorate while in psychotherapy (Lambert \& Ogles, 2004). Despite this high proportion of treatment failure, clinicians are poor at identifying and predicting client deterioration (Hannan et al., 2005). Clinicians also self-evaluate in inaccurate ways. When asked to compare their clinical skills and performance to others, the average clinician rated their skills to be in the $80^{\text {th }}$ percentile and no clinician rated themselves as below average (Walfish et al., 2012). Furthermore, in the absence of client outcome data, clinician experience is no guarantee of better practice. A recent longitudinal study found that on average, clinicians became slightly, albeit significantly, less effective with more experience (Goldberg et al., 2016).

PM measures can address these concerns. PM use has been linked to improved outcomes in therapy (Reese, Norsworthy, et al., 2009), particularly for clients not responding as expected (Lambert et al., 2005). The measures have demonstrated benefits in group (Schuman et al., 2015; Slone et al., 2015) and couple therapy (Anker et al., 2009) as well as in the treatment of eating disorders (Simon et al., 2013), depression (Connolly Gibbons et al., 2015), and substance abuse (Crits-Christoph et al., 2012; Schuman et al., 2015). Trainees who use PM have been shown to improve more over the course of an academic semester than those who do not (Reese, Usher, et al., 2009). The utility of PM has been adequately demonstrated with respect to knowledge inquiry.

Knowledge synthesis has also occurred. Research has been synthesized in the form of meta-analyses (Lambert \& Shimokawa, 2011; Lambert, Whipple, \& Kleinstäuber, 2018; 
Shimokawa et al., 2010) and systematic reviews (Gondek et al., 2016) which support the use of PM. Recent meta-analyses have found that effect sizes range from very small but significant (i.e., .14 for the OQ-45) to small-to-moderate and significant (i.e., .43 for the PCOMS) depending on the measure used (Lambert, Whipple, \& Kleinstäuber, 2018). However, not all synthesized research supports the use of PM. Cochrane Reviews have determined that there is insufficient evidence to reach firm conclusions about the use of PM with adults (Kendrick et al., 2016), as well as children and adolescents (Bergman et al., 2018). In these reviews, the use of PM was not associated with significant differences in outcome (Kendrick et al., 2016) and the quality of the evidence was graded as low (Bergman et al., 2018; Kendrick et al., 2016). Most studies were evaluated as having a high risk of bias due to inadequate masking and significant attrition (Bergman et al., 2018; Kendrick et al., 2016). It should be noted, however, that the use of PM was associated with slight but significant differences in outcome among high risk clients (Bergman et al., 2018). While higher quality PM studies continue to be needed, there remains adequate synthesized evidence supporting the use of PM.

With regard to knowledge tools or products, narrative reviews have been published to support implementation (Lewis et al., 2019). The Canadian Psychological Association (CPA) has published practice guidelines supporting the monitoring and evaluating of psychotherapy practice (Canadian Psychological Association, 2001). Additionally, a CPA Task Force on Outcome and Progress Monitoring in Psychotherapy recommends widespread implementation (Tasca et al., 2019). PM training programs or workshops have been shown to positively impact attitudes (Edbrooke-Childs et al., 2016; Willis et al., 2009), uptake, and sustained use (Persons et al., 2016; Steinfeld et al., 2016). Thus, the Knowledge Creation phase of PM appears to be developing strongly. 
Action Cycle. The subsequent Action Cycle includes 6 stages: identifying a knowledgepractice gap (identify problem); tailoring knowledge (adapt knowledge to the local context); identifying impediments and facilitators (assess barriers to knowledge use); executing diffusion, dissemination, or implementation interventions (select, tailor, and implement interventions); monitoring changes in knowledge, attitudes, and behaviour (monitor knowledge use); determining impact (evaluate outcomes); and finally, maintaining change (sustain knowledge use) (Graham et al., 2006) (Figure 1).

In assessing the work that has been done for PM relative to the Action Cycle, a substantial practice-research gap has been identified as a problem (Hatfield \& Ogles, 2004; Ionita \& Fitzpatrick, 2014; Jensen-Doss et al., 2016; Mours et al., 2009; Overington et al., 2016). With regard to adapting knowledge to the local context, there is evidence that users are adapting measures to better suit their needs. For instance, some have reported adjusting the frequency of use to facilitate adherence (Ionita, 2015). Relative to assessing barriers to knowledge use, clinicians (Hatfield \& Ogles, 2004; Ionita, 2015) and internship training directors (Mours et al., 2009; Overington et al., 2016) have detailed the specific barriers and facilitators to PM implementation. PM training programs and workshops have certainly been useful dissemination interventions (Edbrooke-Childs et al., 2016; Persons et al., 2016; Steinfeld et al., 2016; Willis et al., 2009); however, use and desire to use continue to be low (Ionita \& Fitzpatrick, 2014; JensenDoss et al., 2016). To further develop the selection, tailoring, and implementation of interventions, a wider array of dissemination tools and techniques may be needed. In terms of monitoring knowledge use and evaluating outcomes, recent awareness and usage statistics (Ionita \& Fitzpatrick, 2014; Mours et al., 2009; Overington et al., 2016) could provide benchmarks. 
Qualitative research has pointed to factors which may inform sustaining knowledge use (Knoll et al., 2016); however, large-scale, quantitative research is needed to add weight to these findings.

According to the KTA framework, the next step would be to select, tailor, and implement interventions aimed at increasing PM use. That is, more interventions are needed to promote diffusion, the process by which an innovation such as PM is communicated over time among members of the social system (Rogers, 2003). When diffusion is actively pursued, it is referred to as dissemination. Dissemination models exist that can guide this process.

\section{Diffusion and Dissemination Models}

There are a number of diffusion and dissemination models (Tabak, Khoong, Chambers, \& Brownson, 2012). Tabak, Khoong, Chambers, and Brownson (2012) reviewed and categorized models based on their level of relevance (i.e., individual, organization, community, system, and/or policy). Researchers have already identified barriers to adopting PM at the level of the individual clinician (e.g., lack of knowledge, lack of time, cost, etc.) (Hatfield \& Ogles, 2004; Ionita, 2015). Given that dissemination interventions are more effective when they address barriers to change (Baker et al., 2010), a useful model should describe dissemination at the level of the individual. Rogers' (2003) Diffusion of Innovations (DoI) theory characterizes uptake at the level of the individual, organization, community, and policy (Tabak et al., 2012). Diffusion models also vary based on how frequently they are used and cited among researchers. The DoI theory is currently the most widely used diffusion model, having been cited nearly 20,000 times (Rabin et al., 2016). This theory can provide key insights into how to effectively disseminate PM.

\section{Diffusion of Innovations (DoI)}


Within DoI theory, Rogers' (2003) proposes Innovation-Decision, a five-stage process that individuals follow when adopting an innovation. The stages include knowledge, persuasion, decision, implementation, and confirmation. More specifically, in the process of uptake potential adopters learn (knowledge), form an attitude (persuasion), decide to adopt (decision), begin using (implementation), and then finally commit to using an innovation (confirmation).

\section{Innovation-Decision in Psychotherapy}

Dissemination in psychotherapy has been previously studied; however, implementation scientists have argued that in order to build a useful knowledge base, research needs to be embedded in a theoretical framework (Martinez et al., 2014). We contextualized the psychotherapy dissemination literature through the lens of Rogers' (2003) Innovation-Decision process. To do this, we performed a narrative review of the psychotherapy practice literature to identify the strategies, facilitators and processes involved in the dissemination of psychotherapy innovations. A narrative review was conducted as our research question was too broad and exploratory to conduct a systematic review (Green, Johnson, \& Adams, 2006). Search terms included the names of Rogers' stages or derivatives of these stages (i.e., knowledge, learn, persuasion, attitude, convince, decision, use, implementation, confirmation, and maintenance) with terms related to innovations (i.e., evidence-based practice (EBP), empirically-supported treatment (EST), treatment, practice, tool, technique, skill and research) in psychotherapy (i.e., psychology, psychologist, therapist, clinician and psychotherapy). These terms were searched using Google Scholar in 2015-2016. In 2017, 2018 and 2019, these terms were searched again to find newly published articles. Titles and abstracts were reviewed to identify relevant articles. Reference lists of all relevant articles were also screened to identify additional articles. Studies 
were included that described the means by which clinicians came to adopt a new practice, EST, or EBP.

It is important to differentiate ESTs and EBP, as these terms are sometimes inappropriately conflated. While both terms refer to practice supported by research, ESTs are research-supported psychological treatments and EBP is the integration of the best available research with clinical expertise in the context of patient characteristics, culture, and preferences (American Psychologist, 2006). In this review, we used the terms chosen by the authors of the research.

The review was organized by the stages of Innovation-Decision which permits the characterization of how the different strategies, processes, and facilitators may impact the process of dissemination. In doing this, some strategies, facilitators and processes fit clearly into one stage and others did not. When they did not fit clearly, inferences were made. To improve the reliability of this process, two reviewers discussed the categorization until they reached consensus. Categorizations based on inferences are identified as such. The review was then summarized in a model of psychotherapy dissemination (Figure 2): a proposal of how certain strategies, facilitators, and processes may assist in the dissemination of a psychotherapy innovation. A discussion of how these findings apply to PM follows.

\section{Knowledge}

Three types of knowledge are discussed in the initial stage of Innovation-Decision: awareness-knowledge (what the innovation is), how-to-knowledge (how to use the innovation correctly), and principles-knowledge (how and why the innovation works) (Rogers, 2003). Rogers (2003) postulates that the rapidity and efficiency of mass media make it the most effective communication channel for improving knowledge of an innovation. 
Knowledge acquisition in psychotherapy practice. Factors were categorized as sources of knowledge if the research indicated that they led to changes in knowledge or if they were discussed as sources of learning. The difficulty emerged when factors were identified as sources of learning used to inform practice and could fit into either the decision making or the implementation stages of Innovation-Decision. In these instances, consensus was reached based on emphasis; that is, whether the factor appeared to be primarily a source of information or primarily a factor that changed practice.

Research publications. While earlier surveys suggested that clinicians may be more interested in research than academics have conventionally believed (Beutler, Williams, Wakefield, \& Entwistle, 1995) and that the average psychotherapist read approximately 5 articles a month (Morrow-Bradley \& Elliott, 1986), a more recent study indicated that most clinicians do not regularly read journal articles (Stewart, Stirman, \& Chambless, 2012). A review of training methodologies found that although reading written material frequently resulted in knowledge changes, these changes were short lived and smaller than when compared to more intensive training (Herschell, Kolko, Baumann, \& Davis, 2010).

Some elements increase the utility of research. Clinicians have indicated that research including a specific description of the intervention is more useful (Cohen, Sargent, \& Sechrest, 1986; Morrow-Bradley \& Elliott, 1986) or what they tend to focus on (Gyani, Shafran, Rose, \& Lee, 2013). Viewing this from the perspective of Innovation-Decision, research highlighting how-to-knowledge may be more useful. Clinicians have also indicated that positive findings, replication of positive findings, and use of participants that are representative of their caseloads positively influence their use of research (Cohen et al., 1986). While the role of research in 
knowledge acquisition is ambiguous, these qualities may make it more useful, most likely in later stages of Innovation-Decision.

Preferred sources of knowledge. When considering a new treatment, clinicians have reported that they prefer theoretical and practical material about the treatment's major tenets and how it can be applied (Gyani et al., 2013; Stewart et al., 2012). These preferences indicate that clinicians are looking for how-to- and principles-knowledge, which are generally not the focus of research publications. A more dated study found that clinicians were inclined towards newsletters and conferences (Beutler et al., 1995), whereas more recent research has highlighted the importance of clinical experience and peer networks (Stewart et al., 2012). Practice-Research Networks (PRN) have been established to improve clinician-researcher communication, ultimately supporting psychotherapy practice-research integration (Castonguay et al., 2010; Castonguay, Pincus, \& McAleavey, 2015). Given clinicians' preferences for peer networks (Stewart et al., 2012), PRNs may be an effective means of knowledge transfer. Technology has been suggested as another means of improving the impact of training in mental health EBPs (Beidas, Koerner, Weingardt, \& Kendall, 2011). Although some clinicians have rated online educational sources to be remedial and unattractive (Stewart et al., 2012), most have reported having useful or satisfying experiences (Dimeff et al., 2009; Jones et al., 2014; Larson et al., 2009; McDonough \& Marks, 2002; Puspitasari, Kanter, Murphy, Crowe, \& Koerner, 2013; Rakovshik et al., 2013).

Knowledge conclusions. Based on the psychotherapy practice literature, online resources that provide clinicians with practical and theoretical information, up to date news, opportunities for experience, as well as access to peers and conferences may be the best sources of knowledge. 
If research is used, it should explain how the innovation is used and demonstrate synthesized positive findings across a range of populations (Figure 2).

\section{Persuasion and Decision}

While the knowledge stage is primarily cognitive, the persuasion stage is more emotional or affective (Rogers, 2003). In the persuasion stage, a potential adopter develops a positive or negative attitude about the innovation. During this stage, interpersonal channels are posited to have a greater impact than mass media (Rogers, 2003). In the decision stage, an individual chooses to adopt or reject the innovation. Trial of the innovation has been suggested as a means of speeding up the decision process (Rogers, 2003).

Persuasion and decision in psychotherapy practice. Persuasion and decision were combined because the level of inference required to separate these two stages was deemed too high. For example, one study examined what influenced clinicians' willingness to learn a new therapy (Cook, Schnurr, Biyanova, \& Coyne, 2009). "Willingness to learn a new therapy" could be representative of both the persuasion and decision stages of Innovation-Decision. Willingness may reflect both a noncommittal inclination towards the new treatment (persuasion) as well as a more committed readiness (decision). Thus, while all strategies which demonstrated an impact on "willingness to learn a new therapy" were posited to impact both persuasion and decision, it is possible that this willingness is only representative of one these stages. In general, variables that were linked to attitudes, willingness to learn a new practice, or decision-making, were categorized as strategies, facilitators, and processes involved in the persuasion and decisionmaking stages of Innovation-Decision.

Certain clinician characteristics appear to be associated with attitudes towards ESTs and EBP. CBT oriented clinicians (Stewart \& Chambless, 2007, 2009) and interns (Aarons, 2004) 
demonstrate more positive attitudes. Given CBT's research base and emphasis on empirical findings, it is not surprising that CBT oriented clinicians feel more positively about ESTs. Interns may be more enthusiastic about EBP because they are still developing their practice and probably more open to learning. While clinician characteristics may mediate the impact of dissemination strategies, facilitators, and processes on the uptake of an innovation, a detailed examination of these factors is outside the scope of the current study. What follows is a review of the strategies, facilitators, and processes involved in the general development of positive attitudes or decision-making regarding psychotherapy innovations.

Case studies and anecdotal information. Case studies have outperformed research reviews in impacting attitudes and willingness to obtain training in an empirically supported treatment (Stewart \& Chambless, 2009). Endorsement by a respected therapist has also been rated as one of the greatest influences on willingness to learn a new treatment (Cook, Schnurr, et al., 2009). Anecdotal accounts may take precedence over statistical information because they are more relatable and therefore, more memorable (Borgida \& Nisbett, 1977; Tversky \& Kahneman, 1971).

Training. Clinical experience (Gyani et al., 2013; Stewart \& Chambless, 2007; Stewart et al., 2012) and perceived self-efficacy (Henderson, MacKay, \& Peterson-Badali, 2006) have also been identified as important in treatment related decision-making. One mode of improving selfefficacy is training. Availability of a local training opportunity has been strongly endorsed as a factor contributing to the willingness to learn a new therapy (Cook, Schnurr, et al., 2009). Training style and focus can also influence attitudes. When compared to manualized training, training that emphasizes application and skill facilitates a greater change in positive attitudes 
towards EBP. Negative attitudes may be more reflective of attitudes towards manuals rather than EBP (Borntrager, Chorpita, Higa-McMillan, \& Weisz, 2009).

Research publications. Positive findings in a research journal were one of the least endorsed factors influencing willingness to learn a new therapy (Cook, Schnurr, et al., 2009). Research reviews have even failed to add weight when added to a case study (Stewart \& Chambless, 2009). This may reflect common objections to research: clinicians have reported that research is too controlled and incapable of measuring the interpersonal components of therapy (Stewart et al., 2012). While research may contribute to short term changes in knowledge (Herschell et al., 2010), it appears to be a weak strategy when it comes to persuasion and decision-making.

Persuasion and decision conclusions. To persuade clinicians or help them commit to using an EST or EBP, dissemination efforts should highlight case studies, endorsements by respected therapists and other forms of anecdotal evidence. Opportunities for clinical experience and clinician' self-efficacy should be promoted via training that emphasizes application and skill (Figure 2).

\section{Implementation and Confirmation}

According to DoI, implementation ideally follows the decision to adopt an innovation. If a user changes or modifies an innovation during the process of implementation, this is called reinvention and this can increase the rate of adoption (Rogers, 2003). New users subsequently look for support or confirmation regarding their decision to adopt. Support leads to continued use, whereas exposure to conflicting messages about the innovation can result in discontinuance or a reversal of the decision to adopt (Rogers, 2003). 
Implementation and confirmation in psychotherapy practice. Several of the dissemination strategies identified in the literature were described as influencing both implementation and use at a follow-up period, implying some form of maintained use. For this reason, implementation and confirmation were combined in this review. Whether the strategy was posited to influence implementation, confirmation, or both is indicated below.

Similar to persuasion and decision, clinician characteristics have also been associated with the implementation of EBP. Mirroring the findings relating to attitudes, CBT clinicians (Nelson \& Steele, 2007) and interns (Aarons, 2004) report using EBP more frequently. Clinicians who perceive their clinic to be more open to EBP also report higher levels of use (Nelson \& Steele, 2007). Similar to persuasion and decision, while clinician characteristics may impact implementation and maintenance, this review focuses on the strategies, facilitators, and process that may have a general impact on the implementation and maintenance of psychotherapy innovations.

Training. Training was the most thoroughly discussed strategy for facilitating implementation and maintenance. The impact of training on implementation appears to be partially mediated by negative attitudes towards research (Nelson \& Steele, 2007); while training may not facilitate the development of positive attitudes, it may protect against overly negative attitudes that decrease use. With regard to sustaining use, training that incorporates structured time spent reflecting on what was learned appears to have a positive impact (Bennett-Levy \& Padesky, 2014). As well, the combination of an initial training with ongoing support has been found to support both the implementation and sustained use of a new treatment (Powell, Hausmann-Stabile, \& McMillen, 2013; Simons et al., 2010). 
Other factors. Fidelity monitoring and access to manuals and other educational resources (Powell et al., 2013) have been identified as being important to the implementation of new treatments. Clients liking the intervention (Cook, Schnurr, et al., 2009) and direct experience of an innovation's effectiveness (Powell et al., 2013) have been found to be important to maintaining use. Finally, consultation (Beidas, Edmunds, Marcus, \& Kendall, 2012; Powell et al., 2013; Simons et al., 2010) and supervision (Powell et al., 2013) have been identified as facilitating both the implementation and subsequent sustained use of ESTs or EBP.

Implementation and confirmation conclusions. To promote successful implementation and maintenance of ESTs and EBP, clinicians should be provided with initial and ongoing training that provides access to manuals or other educational resources and encourages reflection. These trainings should promote direct clinical experience that is supported by fidelity monitoring, supervision, and consultation. If direct experience cannot be provided, information on the client experience of the innovation should be made available through research, training or other educational materials (Figure 2).

\section{Innovation-Decision Model}

Figure 2 summarizes this narrative review, demonstrating how certain strategies, facilitators, or processes may impact specific stages of Innovation-Decision. It may be used to guide the dissemination of PM in a more systematic and efficient way. In the section that follows, the state of PM relative to Rogers' (2003) Innovation-Decision is reviewed and dissemination strategies, facilitators, and processes identified in Figure 2 are considered.

\section{PM and Innovation-Decision}

Knowledge of PM. Knowledge is highly relevant to the current state of PM dissemination. Recent estimates suggest that only 33\% of psychologists are aware of PM (Ionita 
\& Fitzpatrick, 2014) compared to $63 \%$ of predoctoral psychology internship training directors (Overington et al., 2016). This disparity suggests that knowledge may be increasing among newly trained clinicians but remains limited among those clinicians who were trained at an earlier time. As Rogers' (2003) suggests, a mass media dissemination strategy may be most effective for bringing this large group of potential users into awareness. Lack of knowledge continues to be an issue among non-users who are aware of PM and even current users (Ionita, 2015). These findings suggest that knowledge is insufficient and that improvements in how-to and principles knowledge may remediate this problem. Considering Figure 2, an effective learning tool may include online resources that provide clinicians with practical and theoretical information on PM, up-to-date PM news, opportunities for use (e.g., free trials), opportunities to communicate with users, and information on upcoming PM conferences or presentations.

Persuasion and decision regarding PM. The literature demonstrates wide variability with respect to therapist attitudes towards PM. Some clinicians have expressed resistance based on concerns that the measures undermine practice flexibility (Callaly, Hyland, Coombs, \& Trauer, 2006), increase workload (Callaly et al., 2006), are too general (Hall, Taylor, et al., 2014; Wolpert, Curtis-Tyler, \& Edbrooke-Childs, 2014), are not appropriate for all patient populations (Perry, Barkham, \& Evans, 2013), hinder normal communication (Hall, Taylor, et al., 2014), or that the data may be misused (Callaly et al., 2006; Unsworth et al., 2012). Conversely, others have reported that the measures are convenient (Hall, Taylor, et al., 2014; Perry et al., 2013), improve treatment structure and focus (Callaly et al., 2006; Omer, Golden, \& Priebe, 2016; Perry et al., 2013; Wolpert et al., 2014), allow clients or patients to see their progress (Omer et al., 2016), empower clients or patients to express themselves (Callaly et al., 2006; Omer et al., 2016; Perry et al., 2013), and facilitate service development (Callaly et al., 2006; Wolpert et al., 2014). 
Unsworth, Cowie, and Green (2012) found that while clinicians were initially anxious and resistant to the measures, they eventually found them useful. They attributed this change to proper training and an ability to use the measures creatively and flexibly over time.

Theoretical approach appears to impact attitude: CBT clinicians feel more positively and psychodynamic clinicians more negatively about PM (Jensen-Doss et al., 2016). It may be that the regular collecting of client data allows CBT oriented clinicians to adapt more easily to PM. Private practitioners also appear to have more negative attitudes than institution-based practitioners (Jensen-Doss et al., 2016; Stedman et al., 2000). This is not surprising, considering that private practitioners are generally less influenced by facilitators to implementing new treatments (e.g., research, training, treatment manuals) (Cook, Biyanova, et al., 2009). While not the focus of the current review, clinician characteristics will clearly have to be considered when pursing PM dissemination.

PM users have reported that they were motivated to start the measures because they fit with their approach, theory, and/or values; contributed to the effectiveness of their practice and professional development; enhanced the role of the client in therapy; increased objectivity and helped them to obtain data; and facilitated accountability to themselves, their clients, and third parties (Knoll et al., 2016). If this is what motivates clinicians, PM's ability to meet these needs should be communicated through training, case studies, and endorsements by respected therapists (Figure 2).

The positive impact of training on attitudes and use of ESTs (Cook, Schnurr, et al., 2009; Nelson \& Steele, 2007) appears to hold in the case of PM measures. A computer based intervention led to more positive attitudes and increases in the belief that feedback promotes motivation, engagement and collaboration (Willis et al., 2009). A live outcome monitoring 
training program also demonstrated increases in positive attitudes and self-efficacy post training; a longer version of the training program (i.e., 3 day vs. 1 day) had an even more significant impact (Edbrooke-Childs et al., 2016). Given this link between training and attitudes, PM's presence in graduate training programs will be an important component of dissemination. The most recent usage and awareness statistics indicate that there is room for improvement. In 2009, more than half of APA accredited, APPIC-membership training sites were not using any form of outcome monitoring to inform decisions, treatment, and clinical practice (Mours et al., 2009). In 2016, 24.8\% of APA accredited internship training directors were aware of, but not implementing PM measures at their site (Overington et al., 2016). Increasing PM training opportunities as well as the presence of PM in psychology training programs will be important to facilitating positive attitudes among clinicians.

Just as clinical experience influences treatment related decision-making (Gyani et al., 2013; Powell et al., 2013; Stewart \& Chambless, 2007; Stewart et al., 2012), experience also appears to positively influence attitude towards PM (Trauer, Pedwell, \& Gill, 2009). Opportunities for trying out PM via training programs or free trials are other promising strategies for the dissemination of PM.

Implementation and confirmation of PM. Six percent of practitioners (Ionita \& Fitzpatrick, 2014) and 12\% of training sites (Overington et al., 2016) reported having used a PM measure and then stopped. These results speak to challenges in PM implementation or confirmation. Typical challenges included practical concerns, dissatisfaction with a particular feature of the measure (e.g., length), or a feeling that the measure did not fit with clientele, orientation, etc. (Ionita, 2015). 
Advice on overcoming challenges has been elicited and includes having support, supervision and training, as well as the adequate computer hardware and software (Callaly et al., 2006; Ionita, 2015). Clinicians have reported reinventing PM to overcome implementation challenges, particularly altering the frequency of use (Ionita, 2015). They have also discussed factors that may ease and simplify implementation, such as having technical support, adequate resources (Aoun, Pennebaker, \& Janca, 2002; Callaly \& Hallebone, 2001) and having a single measure to administer as opposed to multiple (Aoun et al., 2002).

Adequate training is also frequently discussed (Aoun et al., 2002; Callaly \& Hallebone, 2001; Callaly et al., 2006; Unsworth et al., 2012) as being important to implementation. While some studies have found problems in the utility of training programs (Aoun et al., 2002), other implementation efforts involving training have demonstrated significant and sustained increases in PM use (Persons et al., 2016; Steinfeld et al., 2016). Successful PM training programs provide instruction as well as opportunities for practice and regular checking-in with regard to use (e.g., staff meetings, reflection exercises, etc.) (Persons et al., 2016; Steinfeld et al., 2016). Clinicians have suggested that training should highlight PM's usefulness. As well, uncomfortable feelings about negative client feedback is a phenomenon that is often overlooked and should be a focus in PM training (de Jong, 2016).

Maintenance factors tended to mirror the factors that initially motived clinicians to use PM. These include engaging and enhancing the role of clients, improving effectiveness, being convenient, helping to identify issues in therapy, helping to guide treatment, providing information to third parties, and helping to engage the therapist (Knoll et al., 2016). That is, when PM measures performed as the clinician wanted and anticipated, clinicians were more likely to maintain use (Knoll et al., 2016). Clinicians should be encouraged to assess if PM 
delivers on the factors that initially motivated use as this may facilitate adherence. If the measures do not work as hoped, clinicians should be invited to reinvent them. Douglas, Button, and Casey (2016) argue that the field needs to reconsider protocol drift as innovative adaptation which can promote the sustained use of PM. Furthermore, they discuss the importance of monitoring fidelity and use and providing this feedback to PM developers in order to assess the impact of adaptations.

Clients approval of a new practice has been identified as important for sustained use (Cook, Schnurr, et al., 2009). Clients have indicated that they find the measures useful (Perry et al., 2013; Sundet, 2014), comprehensive (Omer et al., 2016), brief, and easy to understand (Alves et al., 2016; Hall, Taylor, et al., 2014; Kilbride et al., 2013; Perry et al., 2013; Solstad et al., 2017; Stedman et al., 2000; Steinfeld et al., 2016; Unsworth et al., 2012). They have also reported that they add structure and focus to sessions (Alves et al., 2016; Hall, Taylor, et al., 2014; Kilbride et al., 2013; Omer et al., 2016; Solstad et al., 2017; Stedman et al., 2000; Steinfeld et al., 2016; Sundet, 2014; Unsworth et al., 2012), allow them to express themselves (Sundet, 2014), and allow them to see their progress (Alves et al., 2016; Hall, Taylor, et al., 2014; Kilbride et al., 2013; Omer et al., 2016; Solstad et al., 2017; Stedman et al., 2000; Steinfeld et al., 2016; Unsworth et al., 2012). While there are many accounts of positive experiences, this is not always the case. Some clients have reported to be suspicious of how the measures are used (Perry et al., 2013; Solstad et al., 2017; Wolpert et al., 2014) and feel that they do not accurately capture the complexity of mental health (Perry et al., 2013; Solstad et al., 2017). Some have felt the measures are not appropriate for all individuals (Sundet, 2014) or that they may negatively impact their relationship with the clinician (Wolpert et al., 2014). Others find the measures too lengthy (Alves et al., 2016; Fornells-Ambrojo et al., 2017), the 
administration too frequent (Fornells-Ambrojo et al., 2017), or the questions negative, intrusive, or upsetting (Alves et al., 2016; Fornells-Ambrojo et al., 2017; Perry et al., 2013). Clients who are not shown the results of their progress tend to have a more negative view of the measures (Hall, Taylor, et al., 2014), supporting the importance of integrating the feedback into sessions. While positive client experiences may be important for maintenance, these negative experiences may be important when it comes to developing or improving measures.

According to the current review, in addition to high quality PM training programs, implementation and maintenance efforts should involve improving access to treatment manuals and educational resources. Clinical experience should be promoted and supported with consultation and supervision and clinicians should be encouraged to solicit feedback from clients regarding their experience of the practice. In the absence of clinical experience, client-focused research should be disseminated via educational resources and training.

\section{Implications}

Dissemination interventions are needed to facilitate the movement of PM through the Action Cycle (Figure 1). Figure 2 provides guidance on how to develop such interventions. Rather than applying a single dissemination intervention to an entire population of non-users, it may be more efficient to first determine where individuals fall on the spectrum of InnovationDecision and subsequently provide them with a variety of resources that may be most effective for them at that moment in time. The model summarizing the current review serves as a starting point for closing the practice-research gap with respect to PM (Figure 2). The development and evaluation of future dissemination interventions will permit a refinement of the model, helping to close the practice-research gap for other psychotherapy innovations. 


\section{Limitations}

This narrative review is limited by the fact that the included studies were conducted outside the context of Rogers' (2003) DoI theory. Thus, links proposed in Figure 2 were based on inferences drawn from the language used in the research. Additionally, the proposed associations are limited by what the authors examined. Absent relationships are related to limitations in the current literature.

A further limitation relates to the population studied. In this paper, the use of the term "clinician" refers to the range of mental health professionals (e.g., psychologists, psychiatrists, mental health counsellors, etc.) who were studied. Different kinds of clinicians are likely different with respect to Innovation-Decision. Certain clinician characteristics, such as theoretical orientation, have already been demonstrated to impact particular stages of dissemination (Aarons, 2004; Stewart \& Chambless, 2007, 2009). Future research should consider how a broader range of clinician characteristics impact dissemination.

Additionally, it was sometimes unclear what the dissemination strategies discussed in the literature constituted (e.g., practical and theoretical material). For these strategies, assumptions will have to be made when developing dissemination interventions. For example, regarding PM, previous research can be used to determine what practical materials may be useful for dissemination. The low time investment, technology support systems, and free trials have all been identified as potential facilitators (Ionita, 2015). PM practical material may therefore include information on the low time investment required, support for implementing the technology systems and access to free trials. It is possible, however, that important practical material may be missed when making these assumptions. 
While Figure 2 serves as a starting point for dissemination, it should be tailored and updated for different psychotherapy innovations. Despite its limitations, the model can be used to develop future dissemination interventions. These interventions will not only serve to further the Action Cycle in psychotherapy, but they also will permit a testing and refinement of the model, improving both our understanding and practice of dissemination. 
Figures

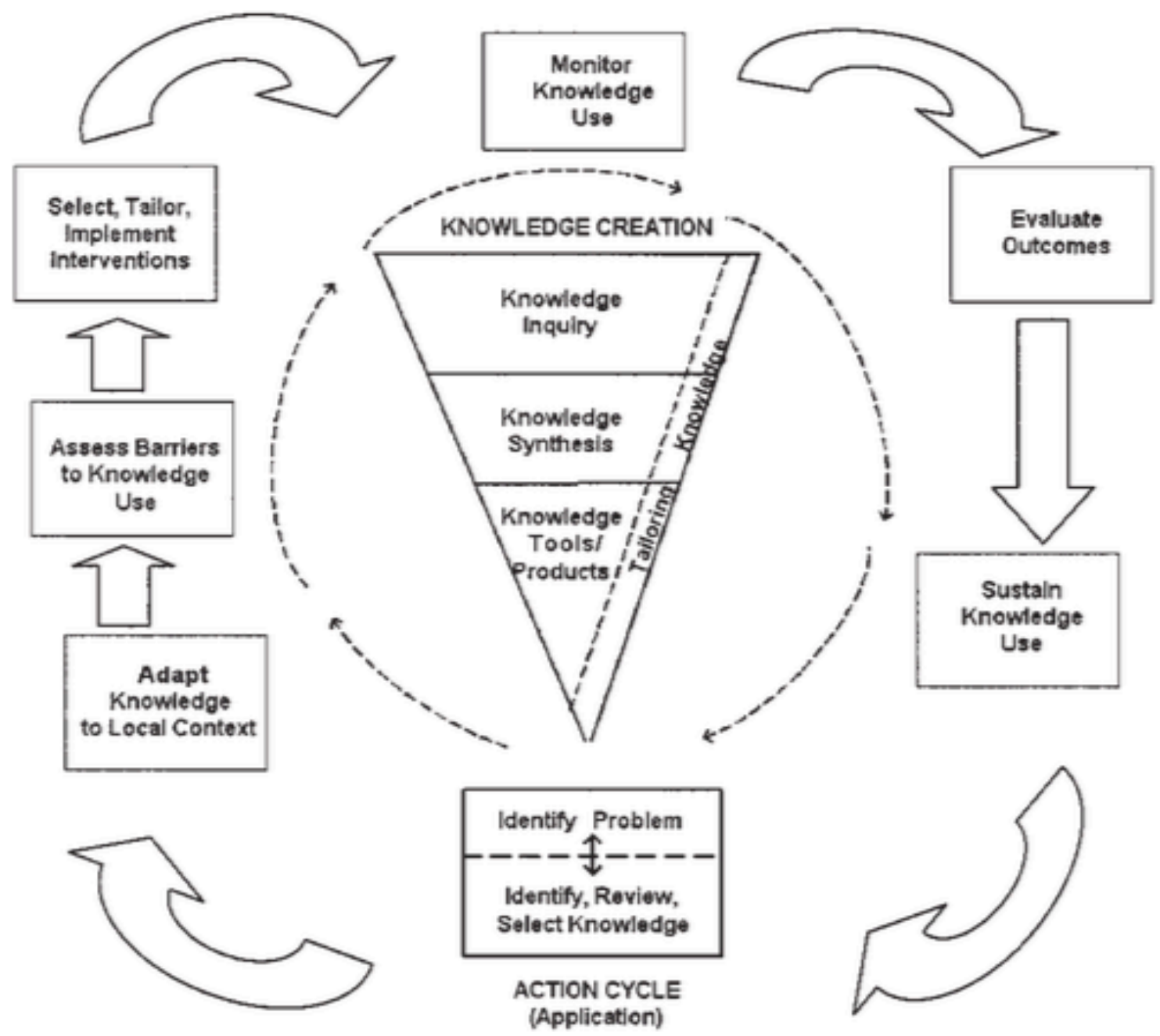

Figure 1. Knowledge to Action model. Figure reprinted with permission from "Lost in knowledge translation: Time for a map?" by I.D. Graham, et al., 2006, The Journal of Continuing Education in Health Profession, 22, p. 19. 


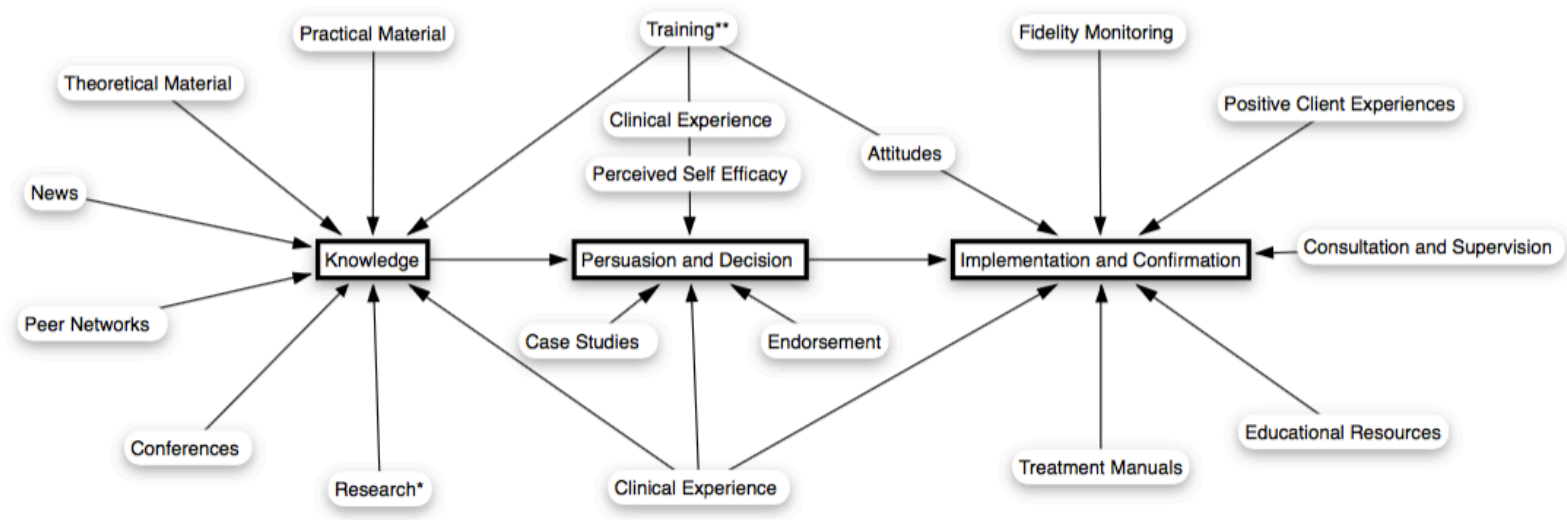

Figure 2. A diagram modeling how different strategies, facilitators, and processes may impact the dissemination of a psychotherapy innovation.

* Research that is conducted on clinically relevant populations and that demonstrates how the innovation was used (how-to research), efficacy, and replication of results may be especially useful.

**Training that is locally available or occurs online which focuses on application and skill, encourages reflection, and includes ongoing support may be especially effective. 


\section{Linking Manuscripts 1 and 2}

The findings of the narrative review serve as a starting point for closing the PM practiceresearch gap. Using the model developed in Manuscript 1, targeted dissemination interventions can be developed. Such interventions need to be evaluated, as the model is theoretical and therefore has not yet been empirically validated.

While previous dissemination interventions certainly exist, most have not been evaluated (Barac et al., 2014). Among those that have been evaluated, assessment instruments generally lack psychometric validation and tend to only be used once (Martinez et al., 2014). This is problematic as interventions cannot be compared, limiting progress in field of implementation science. In order to pursue PM implementation rigorously, a psychometrically sound and reusable assessment instrument is needed. Manuscript 2 responds to this need by developing such an instrument. 


\title{
Manuscript 2
}

\section{Closing the Practice-Research Gap: Development of the Innovation-Decision Scale}

\author{
Megan Knoll ${ }^{1}$, Marilyn Fitzpatrick ${ }^{1}$, and Chiaki Konishi ${ }^{1}$ \\ ${ }^{1}$ Department of Educational and Counselling Psychology, McGill University
}




\begin{abstract}
One example of the practice-research gap in psychology involves the use of Progress Monitoring (PM) measures. Despite the evidence supporting the use of PM, the majority of clinicians do not monitor progress formally. Rogers' (2003) Diffusion of Innovations theory proposes a process which may be useful in closing the PM practice-research gap; however, no instrument currently exists to measure this process. Two studies were conducted to develop and validate an instrument evaluating dissemination based off of Rogers' (2003) theory. In Study 1, items for the Innovation-Decision scale were developed and used to assess 185 clinicians. An exploratory factor analysis indicated two underlying factors: (1) Knowledge, and (2) PersuasionDecision. In Study 2, a confirmatory factor analysis was conducted on a second sample of 97 clinicians; however, the small sample size precluded definitive conclusions. While more research is needed to further validate the scale, this instrument can be used to improve the study and practice of dissemination in psychotherapy.
\end{abstract}


Closing the Practice-Research Gap: Development of the Innovation-Decision Scale The practice-research gap (Beutler et al., 1995; DeAngelis, 2010; Kazdin, 2008) hinders the efficacy of practice as well as the relevance and utility of research. Knowledge Translation (KT) and the field of implementation science have emerged to address this issue. KT has been defined by the Canadian Institute of Health Research (CIHR) as a process including the synthesis, dissemination, exchange and ethically-sound application of knowledge to improve practice (Canadian Institute of Health Research, 2016) . Implementation science is the study of that process; it examines methods which promote the uptake of research findings and other evidence-based practices into routine practice (Eccles \& Mittman, 2006). CIHR has adopted the Knowledge-to-Action (KTA) framework to guide these efforts.

The KTA model divides KT into two major phases: Knowledge Creation and the Action Cycle (Graham et al., 2006) (see Figure 1). In Knowledge Creation, knowledge is generated, aggregated and presented in clear, concise, user-friendly formats. In the Action Cycle, problems in knowledge uptake are identified, knowledge is adapted to the local context, barriers to uptake are assessed, dissemination interventions to address these barriers are created, changes in knowledge uptake are monitored, the impact interventions are determined, and maintenance of these changes is pursued (Graham et al., 2006). This model can be used to guide the uptake of research in practice.

\section{Progress Monitoring Measures}

One example of the practice-research gap in clinical psychology involves the use of Progress Monitoring (PM) measures. Approximately 5-10\% of clients deteriorate while in psychotherapy (Lambert \& Ogles, 2004). Despite this high proportion of treatment failure, clinicians have a tendency to overestimate their clinical efficacy (Walfish et al., 2012) and are 
poor at evaluating and predicting client deterioration (Hannan et al., 2005). PM measures provide clinicians with routine feedback to help them to overcome these challenges. They provide an evaluation of client progress, helping clinicians to make more informed treatment decisions. Their use has been linked to improved outcomes in therapy (Connolly Gibbons et al., 2015; Reese, Norsworthy, et al., 2009), particularly for clients not responding as expected (Lambert et al., 2005). Despite this evidence-base, the majority of clinicians do not monitor progress formally (Hatfield \& Ogles, 2004; Ionita \& Fitzpatrick, 2014; Jensen-Doss et al., 2016). In the largest survey of Canadian psychologists, only $12 \%$ reported using a PM measure (Ionita \& Fitzpatrick, 2014). The largest barrier to use was a lack of knowledge: $67 \%$ of psychologists were unaware that these measures existed. Among those who were aware of, but not using PM, insufficient knowledge and training were important barriers. It appears that the practice-research gap with respect to PM is a function of failed KT.

Reviewing PM within a KTA framework, we can see that efficacy has been demonstrated across several studies (Connolly Gibbons et al., 2015; Lambert et al., 2005; Reese, Norsworthy, et al., 2009), confirmed in systematic reviews and meta-analyses (Gondek et al., 2016; Lambert \& Shimokawa, 2011; Lambert, Whipple, \& Kleinstauber, 2018; Shimokawa et al., 2010), and a Canadian Psychological Association (CPA) Task Force on Outcome and Progress Monitoring in Psychotherapy recommends their widespread implementation (Tasca et al., 2019). This indicates that Knowledge Creation, the first stage of the KTA model, is well established. With respect to the Action Cycle, poor uptake and knowledge of PM has been identified as an issue in the field (Hatfield \& Ogles, 2004; Ionita \& Fitzpatrick, 2014; Jensen-Doss et al., 2016; Mours et al., 2009; Overington et al., 2016). Among those who are using measures, there is evidence that they are adapting measures to better suit their needs (Ionita, 2015). Additionally, PM developers have 
formally adapted some of the measures which now exist in a variety of formats (e.g., paper and pencil, computer kiosk, smartphone applications) which are applicable to specific client populations (e.g., child, youth, adult) and treatment modalities (e.g., individual, group). Barriers to uptake have been identified among individual clinicians and internship training directors (Hatfield \& Ogles, 2004; Ionita, 2015; Mours et al., 2009; Overington et al., 2016). While successful training programs have been developed (Edbrooke-Childs et al., 2016; Persons et al., 2016; Steinfeld et al., 2016; Willis et al., 2009), use and desire to use continue to be low (Ionita \& Fitzpatrick, 2014; Jensen-Doss et al., 2016). In terms of monitoring use and evaluating the outcome of interventions, recent awareness and usage statistics (Ionita \& Fitzpatrick, 2014; Mours et al., 2009; Overington et al., 2016) can serve as benchmarks. In terms of sustaining uptake, qualitative research has pointed to factors which may help to maintain the use of PM in practice (Knoll et al., 2016); however, quantitative research is needed to add weight to these findings.

According to the KTA framework, the next step in the KT of PM is to develop interventions designed to improve clinicians' knowledge and use of PM, beyond training. These interventions should facilitate diffusion, the process by which an innovation such as PM is communicated over time among members of the social system (Rogers, 2003). Dissemination is the active pursual of diffusion. Thus, the development, implementation and evaluation of a PM dissemination intervention is the logical next step in the KT of PM.

\section{Evaluating Dissemination}

Researchers have identified several issues in the field of implementation science. An inconsistent or inadequate use of theory has made it difficult to compare studies and build off of the literature (Martinez et al., 2014). Researchers need to embed their work in theoretical 
frameworks so findings can be compared and a more coherent knowledge base can be developed (Martinez et al., 2014). Another issue is that health related dissemination interventions tend to not be evaluated (Barac et al., 2014). When they are evaluated, assessment instruments lack psychometric validation and are generally only used once (Martinez et al., 2014). In order to facilitate progress in the field of implementation science, a psychometrically sound and reusable evaluation instrument that is rooted in theory is needed.

Many diffusion and dissemination models have been proposed, differing in their focus (e.g., dissemination vs. implementation), frequency of use (i.e., citations), and level of relevance (i.e., individual, organization, community, system, and/or policy) (Tabak et al., 2012). Rogers' (2003) Diffusion of Innovations (DoI) theory is the most widely used model, having been cited nearly 20,000 times (Rabin et al., 2016). The DoI theory's focus on diffusion over implementation makes it suitable for an innovation such as PM, where awareness and knowledge are currently the most significant barriers to uptake (Ionita \& Fitzpatrick, 2014). DoI theory is also broadly applicable for understanding the uptake of an innovation at the level of the individual, organization, community, and policy (Rabin et al., 2016). For these reasons, DoI theory was used to guide the development of a scale which can be used to evaluate PM dissemination.

\section{Diffusion of Innovations}

DoI describes Innovation-Decision, a five-stage process that individuals follow when adopting an innovation. The five stages include knowledge (learning about an innovation), persuasion (forming an attitude about the innovation), decision (deciding to adopt or reject the innovation), implementation (using the innovation), and confirmation (continuing or discontinuing use of the innovation). To evaluate a dissemination intervention, movement 
through these stages needs to be measured. To date, no validated instruments have been developed to quantify Rogers' (2003) Innovation-Decision process. Such an instrument could help to evaluate dissemination interventions, ultimately helping to bridge the practice-research gap in psychology.

\section{The Present Study}

Two studies were conducted to develop and validate the Innovation-Decision scale: an instrument quantifying Rogers' (2003) Innovation-Decision process. The objective of Study 1 was to develop the scale and explore its factor structure using an exploratory factor analysis (EFA). Study 1 first describes the elements of Rogers' (2003) theory that were used to develop the scale. It then describes the procedure, participants, and analysis used. This is followed by a presentation of the preliminary and demographic findings as well as the EFA results. The objective of Study 2 was to validate the factor structure identified in Study 1 using a confirmatory factor analysis (CFA). Study 2 describes the procedure, sample, and analysis used. It subsequently presents the preliminary and demographic findings as well as the CFA results. The results of both Study 1 and 2 are interpreted in the general discussion. Finally, limitations and future directions are considered.

\section{Study 1}

\section{Method}

A scale was created to assess how participants change with regards to the stages of Innovation-Decision, before and immediately after engaging with a dissemination intervention. The decision to measure immediate impact meant that changes in implementation and confirmation, the later stages of Innovation-Decision, were excluded from the scale. The rationale for this decision was to reduce the impact of extraneous variables that may take effect 
post engagement with an intervention. Thus, items were developed to assess only the first three stages of Innovation-Decision: knowledge, persuasion, and decision.

The constructs of knowledge, persuasion, and decision were first defined. Rogers' (2003) drew parallels between the DoI theory and McGuire's (1989) Hierarchy of Effects model. Thus, both Rogers' (2003) and McGuire's (1989) model descriptions were used to develop items to accurately capture the relevant constructs. All items were constructed using the same five-point likert scale format (strongly disagree to strongly agree) to facilitate the EFA and CFA.

\section{Theoretical Components for the Current Scale Development}

Knowledge. According to Rogers' (2003), knowledge begins when an individual is exposed to the existence of an innovation and gains an understanding of how it functions. Rogers' (2003) discussed the phenomena of selective exposure and selective perception. These are the tendencies to attend to and interpret messages in ways that are consistent with existing attitudes and beliefs. Rogers's (2003) hypothesized that individuals will be more likely to pay attention to and accept messages about the innovation if the innovation is perceived as relevant and needed. Thus, items tapping existing attitudes and beliefs about the general idea of feedback were developed. Rogers' (2003) also hypothesized that this stage was made up of awareness that the innovation exists (awareness-knowledge), knowledge of how to use the innovation (how-toknowledge), and knowledge of how and why the innovation works (principles-knowledge). According to the Hierarchy of Effects model, knowledge constitutes the recall of relevant information, a comprehension of the messages about the innovation, and having the knowledge necessary to effectively adopt the innovation. Items were constructed to capture all of these aspects of knowledge (see Table 1). 
Persuasion. Rogers (2003) theorizes that in the persuasion stage, individuals form a favourable or unfavourable attitude about the innovation, actively seek out more information about it, and decide which messages regarding the innovation are credible. To do this, individuals may engage in a vicarious trial, where they imagine themselves using the innovation. They also look for social reinforcement, exploring peers' attitudes about the innovation. According to McGuire's (1989) Hierarchy of Effects model, the persuasion stage can include a positive attitude about the innovation, discussion about the innovation with others, as well as acceptance of messages about the innovation. Items capturing these ideas were developed (see Table 2).

Decision. Decision is the stage where an individual engages in activities that lead to a choice to adopt or reject the innovation (Rogers, 2003). It may involve a trial, which can speed the rate of adoption. Peer trials can substitute for a personal trial. Items capturing these ideas were developed. While Rogers' (2003) model includes information seeking as a component of persuasion, McGuire's (1989) model suggests that it may be a part of decision making. An information seeking item was initially included within the persuasion stage and the EFA was used to categorize this item appropriately.

\section{Procedure}

A certificate of ethical approval was attained from the researchers' academic institution. Items from the Innovation-Decision scale were modified to be relevant to PM (see Tables 1, 2, and 3). They were subsequently embedded into a larger survey including demographic and PM use items. PM use items were included to filter out those who were already using PM (users) and those who had never heard of PM (unaware non-users), as the scale was not relevant to those who have not yet reached the knowledge stage or to those who have already past the decision stage. While all participants completed the demographic items, only previous users and aware 
non-users were assessed using the Innovation-Decision scale. Finally, the survey was pilot tested with psychologists and graduate students in psychology to assess and improve understandability.

Clinicians were recruited via e-mail using addresses attained from public, online psychological association/organization directories across Canada in the Summer of 2018. The email invitation informed potential participants that the purpose of the study was to develop a survey to evaluate a PM dissemination intervention and that participation would entail the completion of an online survey. Interested individuals were directed to an informed consent page before proceeding to the survey.

\section{Participants}

From the initial 5095 e-mail invitations, 455 clinicians completed the survey (8.9\%). Forty-two participants with missing data were excluded from the analysis, over half of whom did not get past the initial question $(n=22)$, resulting in a final sample size of 414 (final response rate $=8.1 \%$ ). Only previous users and aware non-users were assessed with the InnovationDecision scale, resulting in a sample size of 185 for the factor analysis portion of the study. This surpassed the recommended 10:1 subject to item ratio (Costello \& Osborne, 2005) and was therefore deemed adequate.

The majority of participants were female (71.3\%), PhD-level clinicians (59.1\%), of European descent $(80.9 \%)$, who worked mainly in private practice $(58.0 \%)$. They most commonly endorsed a Cognitive-Behavioural orientation (33.3\%) (Table 4).

\section{Analyses}

IBM SPSS Statistics version 25 was used to conduct the descriptive and factor analyses. Chi-squared tests, Fisher's exact tests, and ANOVA analyses were used to characterize 
differences between groups. An EFA was conducted to determine the factor structure of the Innovation-Decision scale.

\section{Results}

\section{Preliminary and Demographic Findings}

The majority of participants either agreed or strongly agreed with the statement "I support the use of EBP" (83.6\%). Similarly, the majority agreed or strongly agreed with the statements, "My clinical setting supports/endorses the use of EBP" (75.8\%) and "My graduate/professional training program supported the use of EBP" (66.7\%) (Table 5). Chisquared analyses demonstrated that individuals who supported the use of EBP were significantly more likely to have been trained in, $\chi^{2}(1)=82.781, p<.05$, or work in a clinical setting, $\chi^{2}(1)=$ $121.555, p<.05$, that was supportive of EBP. Two thirds of participants $(66.4 \%)$ either agreed or strongly agreed that "PM is a form of EBP". Similarly, individuals who believed that PM is a form of EBP were significantly more likely to have been trained in, $\chi^{2}(1)=32.107, p<.05$, or work in a clinical setting, $\chi^{2}(1)=29.703, p<.05$, that was supportive of EBP.

Most participants indicated that they could choose whether or not to use a PM measure (80.2\%) (Table 5). Thirty-nine point four percent of participants identified as current users; $18.8 \%$ had previously used, but were not currently using a measure (previous users); $28.0 \%$ were not using a measure (aware non-users); and 13.8\% were not aware of PM (unaware non-users).

Demographic differences between user groups (i.e., current user, previous user, aware non-user, and unaware non-user) were explored using ANOVA analyses and Fisher's exact tests, as cell counts were too low to conduct Chi-squared tests. No differences were found with respect to age, $F(1,412)=0.597, p=.440$, years of experience, $F(1,412)=1.076, p=.300$, gender $(p=$ 
$.297)$, ethnicity $(p=.221)$, education $(p=.451)$, clinical setting $(p=.312)$, nor theoretical orientation $(p=.103)$.

ANOVA analyses were used to explore differences between user groups with respect to the level of personal support of EBP, $F(3,409)=16.684, p<.05$, clinical settings' support of EBP, $F(3,409)=19.482, p<.05$, training programs' support of EBP, $F(3,409)=7.669, p<.05$, and the perception that PM is a form of $\mathrm{EBP}, F(3,409)=30.414, p<.05$. Bonferroni post hoc analyses indicated significant differences in one's personal support of EBP between users and previous users $(p<.05)$, users and non-users $(p<.05)$, users and unaware non-users $(p<.05)$, as well as previous users and unaware non-users $(p<.05)$. Users were more supportive of EBP when compared to all non-users and previous users were more supportive of EBP when compared to unaware non-users. There were significant differences in the clinical settings' support of EBP between users and previous users $(p<.05)$, users and non-users $(p<.05)$, as well as users and unaware non-users $(p<.05)$. Users reported working in clinical settings that were more supportive of EBP when compared to non-users. Users reported coming from training programs that were more supportive of EBP than unaware non-users $(p<.05)$. Finally, there were significant differences in the perception that PM is a form of EBP between users and previous-users $(p<.05)$, user and non-users $(p<.05)$, users and unaware non-users $(p<.05)$, as well as previous users and unaware non-users $(p<.05)$. Users more strongly agreed that PM is a form of EBP when compared to non-users and previous users more strongly agreed that PM is a form of EBP when compared to unaware non-users.

\section{Exploratory Factor Analysis (EFA)}

To examine the appropriateness of a factor analysis, the correlation matrix was inspected. All items correlated with several other items by at least 0.3 (Tabachnick, Fidell, \& Ullman, 
2007). Bartlett's test of sphericity was significant, $\chi^{2}(136)=1816.722, p<.05$, and the KaiserMeyer-Olkin measure of sampling adequacy was good (0.849) (Tabachnick et al., 2007). Inspection of the commonalities table demonstrated that all items were above 0.3 , further suggesting shared variance. Thus, a factor analysis was deemed appropriate for this data set. A principal component analysis was initially carried out to explore possible factor solutions (Pett, Lackey, \& Sullivan, 2003). An oblimin rotation was used as it was assumed that there were relationships between the factors. Eigen values were over 1 for the first four-factors, with the first two-factors explaining $34.56 \%$ and $19.68 \%$ of the total variance respectively and the third and fourth factors explaining $8.63 \%$ and $6.76 \%$ of the total variance respectively. Inspection of the scree plot (Figure 2) indicated either a two or four-factor solution (Osborne, Costello, \& Kellow, 2008) and so a maximum likelihood extraction was then used to explore both a two and four-factor solution. All the possible factors were named based on the kind of items that generally loaded onto each factor. For the two-factor solution, the factors were labelled: 1) Knowledge, and 2) Persuasion-Decision. For the four-factor solution, the factors were labelled 1) Existing Attitudes and Beliefs, 2) Knowledge, 3) Social Reinforcement, and 4) Persuasion-Decision (see Table 6).

In selecting a solution, several considerations were made. The scree plot favoured a twofactor solution, as the curve levelled off more significantly after the third factor (Figure 2). While names were developed for each factor in both the two and four-factor solution, the names more closely resembled Rogers' (2003) theory for the two-factor solution. Finally, in the four-factor solution, two of the four-factors had only two items. While it is generally recommended that no factor have fewer than three items (Raubenheimer, 2004), it has also been argued that two-item factors may be acceptable when the items are highly correlated with each other $(r>.70)$, and 
fairly uncorrelated with the other items (Yong \& Pearce, 2013). In the present data, while the Existing Attitudes and Belief factor's items were highly correlated $(r=.877)$, the Social Reinforcement factor's items were only moderately correlated $(r=.605)$. For these reasons a two-factor solution was selected. The factor transformation matrix indicated low correlations between factors 1 and 2 (.22) and so finally, a varimax rotation was used (Thompson, 2004). No items were eliminated as they all demonstrated a factor loading of 0.3 or above. This final twofactor solution explained $54.249 \%$ of the total variance. The factor loading matrix for this final solution is presented in Table 7.

Internal consistency of the factors was examined using Cronbach's alpha and determined to be adequate for Knowledge $(\alpha=.775)$ and good for Persuasion-Decision $(\alpha=.879)$ (Nunnally, 1994). Composite scores for both factors were created. The sample demonstrated similar average levels of Knowledge $(M=3.51, S E .05)$ and Persuasion-Decision $(M=3.58, S E$ 0.04) with respect to PM. Both factors demonstrated acceptable levels of skewness (Knowledge $=-0.418$, Persuasion and Decision $=-0.392)$ and kurtosis $($ Knowledge $=0.256$, Persuasion and Decision $=0.767)$. The Shapiro-Wilk test of normality demonstrated normality for PersuasionDecision, $W(185)=0.981, p=.12$, and a deviation from normality for Knowledge, $W(185)=$ $0.981, p<.05$.

Overall, the analyses demonstrated two-factors underlying the Innovation-Decision survey: 1) Knowledge, and 2) Persuasion-Decision. The factors demonstrated acceptable to good internal consistency in the EFA.

\section{Study 2}

As stated earlier, the aim of Study 2 was to validate the factor structure determined in Study 1 using a CFA. 


\section{Method}

\section{Procedure}

A certificate of ethical approval was attained from the academic institution of the researchers. Participants were recruited for a larger, related project. As in Study 1, clinicians were recruited via e-mail using addresses attained from public, online psychological association/organization directories across Canada in the Spring and Summer of 2019. Given issues related to the language, Study 2 did not include clinicians in Quebec. Potential participants were informed of the purpose of the study and what participation entailed. In this case, participation required significantly more time as the participants were asked to complete several surveys and engage with a PM dissemination intervention. The Innovation-Decision scale was administered prior to all other surveys and before using the intervention.

Two hundred and forty-three clinicians started the survey out of a possible 4611 e-mail invitations. Thirty-six participants with missing data were excluded from the analysis, most of whom $(n=26)$ did not get past the initial question, resulting in a sample size of 207 (final response rate $=4.5 \%$ ). Given that only previous users and aware non-users were included in the CFA, the sample size was further reduced to 97 . While this did not meet the targeted recommendation of a subject to item ratio of 10:1 (Schreiber, Amaury, Stage, Barlow, \& King, 2006), lower minimum sample sizes are permissible with higher item to factor ratios (Mundfrom, Shaw, \& Ke, 2005). For the item to factor ratio in the present study Mundfrom et al. (2005) recommends a sample size ranging from 60 (good) to 130 (excellent), which this study attained.

\section{Participants}


As in the initial sample, the majority of participants were female $(68.1 \%), \mathrm{PhD}$-level clinicians (68.6\%), of European descent (79.7\%), who worked mainly in private practice (66.2\%). They most commonly endorsed a Cognitive-Behavioural orientation (40.1\%) (Table 8).

\section{Analyses}

IBM SPSS Statistics version 25 was used to conduct the descriptive analyses. Chisquared tests, Fisher's exact tests, and ANOVA analyses were used to characterize differences between groups. Mplus 8 version 1.6 was used to conduct a CFA to validate the InnovationDecision scale developed in Study 1.

\section{Results}

\section{Preliminary and Demographic Findings}

The majority of participants either agreed or strongly agreed with the statement "I support the use of EBP” (90.8\%). Similarly, the majority agreed or strongly agreed with the statements, "My clinical setting supports/endorses the use of EBP" (82.1\%) and "My graduate/professional training program supported the use of EBP” (73.9\%) (Table 9). Individuals who either agreed or strongly agreed that they supported the use of EBP were significantly more likely to have been trained in, $\chi^{2}(1)=14.910, p<.05$, or work in a clinical setting, $\chi^{2}(1)=$ $36.412, p<.05$, that was supportive of EBP. Most participants $(79.7 \%)$ either agreed or strongly agreed that PM was a form of EBP and individuals who believed this were more likely to have been trained in, $\chi^{2}(1)=12.670, p<.05$, or work in a clinical setting, $\chi^{2}(1)=18.336, p<.05$, that was supportive of EBP.

Most participants indicated that they could choose whether or not to use a PM measure $(84.5 \%)$ (Table 9). Forty-one point five percent identified as current users; $16.4 \%$ had previously 
used, but were not currently using the measures; $30.4 \%$ were not using the measures; and $11.6 \%$ were not aware of PM.

ANOVA analyses and Fisher's Exact Tests were used to explore demographic differences between user groups (i.e., current user, previous user, aware non-user, and unaware non-user). Two-sided Fisher's exact tests were used as cell counts were too low to conduct Chi squared tests. No differences were found with respect to years of experience, $F(3,203)=1.720, p=$ .164 , gender $(p=.155)$, education $(p=.866)$, clinical setting $(p=.105)$, or theoretical orientation $(p=.054)$. Significant differences were found with respect to age, $F(3,203)=3.666), p<.05$, with Bonferroni post hoc tests demonstrating that unaware non-users were significantly older than previous users $(p<.05)$. Significant differences were also found with respect to ethnicity ( $p$ $<.05$ ); post hoc tests were not performed because several cell counts were less than 5 .

ANOVA analyses explored differences between user groups with respect to the level of personal support of EBP, $F(3,203)=6.624, p<.05$, clinical settings' support of EBP, $F(3,203)$ $=4.785, p<.05$, training programs' support of EBP, $F(3,203)=2.749, p<.05$, and the perception that $\mathrm{PM}$ is a form of $\mathrm{EBP}, F(3,203)=6.389, p<.05$. Bonferroni post hoc analyses indicated significant differences in one's personal support of EBP between users and non-users $(p<.05)$, users and unaware non-users $(p<.05)$, as well as previous users and unaware nonusers $(p<.05)$. Users were more supportive of EBP when compared to non-users and previous users were more supportive of EBP when compared to unaware non-users. There were significant differences in the clinical settings' support of EBP between users and non-users $(p<$ $.05)$ as well as users and unaware non-users $(\mathrm{p}<.05)$. Users reported to be working in clinical settings that were more supportive of EBP when compared to non-users. Users reported coming from training programs that were more supportive of EBP than unaware non-users $(p<.05)$. 
Finally, there were significant differences in the perception that PM is a form of EBP between users and non-users $(p<.05)$, users and unaware non-users $(p<.05)$, previous users and unaware non-users $(p<.05)$, as well as non-users and unaware non-users $(p<.05)$. Users more strongly agreed that PM is a form of EBP when compared to non-users, previous users more strongly agreed that PM is a form of EBP when compared to unaware non-users, and non-users more strongly agreed that PM is a form of EBP when compared to unaware non-users.

\section{Confirmatory Factor Analysis}

A CFA was conducted to evaluate the two-factor solution determined in the Study 1. A weighted least squares mean and variance adjusted estimator was used because the data was categorical. The CFI and TLI were .837 and .813 respectively, and the RMSEA was above the recommended .05 and therefore not acceptable at .192 (see Table 10) (Browne \& Cudeck, 1993; Hu \& Bentler, 1999). The unstandardized parameter estimates, standard errors, and $p$ values are presented in Table 8. Given that the low fit indices, the CFA was re-attempted using the previously considered four-factor solution. The CFI and TLI both improved to .945 and .934 respectively; however, the RMSEA remained in the not acceptable range at .114 (see Table 10) (Browne \& Cudeck, 1993; Hu \& Bentler, 1999). The standardized estimates, standard errors, and $\mathrm{p}$ values for each item are presented for both the two (see Table 11) and four (see Table 12) factor solution. Despite improvements in the CFI, TLI, and RMSEA for the modified CFA, the improvements were considered insufficient to modify the factor structure determined in the initial EFA.

\section{Discussion}

In both Study 1 and 2, most participants were supportive of EBP and came from training sites and clinical settings that were also supportive of EBP. In both samples, individuals who 
were supportive of EBP were more likely to have been trained in or work in a setting that was also supportive of EBP. Additionally, PM users tended to be more supportive of EBP and come from training sites or clinical settings that were more supportive of EBP. As has been reported previously (Aarons, 2004; Borntrager et al., 2009; Nelson \& Steele, 2007; Stewart \& Chambless, 2007, 2009), training and work environment appear to influence attitudes towards and use of EBP. Given that recent estimates found that only $26.5 \%$ of APA accredited sites were using PM (Overington et al., 2016), improving uptake in training sites may be an effective route to improving overall adoption.

Previous researchers have also found that demographic factors such as theoretical orientation (Stewart \& Chambless, 2007) and work setting (Nelson \& Steele, 2007) relate to attitudes towards or use of EBP. However, the present sample did not confirm these findings: participant demographics were generally not meaningfully related to attitudes towards or use of EBP.

Higher levels of PM use (39.4\% in Study 1, 41.5\% in Study 2) were reported when compared to previous Canadian estimates, in which only $12 \%$ of psychologists identified as users (Ionita, 2015). The present results align more closely with an American survey which found that $38.5 \%$ of participants were monitoring progress and using feedback (Jensen-Doss et al., 2016). In the American survey, however, use was intermittent: most were using the measures less than once a month and only 5.2\% were using the measures every 1-2 sessions. In the present study, around half of users (i.e., $47.8 \%$ in Study 1, 53.7\% in Study 2) reported using the measures regularly. This high proportion of regular PM users may reflect an increase in use, but it may also be a function of sampling bias. Our invitation to participate, which indicated our research interest in PM, may have attracted more individuals who were already using the measures. 
Despite the research support for PM (Connolly Gibbons et al., 2015; Dyer et al., 2016; Gondek et al., 2016; Goodman et al., 2013; Lambert et al., 2005; Lambert \& Shimokawa, 2011; Reese, Norsworthy, et al., 2009), only $66.4 \%$ of participants in Study 1 and $79.7 \%$ of participants in Study 2 either agreed or strongly agreed that PM is a form of EBP. It may be that clinicians are confusing EBP with empirically supported treatments (ESTs). ESTs are treatments. EBP is a broader term that refers to the integration of the best available research with clinical expertise in the context of patient characteristics, culture, preferences (American Psychologist, 2006). If participants understood EBP as being limited to ESTs, it could explain why a large proportion of clinicians did not recognize PM as a form of EBP. This may be due to training: clinicians who believed that PM is a form of EBP tended to have been trained at institutions that were more supportive of EBP. It may also be that participants are either unaware of or unconvinced by the body of research supporting PM. Given that users tended to be significantly more likely to perceive PM as an EBP, this belief may be an important mediator in PM adoption. Increasing uptake may involve showing clinicians how PM is an EBP, either through educating clinicians on what constitutes EBP or through disseminating PM research more effectively.

\section{Scale Development and Validation}

Both two- and four-factor solutions were thoroughly considered in the analyses. The researchers ultimately decided on a two-factor structure which included the factors Knowledge and Persuasion-Decision. Most items developed under the knowledge construct loaded onto the Knowledge factor with some exceptions. The credibility of the message item (i.e., I believe that what I have learned about PM to date is credible) as well as the discussion with others item (i.e., I have discussed PM with others), which were expected to load onto persuasion, loaded onto Knowledge. It appears that if information is not deemed credible, not only is it not persuasive, 
but it is also not even absorbed as knowledge. While Rogers' (2003) hypothesized that credibility would weigh more heavily in attitude development, it may actually have a stronger impact earlier; people do not learn what they do not believe to be true. Similarly, discussion with peers appears to be more of a source of new information and knowledge than persuasion.

In both the two and four factor solutions, the items did not effectively distinguish between persuasion and decision. It appears that the space between knowledge of the measures and having a positive attitude about them is larger than the space between having a positive attitude about the measures and deciding to use them. In recent decades, researchers in the field of psychology and economics have begun to pay more attention to the significant (Kahneman, 2013; Lerner, Li, Valdesolo, \& Kassam, 2015) and sometimes driving role (Kahneman, 2013; Loewenstein, Weber, Hsee, \& Welch, 2001) that affect or emotions have in decision making. Emotions can impact decisions directly and indirectly as well as consciously and unconsciously (Lerner et al., 2015). They do so via impacting the content and depth of thought as well as motivation (Lerner et al., 2015). Despite assumptions that we are rational beings, humans tend to rely on a frequently flawed, automatic, emotion-driven system when making decisions (Kahneman, 2013). Our analysis mirrors these ideas: knowledge, the basis for logic, was a distinct construct. Attitude and decision, however, were so tightly linked that they were not distinguishable.

Most items developed for the persuasion and decision constructs loaded onto the Persuasion-Decision factor. The exceptions were the items relating to whether the innovation is relevant and needed (i.e., In general, routine, systematic feedback is important, and in general, routine, systematic feedback is useful). These items were developed to account for the idea that individuals are more likely to attend to and interpret messages in ways that are consistent with 
their existing attitudes and beliefs. That is, if an individual already believes that feedback is relevant to their practice or believes that it could be useful for them, then they are more likely to pay attention to and agree with messages about PM. Interestingly, these items loaded onto the Persuasion-Decision factor. While general attitudes and beliefs may impact attention and interpretation of messages, it appears that they are more strongly linked to the affective reaction to messages. In this way, aspects of persuasion may impact knowledge, confirming Rogers' (2003) idea that Innovation-Decision is not always a linear process.

Despite targeting 170 previous users and aware non-users for Study 2, only 97 clinicians participated and so results should be interpreted with caution. The fact that the CFA did not confirm the factor solution determined in Study 1 may be a function of the small sample size. While this study proposed an initial version of the Innovation-Decision scale, future researchers should confirm the proposed factor structure with larger populations.

\section{Limitations and Future Directions}

While this study developed the first instrument to measure Rogers' (2003) InnovationDecision process, the scale is limited in the following ways. Firstly, it only evaluates the initial stages of diffusion: knowledge, persuasion, and decision. This was done to limit the impact of extraneous variables and measure the immediate impact of an intervention. Similarly, the scale items are not relevant for users, who are already past the implementation stage, as well as unaware non-users, who have not yet reached the knowledge stage. The scale is therefore limited to studying aware non-users prior to implementation and is therefore not a comprehensive measure of diffusion.

To conduct an EFA where legitimate inferences can be made about underlying factors, item response sets should be identical. To meet this requirement, some items that would have 
been more appropriately formatted as "yes or no" questions (i.e., I know what PM is) were instead associated with the five-point likert scale response set (strongly disagree to strongly agree). This may have negatively impacted the user-experience of the survey or obscured some of the data.

The final limitation was the low sample size for the CFA, in which only 97 of the targeted 170 participants was attained. Despite using a similar recruiting technique to Study 1, half of the number of participants were recruited for Study 2. This was likely due to the increased demands on the Study 2 participants; participants were asked to complete several surveys, partake in a continuing education intervention, and complete a quiz to evaluate learning. Participants were offered CE credits in exchange for participation; however, this was insufficient to achieve the targeted sample size.

The Innovation-Decision scale developed with this data set should be used as a preliminary version. Future researchers should use larger and more diverse samples to continue to improve the validity of the scale.

\section{Conclusion}

This is the first study to attempt to develop a validated measure based on Rogers' (2003) Innovation-Decision process. Future research on this scale should determine its efficacy in a testretest style setting, which will permit researchers to determine the quantitative impact of certain dissemination interventions. Future researchers may also combine this scale with a more longitudinal evaluation of dissemination, permitting an examination of implementation and confirmation, and hence the full Innovation-Decision process. Ultimately, the scale will improve our understanding of KT and facilitate the development of effective dissemination interventions. 
Tables and Figures

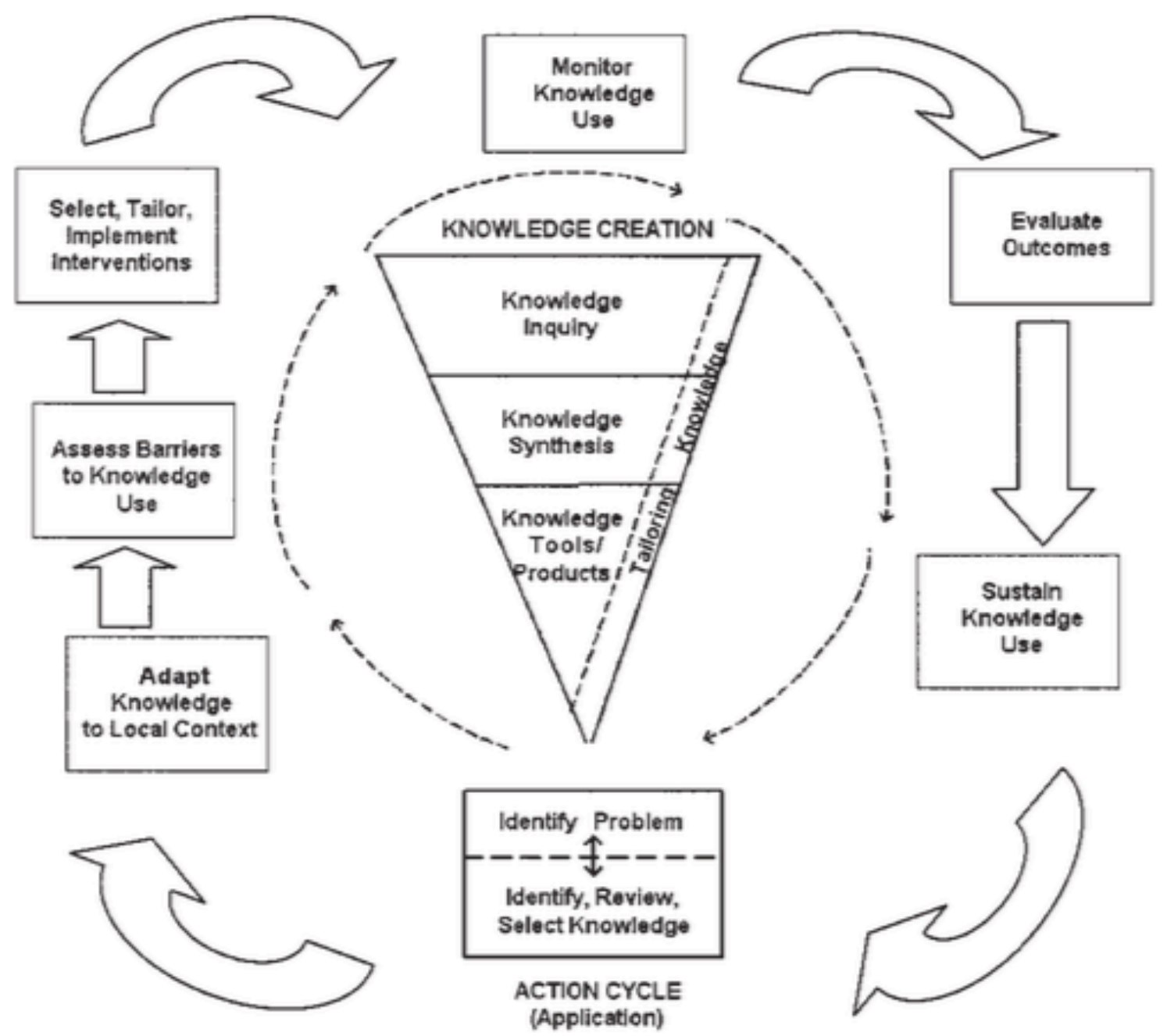

Figure 1. Knowledge to Action model. Figure reprinted with permission from "Lost in knowledge translation: Time for a map?" by I.D. Graham, et al., 2006, The Journal of Continuing Education in Health Profession, 22, p. 19. 


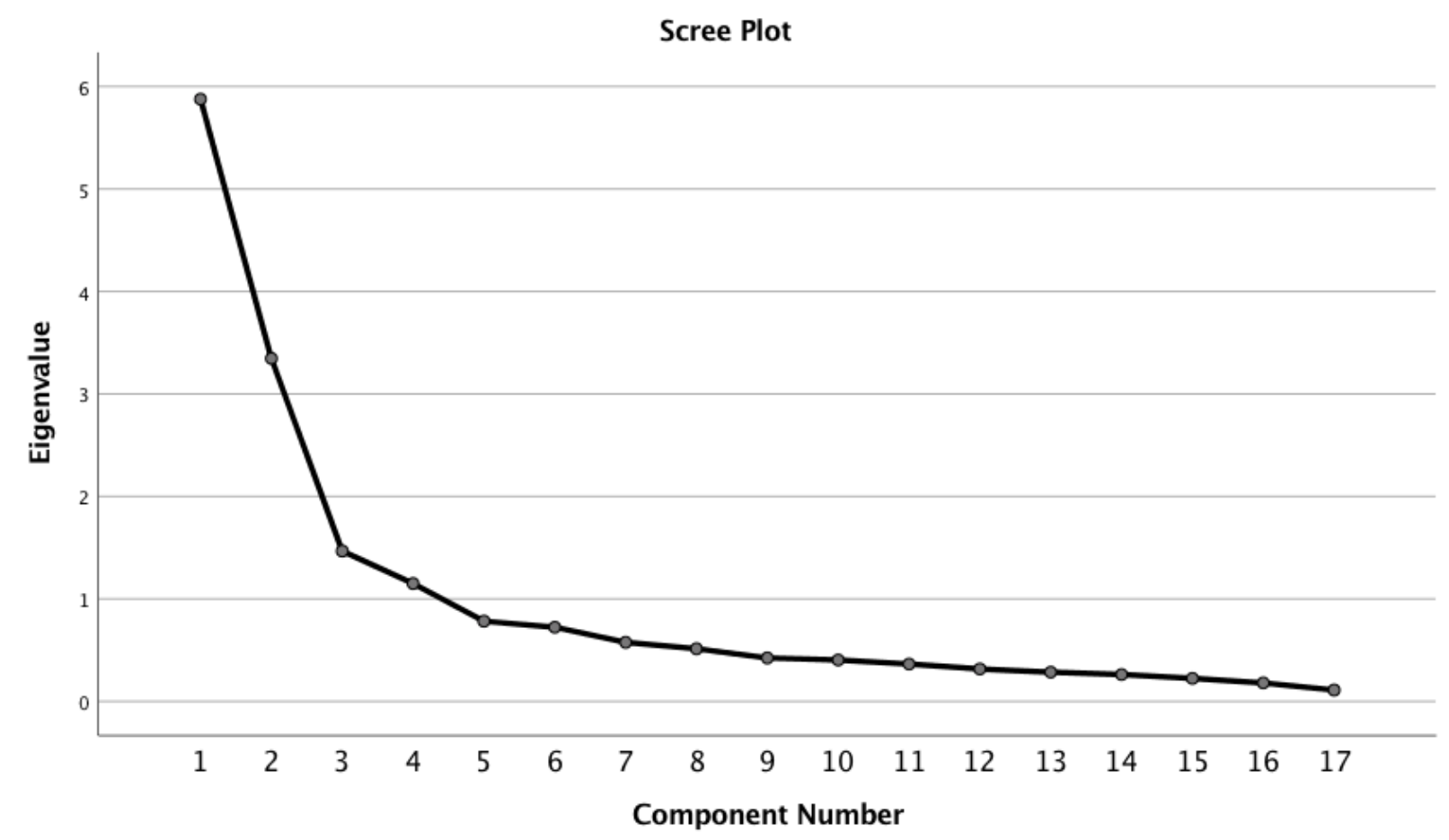

Figure 2. Scree plot from the principle components analysis.

Table 1

Items Developed from Rogers' (2003) Diffusion of Innovations Model and McGuire's (1989) Hierarchy of Effects Model Representing the Factor Knowledge

Knowledge items (PM Knowledge items (general survey) survey)

Relevance of Innovation

Need for Innovation

Awareness

How-to

Principles

Recall of Information
In general, routine, systematic feedback is important.

In general, routine, systematic feedback is useful. $\mathrm{I}$ know what PM is.

I know how to use PM.

I understand why PM works.

I can easily really basic information about PM without having to consult other sources.
In general, [function of innovation] is important. In general, [function of innovation] is useful. I know what [innovation] is.

I know how to use [innovation].

I understand why [innovation] works.

I can easily really basic information about [innovation] without having to consult other sources. 


\begin{tabular}{lll}
\hline Comprehension of message & $\begin{array}{l}\text { I understand what I have } \\
\text { learned about PM to date. }\end{array}$ & $\begin{array}{l}\text { I understand what I have } \\
\text { learned about [innovation] to } \\
\text { date. }\end{array}$ \\
$\begin{array}{l}\text { Knowledge for effective } \\
\text { adoption }\end{array}$ & $*$ Captured with how-to item & $*$ Captured with how-to item \\
\hline
\end{tabular}

Table 2

Items Developed from Rogers' (2003) Diffusion of Innovations Model and McGuire's (1989) Hierarchy of Effects Model Representing the Factor Persuasion

Persuasion items (PM survey) Persuasion items (general
survey)

\begin{tabular}{|c|c|c|}
\hline Attitude & $\begin{array}{l}\text { I have a positive attitude about } \\
\text { PM. }\end{array}$ & $\begin{array}{l}\text { I have a positive attitude about } \\
\text { [innovation]. }\end{array}$ \\
\hline Information seeking & $\begin{array}{l}\text { I intend to learn more about } \\
\text { PM. }\end{array}$ & $\begin{array}{l}\text { I would like to learn more } \\
\text { about [innovation]. }\end{array}$ \\
\hline Credibility of the message & $\begin{array}{l}\text { I believe that what I have } \\
\text { learned about PM to date is } \\
\text { credible. }\end{array}$ & $\begin{array}{l}\text { I believe that what I have } \\
\text { learned about [innovation] to } \\
\text { date is credible. }\end{array}$ \\
\hline Mental vicarious trial & $\begin{array}{l}\text { I can imagine myself using } \\
\text { PM. }\end{array}$ & $\begin{array}{l}\text { I can imagine myself using } \\
\text { [innovation]. }\end{array}$ \\
\hline Social reinforcement seeking & $\begin{array}{l}\text { I would like to know what my } \\
\text { colleagues think about PM. }\end{array}$ & $\begin{array}{l}\text { I would like to know what my } \\
\text { colleagues think about } \\
\text { [innovation]. }\end{array}$ \\
\hline Attitude & *Captured with attitude item & *Captured with attitude item \\
\hline Discussion with others & $\begin{array}{l}\text { I have discussed PM with } \\
\text { others. }\end{array}$ & $\begin{array}{l}\text { I have discussed [innovation] } \\
\text { with others. }\end{array}$ \\
\hline Acceptance of message & PM is useful. & [innovation] is useful. \\
\hline
\end{tabular}

Table 3

Items Developed from Rogers' (2003) Diffusion of Innovations Model and McGuire's (1989) Hierarchy of Effects Model Representing the Factor Decision

\begin{tabular}{|c|c|c|}
\hline & Decision items (PM survey) & $\begin{array}{c}\text { Decision items (general } \\
\text { Survey) }\end{array}$ \\
\hline Decision & I have decided to use PM. & $\begin{array}{l}\text { I have decided to use } \\
\text { [innovation]. }\end{array}$ \\
\hline
\end{tabular}




\begin{tabular}{lll} 
Information seeking trial & $\begin{array}{l}\text { I would like to try out PM to } \\
\text { see if it is useful for me. }\end{array}$ & $\begin{array}{l}\text { I would like to try out } \\
\text { [innovation] to see if it is } \\
\text { useful for me. }\end{array}$ \\
Vicarious trial & $\begin{array}{l}\text { I would like to know about the } \\
\text { experiences of my colleagues } \\
\text { who have used PM. }\end{array}$ & $\begin{array}{l}\text { I would like to know about the } \\
\text { experiences of my colleagues } \\
\text { who have used [innovation]. }\end{array}$ \\
Information seeking & $\begin{array}{l}\text { *Captured with information } \\
\text { seeking item in among } \\
\text { Persuasion Items }\end{array}$ & $\begin{array}{l}\text { *Captured with information } \\
\text { seeking item in among } \\
\text { Persuasion Items }\end{array}$ \\
\hline
\end{tabular}

Table 4

Study 1 Demographics Characteristics $(N=413)$

\begin{tabular}{|c|c|}
\hline & $\mathrm{n}(\%)$ \\
\hline \multicolumn{2}{|l|}{ Gender } \\
\hline Male & $115(27.8 \%)$ \\
\hline Female & $295(71.3 \%)$ \\
\hline Undisclosed & $2(0.5 \%)$ \\
\hline Other & $2(0.5 \%)$ \\
\hline \multicolumn{2}{|l|}{ Ethnicity } \\
\hline Aboriginal & $3(0.7 \%)$ \\
\hline African/Caribbean & $5(1.2 \%)$ \\
\hline East Asian & $48(11.6 \%)$ \\
\hline South Asian & $6(1.5 \%)$ \\
\hline Southeast Asian & $1(0.2 \%)$ \\
\hline European & $335(81.1 \%)$ \\
\hline Latin American & $3(0.7 \%)$ \\
\hline Middle Eastern & $12(2.9 \%)$ \\
\hline \multicolumn{2}{|l|}{ Education } \\
\hline MA & $95(22.9 \%)$ \\
\hline $\mathrm{MSc}$ & $26(6.3 \%)$ \\
\hline $\mathrm{PhD}$ & $220(53.1 \%)$ \\
\hline PsyD & $15(3.6 \%)$ \\
\hline MD & $3(0.7 \%)$ \\
\hline Ed.D & $7(1.7 \%)$ \\
\hline Other & $48(11.6 \%)$ \\
\hline \multicolumn{2}{|l|}{ Primary employment setting } \\
\hline Private practice & $240(58.0 \%)$ \\
\hline Hospital & $60(14.5 \%)$ \\
\hline Community clinic & $45(10.9 \%)$ \\
\hline $\begin{array}{l}\text { School/college/university } \\
\text { counselling centre }\end{array}$ & $37(8.9 \%)$ \\
\hline
\end{tabular}


Other

Primary Theoretical Orientation

Cognitive Behavioral

Third-wave Cognitive Behavioral

Psychodynamic

Humanistic

Existential

Experiential

Systemic

Narrative

Interpersonal

Integrative/Eclectic

Other
$32(7.7 \%)$

$138(33.3 \%)$

$67(16.2 \%)$

$49(11.8 \%)$

$20(4.8 \%)$

$4(1.0 \%)$

$4(1.0 \%)$

$11(2.7 \%)$

$5(1.2 \%)$

$11(2.7 \%)$

$89(21.5 \%)$

$16(3.9 \%)$

Table 5

Proportion of Clinicians Either Agreeing or Strongly Agreeing

\begin{tabular}{ll} 
Item & $\mathrm{n}(\%)$ \\
\hline $\begin{array}{l}\text { I support the use of EBP } \\
\text { My clinical settings supports/endorses the use }\end{array}$ & $346(83.6 \%)$ \\
$\begin{array}{l}\text { of EBP } \\
\text { My graduate/professional training program }\end{array}$ & $276(66.7 \%)$ \\
$\begin{array}{l}\text { supported the use of EBP } \\
\text { PM is a form of EBP }\end{array}$ & $275(66.4 \%)$ \\
$\begin{array}{l}\text { I can choose whether or not I use a PM } \\
\text { measure }\end{array}$ & $332(80.2 \%)$ \\
\hline
\end{tabular}

Table 6

Factor Solutions Considered After the Initial EFA

\section{Two factor solution}

\section{Knowledge}

I know what PM is. (K3)

I know how to use PM. (K4)

I understand why PM works. (K5)

I can easily recall basic information about

PM without having to consult other

sources. (K6)

I understand what I have learned about PM

to date. (K7)

I believe that what I have learned about

$\mathrm{PM}$ to date is credible. (P3)
Four factor solution

\section{Existing Attitudes and Beliefs}

In general, routine and systematic feedback is useful. (K1)

In general, routine and systematic feedback is important. (K2)

\section{Knowledge}

I know what PM is. (K3)

I know how to use PM. (K4)

I understand why PM works. (K5) 
I have discussed PM with others. (P6)

\section{Persuasion and Decision}

In general, routine and systematic feedback is useful. (K1) In general, routine and systematic feedback is important. (K2) I have a positive attitude towards PM. (P1) I intend to learn more about PM. (P2)

I can imagine myself using PM. (P4)

I would like to know what my colleagues think about PM. (P5)

$\mathrm{PM}$ is useful. (P7)

I have decided to use PM. (D1)

I would like to try PM to see if it is useful for me. (D2)

I would like to know about the experiences of my colleagues who have used PM. (D3)
I can easily recall basic information about PM without having to consult other sources. (K6)

I understand what I have learned about PM to date. (K7)

I believe that what I have learned about $\mathrm{PM}$ to date is credible. (P3)

I have discussed PM with others. (P6)

\section{Social Reinforcement}

I would like to know what my colleagues think about PM. (P5)

I would like to know about the experiences of my colleagues who have used PM. (D3)

\section{Persuasion and Decision}

I have a positive attitude towards PM. (P1)

I intend to learn more about PM. (P2)

I can imagine myself using PM. (P4)

PM is useful. (P7)

I have decided to use PM. (D1)

I would like to try PM to see if it is useful for me. (D2)

Table 7

Factor Loadings Based on Maximum Likelihood Extraction with a Varimax Rotation for Each Item in the Innovation-Decision Scale $(N=185)$.

\begin{tabular}{|c|c|c|}
\hline Item & $\begin{array}{l}\text { Factor 1: Persuasion } \\
\text { and Decision }\end{array}$ & Factor 2: Knowledge \\
\hline $\begin{array}{l}\text { In general, routine and systematic feedback is } \\
\text { useful. }(\mathrm{K} 1)\end{array}$ & .423 & .224 \\
\hline $\begin{array}{l}\text { In general, routine and systematic feedback is } \\
\text { important. (K2) }\end{array}$ & .442 & .255 \\
\hline I know what PM is. (K3) & .058 & .786 \\
\hline I know how to use PM. (K4) & -.016 & .775 \\
\hline I understand why PM works. (K5) & .278 & .717 \\
\hline $\begin{array}{l}\text { I can easily recall basic information about PM } \\
\text { without having to consult other sources. (K6) }\end{array}$ & -.046 & .584 \\
\hline $\begin{array}{l}\text { I understand what I have learned about PM to } \\
\text { date. }(\mathrm{K} 7)\end{array}$ & -.0445 & .833 \\
\hline I have a positive attitude towards PM. (P1) & .711 & .283 \\
\hline I intend to learn more about PM. (P2) & .808 & -.074 \\
\hline
\end{tabular}


I believe that what I have learned about PM to .288

date is credible. (P3)

I can imagine myself using PM. (P4)

.780

.229

I would like to know what my colleagues

.370

$-.031$

think about PM. (P5)

I have discussed PM with others. (P6)

.173

.571

$\mathrm{PM}$ is useful. (P7)

.616
.398

I have decided to use PM. (D1)

$.698 \quad .126$

I would like to try PM to see if it is useful for

.882

.005

me. (D2)

I would like to know about the experiences of

.520

$-.130$

my colleagues who have used PM. (D3)

Table 8

Study 2 Demographics Characteristics $(N=207)$

\begin{tabular}{ll}
\hline & $\mathrm{n}(\%)$ \\
\hline Gender & $65(31.4 \%)$ \\
Male & $141(68.1 \%)$ \\
Female & $1(0.5 \%)$ \\
Undisclosed & \\
Ethnicity & $1(0.5 \%)$ \\
Aboriginal & $2(1.0 \%)$ \\
African/Caribbean & $6(2.9 \%)$ \\
East Asian & $8(3.9 \%)$ \\
South Asian & $1(0.5 \%)$ \\
Southeast Asian & $165(79.7 \%)$ \\
European & $5(2.4 \%)$ \\
Latin American & $5(2.4 \%)$ \\
Middle Eastern & $12(5.8 \%)$ \\
Other & \\
Education & $37(17.9 \%)$ \\
MA & $11(5.3 \%)$ \\
MSc & $126(60.9 \%)$ \\
PhD & $12(5.8 \%)$ \\
PsyD & $4(1.9 \%)$ \\
EdD & $17(8.2 \%)$ \\
Other & \\
Primary employment setting & $137(66.2 \%)$ \\
Private practice & $17(8.2 \%)$ \\
Hospital & $12(5.8 \%)$ \\
Community clinic & $31(15.0 \%)$ \\
School/college/university & \\
counselling centre & $10(4.8 \%)$ \\
Other & \\
Primary Theoretical Orientation & \\
\hline
\end{tabular}




\begin{tabular}{ll}
\hline Cognitive Behavioral & $83(40.1 \%)$ \\
Third-wave Cognitive Behavioral & $32(15.5 \%)$ \\
Psychodynamic & $16(7.7 \%)$ \\
Humanistic & $8(3.9 \%)$ \\
Existential & $1(0.5 \%)$ \\
Experiential & $4(1.9 \%)$ \\
Systemic & $4(1.9 \%)$ \\
Interpersonal & $3(1.4 \%)$ \\
Integrative/Eclectic & $47(22.7 \%)$ \\
Other & $9(4.3 \%)$ \\
\hline
\end{tabular}

Table 9

Proportion of Clinicians Either Agreeing or Strongly Agreeing

\begin{tabular}{ll}
\hline Item & $\mathrm{n}(\%)$ \\
\hline $\begin{array}{l}\text { I support the use of EBP } \\
\text { My clinical settings supports/endorses the use } \\
\text { of EBP }\end{array}$ & $188(90.8 \%)$ \\
$\begin{array}{l}\text { My graduate/professional training program } \\
\text { supported the use of EBP }\end{array}$ & $153(73.9 \%)$ \\
PM is a form of EBP & $165(79.7 \%)$ \\
$\begin{array}{l}\text { I can choose whether or not I use a PM } \\
\text { measure }\end{array}$ & $175(84.5 \%)$ \\
\hline
\end{tabular}

Table 10

CFA Results for Both the Two- and Four-Factor Solutions

\begin{tabular}{llllll}
\hline Number of factors in CFA & CFI & TFI & RMSEA & Chi $^{2}$ & P value \\
\hline Two factor model & 0.837 & 0.813 & 0.192 & 540.222 & 0.00 \\
Four factor model & 0.945 & 0.934 & 0.144 & 255.179 & 0.00 \\
\hline
\end{tabular}

Table 11

Standardized Estimates, Standard Errors, and P-Values for the Two Factor CFA Solution

\begin{tabular}{lccc}
\hline Item & Estimate & Standard Error & P Value \\
\hline Knowledge & & & \\
$\quad$ I know what PM is. (K3) & 0.838 & 0.046 & 0.000 \\
I know how to use PM. (K4) & 0.699 & 0.056 & 0.000 \\
$\quad$ I understand why PM works. (K5) & 0.742 & 0.058 & 0.000 \\
$\quad$ I can easily recall basic information about PM & 0.613 & 0.061 & 0.000 \\
$\quad$ without having to consult other sources. (K6) & & & 0.000 \\
$\quad$ I understand what I have learned about PM to & 0.743 & 0.058 & \\
$\quad$ & & & \\
\hline
\end{tabular}




\begin{tabular}{|c|c|c|c|}
\hline $\begin{array}{l}\text { I believe that what I have learned about PM to } \\
\text { date is credible. (P3) }\end{array}$ & 0.851 & 0.054 & 0.000 \\
\hline I have discussed PM with others. (P6) & 0.739 & 0.063 & 0.000 \\
\hline \multicolumn{4}{|l|}{ Persuasion and Decision } \\
\hline $\begin{array}{l}\text { In general, routine and systematic feedback is } \\
\text { useful. (K1) }\end{array}$ & 0.852 & 0.025 & 0.000 \\
\hline $\begin{array}{l}\text { In general, routine and systematic feedback is } \\
\text { important. (K2) }\end{array}$ & 0.829 & 0.026 & 0.000 \\
\hline I have a positive attitude towards PM. (P1) & 0.897 & 0.027 & 0.000 \\
\hline I intend to learn more about PM. (P2) & 0.683 & 0.054 & 0.000 \\
\hline I can imagine myself using PM. (P4) & 0.872 & 0.032 & 0.000 \\
\hline $\begin{array}{l}\text { I would like to know what my colleagues think } \\
\text { about PM. (P5) }\end{array}$ & 0.744 & 0.040 & 0.000 \\
\hline $\mathrm{PM}$ is useful. (P7) & 0.668 & 0.055 & 0.000 \\
\hline I have decided to use PM. (D1) & 0.727 & 0.047 & 0.000 \\
\hline $\begin{array}{l}\text { I would like to try PM to see if it is useful for } \\
\text { me. (D2) }\end{array}$ & 0.752 & 0.041 & 0.000 \\
\hline $\begin{array}{l}\text { I would like to know about the experiences of } \\
\text { my colleagues who have used PM. (D3) }\end{array}$ & 0.885 & 0.035 & 0.000 \\
\hline
\end{tabular}

Table 12

Standardized Estimates, Standard Errors, and P-Values for the Four Factor CFA Solution

\begin{tabular}{|c|c|c|c|}
\hline Item & Estimate & Standard Error & P Value \\
\hline \multicolumn{4}{|l|}{ Existing Attitudes and Beliefs } \\
\hline $\begin{array}{l}\text { In general, routine and systematic feedback is } \\
\text { useful. }(\mathrm{K} 1)\end{array}$ & 0.959 & 0.036 & 0.000 \\
\hline $\begin{array}{l}\text { In general, routine and systematic feedback is } \\
\text { important. (K2) }\end{array}$ & 0.925 & 0.038 & 0.000 \\
\hline \multicolumn{4}{|l|}{ Knowledge } \\
\hline I know what PM is. (K3) & 0.827 & 0.045 & 0.000 \\
\hline I know how to use PM. (K4) & 0.706 & 0.056 & 0.000 \\
\hline I understand why PM works. (K5) & 0.751 & 0.058 & 0.000 \\
\hline $\begin{array}{l}\text { I can easily recall basic information about PM } \\
\text { without having to consult other sources. (K6) }\end{array}$ & 0.628 & 0.062 & 0.000 \\
\hline $\begin{array}{l}\text { I understand what I have learned about PM to } \\
\text { date. (K7) }\end{array}$ & 0.745 & 0.058 & 0.000 \\
\hline $\begin{array}{l}\text { I believe that what I have learned about PM to } \\
\text { date is credible. (P3) }\end{array}$ & 0.828 & 0.052 & 0.000 \\
\hline I have discussed PM with others. (P6) & 0.748 & 0.060 & 0.000 \\
\hline \multicolumn{4}{|l|}{ Social Reinforcement } \\
\hline $\begin{array}{l}\text { I would like to know what my colleagues think } \\
\text { about PM. (P5) }\end{array}$ & 0.734 & 0.070 & 0.000 \\
\hline $\begin{array}{l}\text { I would like to know about the experiences of } \\
\text { my colleagues who have used PM. (D3) }\end{array}$ & 0.198 & 0.106 & 0.000 \\
\hline Persuasion and Decision & & & 0.000 \\
\hline
\end{tabular}




\begin{tabular}{llll}
\hline I have a positive attitude towards PM. (P1) & 0.926 & 0.026 & 0.000 \\
I intend to learn more about PM. (P2) & 0.718 & 0.055 & 0.000 \\
I can imagine myself using PM. (P4) & 0.891 & 0.033 & 0.000 \\
PM is useful. (P7) & 0.767 & 0.058 & 0.000 \\
I have decided to use PM. (D1) & 0.823 & 0.050 & 0.000 \\
I would like to try PM to see if it is useful for & 0.792 & 0.043 & 0.000 \\
me. (D2) & & \\
\hline
\end{tabular}




\section{Linking Manuscripts 2 and 3}

The findings from Manuscript 1 and 2 provide the foundation necessary to develop and test a PM dissemination intervention. The narrative review conducted in Manuscript 1 proposed how certain strategies, facilitators and processes may assist in the dissemination of a psychotherapy innovation such as PM. The Innovation-Decision scale developed in Manuscript 2 provides a validated and reusable instrument that can assess a PM dissemination intervention. Thus, the final paper of this dissertation describes the development and evaluation of such an intervention.

PsySuccess, our PM dissemination intervention, bundled a variety of dissemination strategies into a single online source. The featured strategies were based on the model developed in Manuscript 1. The Innovation-Decision scale was then used to evaluate PsySuccess and in doing so, the theoretical findings of Manuscript 1 were empirically validated. 


\title{
Manuscript 3
}

\section{PsySuccess: Evaluation of a Dissemination Intervention}

\author{
Megan Knoll ${ }^{1}$, Marilyn Fitzpatrick ${ }^{1}$, and Chiaki Konishi ${ }^{1}$ \\ ${ }^{1}$ Department of Educational and Counselling Psychology, McGill University
}




\begin{abstract}
The poor uptake of Progress Monitoring (PM) measures in psychotherapy is an example of the practice-research gap in psychology. To bridge this gap, effective dissemination strategies are needed. The authors of this paper developed an online PM dissemination intervention and the present study aimed to evaluate this intervention. Using the Innovation-Decision scale, weighted averages of (1) Knowledge and (2) Persuasion-Decision were calculated pre- and post-exposure to the intervention. Changes in (1) Knowledge and (2) Persuasion-Decision were calculated and $t$ tests were used to determine the significance of these changes. Overall, the intervention was effective. The impact of individual strategies employed on the intervention were also examined using repeated measures ANOVAs. Research and practical material were identified as strategies which contributed to changes in Knowledge and anecdotal material was identified as a strategy which contributed to changes in Persuasion-Decision. Contradictions were noted between the strategies that clinicians experienced as effective and those which were determined to be effective by the Innovation-Decision scale. A challenge in recruitment prompted a follow-up survey which assessed reasons for participation, non-participation, and non-completion among the initial pool of participants. Time was identified as the major barrier to clinician engagement. Implications for researchers looking to disseminate knowledge in the field of psychotherapy are discussed.
\end{abstract}




\section{PsySuccess: Evaluation of a Dissemination Intervention}

While psychotherapy is generally effective (Hunsley et al., 2014), effectiveness cannot be generalized to each case. A review of naturalistic psychotherapy data found that depending on the treatment site, between $3 \%-14 \%$ of patients deteriorated and $46 \%-61 \%$ of patients demonstrated no change while in psychotherapy (Hansen et al., 2002). Adding to these high rates of treatment failure, clinicians are poor at evaluating client progress and predicting client deterioration (Hannan et al., 2005). They also tend to overestimate how effective they are: on average, clinicians perceive their skills to be in the 80th percentile and no clinician perceives their skill to be below average (Walfish et al., 2012). Given that professional self-doubt has emerged as a factor contributing to therapist efficacy (Nissen-Lie et al., 2013; Nissen-Lie et al., 2017), this tendency for clinicians to be overconfident may be especially problematic.

The use of Progress Monitoring (PM) measures can help clinicians overcome these challenges. PM measures provide clinicians with regular, systematic feedback on client progress. Their use has been associated with improved outcomes across treatment type and patient population (Anker et al., 2009; Bickman et al., 2011; Connolly Gibbons et al., 2015; Dyer et al., 2016; Gondek et al., 2016; Goodman et al., 2013; Lambert, Whipple, \& Kleinstauber, 2018; Reese, Norsworthy, et al., 2009; Schuman et al., 2015; Simon et al., 2013; Slone et al., 2015), particularly for clients not responding as expected (Crits-Christoph et al., 2012; Lambert et al., 2005; Lambert, Whipple, \& Kleinstauber, 2018; Newnham et al., 2010). Despite the evidence supporting PM, most North American clinicians are not using the measures (Hatfield \& Ogles, 2004; Ionita \& Fitzpatrick, 2014; Jensen-Doss et al., 2016). Among Canadian psychologists, only $12 \%$ reported to be users (Ionita \& Fitzpatrick, 2014), making PM a case in point of the 
practice-research gap in psychology. To bridge this gap, PM needs more effective dissemination among clinicians.

\section{Diffusion of Innovations}

To pursue dissemination, Martinez (2014) recommends working from a theoretical framework (Martinez et al., 2014). Rogers' (2003) Diffusion of Innovations is the most extensively used dissemination theory (Rabin et al., 2016). It is widely applicable as it characterizes diffusion at the level of the individual, organization, community, and policy (Tabak et al., 2012). Included in the theory is Innovation-Decision, a five-stage process which includes knowledge (learning about an innovation), persuasion (forming an attitude about the innovation), decision (deciding to use the innovation), implementation (using the innovation), and confirmation (continuing use of the innovation). According to this model, in order to improve the implementation and long-term maintenance of an innovation, potential users need to learn about, form an attitude on, and make a decision regarding the innovation. To facilitate this process, the authors of this paper designed a dissemination intervention which can help clinicians move through these first three stages of Innovation-Decision.

\section{PsySuccess}

PM dissemination has been pursued previously. PM training programs have been developed and demonstrated to have a positive impact on attitudes (Edbrooke-Childs et al., 2016; Willis et al., 2009) and self-efficacy (Edbrooke-Childs et al., 2016). Training programs using self-monitoring or ongoing meetings to support implementation have had a particularly positive impact on uptake and sustained use (Persons et al., 2016; Steinfeld et al., 2016). While these programs are effective, they may not address the current challenges to PM uptake. In these studies, implementation was pursued at the level of the organization (Steinfeld et al., 2016), and 
many participants were already using some form of PM (Edbrooke-Childs et al., 2016; Persons et al., 2016) or working in a country where use was mandated (Willis et al., 2009). Training programs generally occurred in-person and in groups (Edbrooke-Childs et al., 2016; Persons et al., 2016; Steinfeld et al., 2016; Willis et al., 2009). In Canada, a large proportion of clinicians work independently (Hunsley et al., 2013), and so implementation efforts at the level of the organization will miss these important potential users. PM use is also not mandated and many clinicians are unaware that PM measures exist (Ionita \& Fitzpatrick, 2014). Mass media has been proposed to be the most efficient and effective communication channel when knowledge is lacking (Rogers, 2003). Thus, a wide-reaching, online learning tool which primarily aims to improve the early stages of Innovation-Decision may be a timely intervention.

To design such an intervention, a narrative review of the psychotherapy literature was conducted (Knoll \& Fitzpatrick, in press). Strategies, facilitators, and processes involved in the dissemination of psychotherapy innovations were identified and considered through Rogers' (2003) Diffusion of Innovations lens. The findings are summarized in a figure hypothesizing how the various strategies, facilitators, and processes may assist the specific stages of Innovation-Decision (Figure 1). The model provided a useful framework for the development of PsySuccess, the online PM dissemination intervention.

PsySuccess used strategies identified in the review of the psychotherapy literature (Figure 1) that were feasible to employ in an online format (Table 1). Certain strategies, including peer networks, conferences, clinical experience, fidelity monitoring, consultation and supervision were not suitable for this format. However, efforts were made to facilitate these experiences when possible. A conference page provided detailed information on upcoming live conferences. Links to free trials, which were provided as a form of practical material, were reasoned to be 
potential facilitators of clinical experience. While no specific page was dedicated specifically to educational resources, several of the already employed strategies (e.g., theoretical material, research, training videos, PM manuals, etc.) constituted this kind of material. For a complete list of the strategies employed on PsySuccess, see Table 1.

Upon arriving on the PsySuccess landing page, users were presented with the option to visit three different sections: (1) PM: The Basics, (2) About Us, and (3) Learn More. PM: The Basics provided a 2-minute video describing what PM measures are and how they work. About Us provided a description of the purpose of the website and the research. Learn More was the main intervention page which featured a thumbnail for each strategy page that users could visit (e.g., research, news and blogs, PM theory, etc.) (Table 1). By selecting different pages, users were able choose the strategy they wanted to learn from.

Within each strategy page, content was created. When possible, PM facilitators which had been identified in the research were used to determine this content. For example, some facilitators include learning that the measures are brief, learning that the measures can improve outcomes, and receiving advice from PM users (Ionita, Fitzpatrick, Tomaro, Chen, \& Overington, 2016). These facilitators were embedded into different strategy pages (e.g., research, case studies, training videos) and when possible, the same facilitator was communicated via multiple strategies to reduce the confounding effect of the facilitator. For example, the facilitator: learning that the measures can improve clinician effectiveness was communicated in both a case example as well as via endorsements on the clinician experience page. See Appendix A for a table of the strategy pages and facilitators used on PsySuccess.

PsySuccess is a theory driven intervention and so an evaluation of its impact is necessary. To evaluate PsySuccess, the authors of this paper previously developed a scale based on Rogers' 
(2003) Innovation-Decision process (Knoll, Fitzpatrick, \& Konishi, under review). Rogers’

(2003) theory was used to develop items capturing the constructs of knowledge, persuasion, and decision. An exploratory factor analysis retrieved two factors: (1) Knowledge and (2)

Persuasion-Decision (Knoll et al., under review). This scale can be used to capture where a clinician falls with respect to the initial stages of Innovation-Decision. When used in a test-retest manner, the scale can be used to evaluate the efficacy of dissemination efforts such as PsySuccess. For details regarding the development of this scale, please see Knoll, Fitzpatrick, and Konishi (under review).

The aim of the present study was to evaluate the impact of PsySuccess in order to improve our understanding of the process of dissemination. The Innovation-Decision scale (Knoll et al., under review) was used to examine how clinicians' levels of (1) Knowledge and (2) Persuasion-Decision changed before and after using the intervention. In addition to evaluating overall efficacy, the effects of the individual strategy pages were also examined (Table 1). It was hypothesized that the relationships hypothesized in Figure 1 would generally hold. Specifically, it was posited that the research, news and blogs, PM theory and practical material would contribute to increases in clinician Knowledge and that the case examples, clinician endorsements, and training videos would contribute to increases in Persuasion-Decision. A challenge in recruitment prompted a follow-up survey which assessed reasons for participation, non-participation, and non-completion among the initial pool of participants.

\section{Method}

\section{Participants}

Of 4611 e-mail invitations, 207 clinicians completed the pre-navigation survey resulting in an initial response rate of $4.5 \%$. One hundred clinicians completed all portions of the study 
(i.e., both the pre- and post-navigation surveys) resulting in a final response rate of $2.2 \%$. The majority of participants were female (67\%), PhD-level clinicians (65\%), of European descent (75\%), who worked mainly in private practice $(69 \%)$. They primarily endorsed a CognitiveBehavioural orientation (42\%) (Table 2). The mean age of participants was 48.7 and the mean years in practice was 17.5 .

\section{Procedure}

Ethical approval was obtained from the Research Ethics Board at the authors' academic institution. Clinicians were recruited via e-mail using addresses attained from public, online psychological association and organization directories across Canada in the Spring and Summer of 2019. An e-mail invitation informed potential participants that the purpose of the study was to determine the efficacy of PsySuccess and improve our understanding of how clinicians learn and come to implement EBP. Details on what participation entailed and confidentiality were also provided. Potential participants were offered 6 continuing education (CE) credits conferred by the Canadian Psychological Association (CPA) in exchange for participation. They were informed that individuals interested in obtaining $\mathrm{CE}$ credits would be required to achieve at least a $75 \%$ on a CE credit quiz and that they would be permitted to take the quiz as many times as necessary to achieve a passing grade. Instructions for participation were provided and interested individuals were directed to an informed consent page before proceeding to a pre-navigation survey and then PsySuccess.

Once arriving at the website, participants were free to engage with the strategy pages they chose for as long as they wanted. When they were finished, they were instructed to complete a post-navigation survey and CE credit quiz which they could access at the bottom of every page. Participants were given up to two weeks to navigate PsySuccess, complete the post-navigation 
survey, and complete the $\mathrm{CE}$ credit quiz after receiving the e-mail invitation. During the twoweek period, they were free to start and then leave the website at their convenience. If they required more time, they were instructed to e-mail the authors requesting an extension. Participants were permitted up to several months to complete the study if needed.

A follow-up survey was conducted among the same 4611 clinicians from the initial email distribution list. A second e-mail invitation informed potential participants that the purpose of the survey was to better understand why individuals participated, did not participate, or did not complete participation in PsySuccess. Details on what participation in the survey entailed and confidentiality were also provided. Individuals who elected to participate in this follow-up were directed to a quick survey where they were provided with a list of possible reasons which may have contributed to their decision regarding participation. They were asked to select all that apply and were provided with an open text box if they wanted to share "other" reasons.

\section{Instruments}

Innovation-Decision scale. The Innovation-Decision scale (Knoll et al., under review) was embedded into both the pre- and post-navigation surveys to assess changes in (1) Knowledge, and (2) Persuasion-Decision. The scale has demonstrated adequate to good reliability ( $\alpha=.775$ for Knowledge, $\alpha=.879$ for Persuasion-Decision) (Nunnally, 1994). A confirmatory factor analysis demonstrated variable but adequate fit indices $(\mathrm{CFI}=.837$; TFI $=$ .813; RMSEA = .192) $($ Browne \& Cudeck, 1993; Hu \& Bentler, 1999; Knoll et al., 2018). While the psychometrics do not necessarily demonstrate a strong model fit, the Innovation-Decision scale is currently the only validated measure characterizing Rogers' (2003) DoI theory. PsySuccess was developed using this theory and an important objective of this study was to evaluate the impact of various dissemination strategies on the different stages of Innovation- 
Decision. The Innovation-Decision scale is currently the only scale which would permit this kind of analysis and so it was deemed the most appropriate instrument.

Pre-navigation survey. Participants completed a survey prior to navigating PsySuccess. This survey included demographic items, questions about PM use, and the Innovation-Decision scale. Items related to PM use were included to filter out users (those past the decision stage) and unaware non-users (those who had not yet reached the knowledge stage) from being assessed with the scale, as the scale is only appropriate for clinicians within the first three stages of Innovation-Decision. Thus, all participants completed the demographic and PM use items, but only previous users and aware non-users were assessed using the Innovation-Decision scale. After completing the pre-navigation survey, participants were taken directly to PsySuccess where they had up to two weeks (or more if requested) to complete the post-navigation survey and CE credit quiz.

Post-navigation survey. After using PsySuccess, all participants were asked which pages they visited and about their perceptions of changes in knowledge, persuasion, and decision as a result of these pages. Using a 5-point likert scale (strongly agree to strongly disagree), they were asked to indicate their level of agreement with the statements, "I learned a lot from this page" (self-perceived knowledge), "I was persuaded by this page" (self-perceived persuasion), and "My intention to use PM was positively impacted by this page" (self-perceived decision). Previous users and aware non-users were then assessed using the Innovation-Decision scale to obtain a validated measure of change in Knowledge and change in Persuasion-Decision.

CE credit quiz. Finally, participants were given the option to take a CE credit quiz. Multiple choice items were used to test participants on the content of PsySuccess. Participants 
were permitted to take the quiz as many times as necessary in order to achieve the $75 \%$ passing grade.

\section{Analyses}

IBM SPSS Statistics, version 26, was used to conduct all analyses. Descriptive analyses were used to characterize the sample as well as the strategy pages that participants used and found useful. $T$-tests were used to explore associations between use of PM and support of EBP.

The Innovation-Decision scale (Knoll et al., under review) determined differences in levels of Knowledge and Persuasion-Decision between demographic groups. Knowledge and Persuasion-Decision scores were determined by calculating the weighted averages of all Knowledge items and Persuasion-Decision items respectively. Each participant therefore had both pre- and post-Knowledge scores as well as both pre- and post-Persuasion-Decision scores. ANOVA analyses and Spearman's rho were used to examine differences between demographic groups for Knowledge and Persuasion-Decision. The results of the Innovation-Decision scale were also used to assess the overall efficacy of PsySuccess. Changes in Knowledge were calculated using differences between individuals' pre- and post-scores; the same was done for Persuasion-Decision. Paired samples $t$-tests assessed the significance of these changes.

Repeated Measures ANOVAs evaluated the efficacy of the individual strategy pages. For each strategy, the sample was divided into those who visited the page and those who did not. Changes in Knowledge and Persuasion-Decision were compared between groups to determine which pages were effective. For the follow-up survey, frequency counts characterized reasons for clinicians' participation, non-participation, or non-complete participation in PsySuccess.

\section{Results}

\section{Preliminary Analyses}


Most participants indicated that they had a choice about whether or not they used a PM measure (85\%). Forty six percent identified as current users, $16 \%$ had previously used, but were not currently using PM, 30\% were not using PM, and 8\% were unaware of PM. Among users, $41.3 \%$ were using the measures regularly with most or all of their clients and $33 \%$ were using them regularly with some of their clients. Compared to non-users, users were more likely to be supportive of EBP, $t(98)=1.489, p<.05$, to be working in a setting that was supportive of EBP, $t(98)=1.721, p<.05$, and to believe that PM is a form of EBP, $t(98)=3.238, p<.05$. They were not more likely to be trained in a setting that was supportive of EBP, $t(98)=0.274, p=.584$.

Participants reported visiting the efficacy research (76\%), training (69\%), and theory (69\%) pages most frequently and the case examples (42\%), why clinicians continue using PM (42\%), and news (30\%) pages least frequently (Table 3). Means and standard deviations were used to assess participants self-perceived changes in knowledge, persuasion, and decision attributable to PsySuccess (Table 4). The scale ranged from one to five with higher numbers connoting larger positive changes. Means were calculated using only the participants who visited each page. Because each mean was based off of a different group of participants, statistical analysis could not be conducted to compare differences between pages; however, patterns were noted.

After visiting PsySuccess, participants reported experiencing a general increase in knowledge $(M=4.34, S D=.639)$, persuasion $(M=3.96, S D=3.98)$, and decision regarding PM $(M=3.98, S D=.752)$. The same three pages emerged as top resources for self-perceived changes in knowledge, persuasion, and decision: the synthesized research page, the efficacy research page, and the PM theory page (Table 4). The manuals, free trials, advice, and technology support systems pages emerged at the bottom with regard to changes in knowledge. 
The cost, technology support systems, and manuals pages emerged at the bottom with regard to changes in persuasion. Finally, the cost, advice, and manuals pages emerged at the bottom with regard to changes in decision (Table 4). On average, participants took the CE credit quiz 1.27 times and most participants only took the quiz once.

\section{Analyses Using the Innovation-Decision Scale}

Only a subset of the sample $(n=41)$ completed all portions of the study and identified as either previous users or aware non-users. These were the participants who could be assessed using the Innovation-Decision scale (Knoll et al., under review).

Knowledge. Items assessing PM knowledge used a 5-point likert scale ranging from one to five, with higher numbers connoting greater levels of knowledge. A weighted average was computed to represent the Knowledge score. Mean Knowledge before visiting PsySuccess was $3.446(S D=0.690)$ and the Shapiro-Wilk test demonstrated a normal distribution, $W(41)=$ $0.045, p=.149$. ANOVA analyses explored relationships between demographics and Knowledge scores before visiting PsySuccess. No differences were found with respect to gender, $F(1,39)=$ $0.043, p=.837$, ethnicity, $F(5,35)=1.021, p=.420$, education, $F(3,37)=1.449, \mathrm{p}=.244$, work setting, $F(3,37)=0.418, p=.741$, or theoretical orientation, $F(6,34)=0.949, p=.473$. Spearman's rho was calculated to explore any relationships with respect to age and years of experience, as these demographic variables both violated the assumption of normality (age: $W(41)=0.906, p<.05$ and years of experience: $W(41)=0.906, p<.05))$. Neither age $(r=-$ $0.018, p=.910)$ nor years of experience $(r=0.127, p=.428)$ were related to the level of knowledge prior to navigation.

Change in Knowledge was obtained by calculating the difference between the pre- and post-Knowledge scores. On average, there was an increase in Knowledge after visiting 
PsySuccess $(M=0.638, S D=0.529)$ and a paired samples $t$-test suggested that this difference was significant, $t(4)=-7.734, p<.05$.

Persuasion-Decision. Mean Persuasion-Decision before visiting PsySuccess was 4.015 $(S D=0.474)$ and the Shapiro-Wilk test demonstrated a normal distribution, $W(41)=0.982, p=$ .746. ANOVA analyses demonstrated no differences with respect to gender, $F(1,39)=0.522, p$ $=.474$, ethnicity, $F(5,35)=0.728, p=.607$, education, $F(3,37)=1.412, p=.255$, or work setting, $F(3,37)=0.954, p=.425$. Significant differences were demonstrated with respect to theoretical orientation, $F(6,34)=2.561, p=.037$. Post hoc analyses could not be performed due to low observed cell counts. However, an inspection of the means of the most commonly endorsed orientations showed higher levels of Persuasion-Decision among CBT oriented clinicians, $n=17, M=4.135, S D=0.464$, when compared to integrative or eclectic clinicians, $n$ $=10, M=3.900, S D=0.4269$. When comparing $\mathrm{CBT}$ to integrative or eclectic clinicians statistically, the difference was not significant, $t(25)=1.310, p=.202$. Spearman's rho was calculated to explore relationships with respect to age and years of experience. Neither age ( $r=-$ $0.110, p=.493)$ nor years of experience $(r=0.076, p=.636)$ were related to the level of Persuasion-Decision prior to visiting PsySuccess.

On average, there was a small increase in Persuasion-Decision after visiting PsySuccess, $M=0.115, S D=0.273$. A paired samples $t$-test suggested that this difference was significant, $t(40)=-2.684, p<.05$.

Pages associated with changes in Knowledge and Persuasion-Decision. Two-Way Repeated Measures ANOVAs determined which pages were associated with changes in Knowledge and Persuasion-Decision. The how-to research page, $F(1,39)=5.98, p=.019, \eta^{2}=$ .133 , and the cost page, $F(1,39)=4.80, p=.035, \eta^{2}=.110$, were both significantly related to 
increases in Knowledge. The efficacy research page, $F(1,39)=4.04, p=.051, \eta^{2}=.094$, and technology support systems page, $F(1,39)=3.88, p=.056, \eta^{2}=.091$, both approached significance. Line graphs demonstrating the impact of these pages can be seen in Figures 2-5. The line graphs demonstrated a pattern of visitors having lower levels of knowledge that nonvisitors prior to visiting PsySuccess. Independent $t$-tests demonstrated that this difference was significant for the efficacy research page, $t(39)=2.07, \mathrm{p}<.05$, and approached significance for the cost page, $t(39)=2.00, \mathrm{p}=.053$. Only the why start using $P M$ page, $F(1,39)=5.52, p=$ $.024, \eta^{2}=.124$, was associated with changes in Persuasion-Decision (Figure 6).

PsySuccess was effective in increasing both self-perceived levels of knowledge, persuasion, and decision as well as increasing levels of Knowledge and Persuasion-Decision as measured by the Innovation-Decision scale. While participants reported that the efficacy research, synthesized research, and theory pages were especially helpful for all three stages, the results from the Innovation-Decision scale point to the how-to and efficacy research as well as information on cost and technology support systems for increasing Knowledge. Anecdotal endorsements relating to why clinicians started using PM increased Persuasion-Decision.

\section{Follow-up Survey}

A follow-up survey was conducted to assess reasons for participation, non-participation, and non-completion among the initial pool of participants. One-hundred and eighty-one participants completed the survey, resulting in a total response rate of $3.9 \% ; 10.5 \%$ identified as participants of PsySuccess, 79\% identified as non-participants, and 10.5\% identified as noncompleters. The proportion of respondents endorsing the various reasons for participating in, not participating in, or not completing PsySuccess is displayed in Table 5. Non-participants most commonly endorsed not having enough time $(37.1 \%)$, never getting around to it $(25.9 \%)$, or 
being unaware that they were invited to participate (18.9\%). The highly endorsed other (24.5\%) reasons for not participating included being retired or not practicing psychotherapy for some other reason, not having time or interest in PM, or already knowing about or using PM. Over half of those who participated reported doing so for reasons related to convenience (e.g., they were interested in the online format (57.9\%), they could participate when they wanted to $(73.7 \%)$, and they could go at their own speed $(52.6 \%))$ or because they were interested in PM (78.9\%) or interested in receiving CE credits (63.2\%). Non-completers commonly endorsed not finishing due to a lack of time $(57.9 \%)$, forgetting to finish $(21.1 \%)$, and reasons related to dissatisfaction with the website, such as the perception that there was too much information $(21.1 \%)$.

\section{Discussion}

This study developed and evaluated a PM dissemination tool. Prior to using the intervention, about half of participants identified as current PM users. This is higher than what has been found in previous Canadian research (Ionita, 2015). While this may reflect an actual increase in uptake, it may also be that users were more motivated than non-users to participate in an activity involving PM. Users were more likely to be supportive of EBP, to be in a workplace that was supportive of EBP, and to believe that PM is a form of EBP. Non-users tended to be more skeptical about EBP and PM as well as to be working in settings which confirm their beliefs. This demonstrates the need for interventions such as PsySuccess which can disseminate accurate information about EBP and PM.

Among these participants, being trained in a setting that was supportive of EBP was not related to PM use. While implementing PM into clinician training programs is a useful strategy (Tasca et al., 2019), post-graduate PM training or implementation efforts in clinical practice settings may have a more direct impact (Lambert \& Harmon, 2018; Tasca et al., 2019). 
PsySuccess. Overall, the intervention was effective. Most participants reported perceived improvements in knowledge, persuasion, and decision. These perceived changes mirrored changes in Knowledge and Persuasion-Decision as measured by the Innovation-Decision scale.

Self-perceived experiences. Clinicians tended to report that the research pages were more useful. This was surprising, given that previous research has characterized clinicians as being relatively uninterested in journal articles (Gyani et al., 2013; Stewart et al., 2012). For copyright purposes, our research pages did not feature full length journal articles. Instead, we created detailed infographics, which used a combination of text, images, and data visualizations to summarize the most important points of each paper. Some have suggested that it is the format of research articles that dissuades clinician interest (Stewart et al., 2012) and that user-friendly evidence may facilitate the uptake of research (Pagoto et al., 2007). Our findings add weight to this idea. The utility of the research pages may also have been a function of their content. The pages featuring positive findings (i.e., efficacy research) and replication (i.e., synthesized findings) were consistently among the most well endorsed pages for perceived changes in knowledge, persuasion, and decision. The pages featuring representativeness (i.e., population specific research) and research describing how the intervention was used (i.e., how-to-research) were also relatively well endorsed. Previous studies have found that positive findings, replication, use of representative participants (Cohen et al., 1986), and including a specific description of how the intervention was used can help to make research more useful (Cohen et al., 1986; Gyani et al., 2013; Morrow-Bradley \& Elliott, 1986). The positive response to the research pages may have be due to a combination of the format in which they were presented and profiling the kinds of research that clinicians are interested in. As was argued 25 years ago, clinicians may be more interested in research than researchers conventionally believe (Beutler et 
al., 1995). To facilitate its dissemination, however, research may need to be relevant, succinct, and digestible.

Clinicians used the anecdotal resources less (e.g., case studies, endorsements) and reported finding the anecdotal and practical materials less useful. This trend also contradicted previous research. Clinicians have previously reported having a preference for practical material (Gyani et al., 2013; Stewart et al., 2012) and endorsements by a respected therapist (Cook, Schnurr, et al., 2009) and case studies have been identified as being especially impactful on their willingness to learn a new treatment (Stewart \& Chambless, 2009). While PsySuccess featured endorsements via a page profiling the experiences of PM users, a lack of information about these users may have rendered the endorsements less convincing. Additionally, our case examples were brief and taken from larger published articles (Kopta, Owen, \& Budge, 2015; Lambert \& Shimokawa, 2011; Tzur Bitan, Zilcha-Mano, Ganor, Biran, \& Bloch, 2018). It is possible that the stories profiled lacked the depth and detail necessary to teach, persuade and increase intent to use. It is also worth considering that clinicians may have historically preferred anecdotal material because it is engaging and easily integrated into clinical knowledge (Dattilio, 2006). When research, anecdotal, and practical material are all accessible, clinicians may actually prefer to learn through research.

Experiences as measured by the Innovation-Decision scale. While initial levels of Knowledge were consistent across groups, CBT oriented clinicians tended to be slightly though not significantly more persuaded and decided regarding PM. This is consistent with research demonstrating that CBT clinicians tend to have more positive attitudes towards EBP (Stewart \& Chambless, 2007, 2009) and PM (Jensen-Doss et al., 2016). CBT is a theoretical orientation which embraces systematic data collection. If CBT clinicians already buy into the some of the 
principles behind PM, it is not surprising that they are closer to implementation. Future dissemination efforts should examine the resistance to data collection among non-CBT clinicians and tailor dissemination efforts to help them overcome this. For example, some clinicians have reported that the measures hinder the normal flow of conversation (Hall, Moldavsky, et al., 2014). For these clinicians, it would be important to highlight how the measures can be smoothly integrated into sessions and how data collection can be useful for improving communication (Sparks \& Duncan, 2018). The current research suggests that these messages may be especially effective when coming from PM users, rather than developers.

The how-to research page was associated with significant increases in Knowledge. Rogers' (2003) conceptualized that there are three types of knowledge: (1) awareness-knowledge (what the innovation is), (2) how-to-knowledge (how to use the innovation correctly), and (3) principles-knowledge (how and why the innovation works). The how-to-research page profiled efficacy studies which also included a specific description of how the measures were used. Our findings are consistent with previous research demonstrating the utility of how-to research for learning (Cohen et al., 1986; Gyani et al., 2013; Morrow-Bradley \& Elliott, 1986). The other forms of how-to-knowledge on PsySuccess, PM manuals and training videos, did not have a significant impact on Knowledge. That is, how-to-knowledge was most appealing in the form of research. Aligning with what participants perceived, the efficacy research page also approached significance with regard to changes in Knowledge. These findings lend further support to the idea that the format of research is important. Clinicians appear to learn from research that is both useful and easy to absorb. This is not to say that clinicians did not learn from the practical information: information on cost and technology support systems were both also associated with increases in Knowledge. Both research and practical material appear to helpful when it comes to 
knowledge; however, embedding practical information into effectively presented research may be an especially efficient way of helping clinicians to learn.

The only page associated with changes in Persuasion-Decision was an anecdotal endorsement page entitled, why start using PM? This resource was embedded in a family of pages featuring qualitative research findings on the clinician experience of PM. The page specifically detailed reasons why clinicians have started using the measures. While the utility of this page aligns with what has been found in previous research (Cook, Schnurr, et al., 2009; Stewart \& Chambless, 2009), it contradicts with what participants thought persuaded them or helped them to decide (i.e., the research and theory pages). This inconsistency between clinicians' perceptions and the findings of the Innovation-Decision scale was representative of a larger pattern in the results.

For both the anecdotal and practical material, contradictions existed between clinicians' perceptions about what was useful and usefulness as measured by the scale. Given that only descriptive analyses could be conducted on the clinician perception data, the trends observed may not reflect statistically significant differences. However, it may also be that clinicians are relatively unaware of the factors that impact their learning, attitudes, and decision-making. For PsySuccess specifically, a positive experience with the research resources may have biased participants' impressions of learning, attitudes, and decision-making in favour of the research. That is, it may not be that the practical material was unhelpful for learning or that the anecdotal endorsements were not convincing. It may be that the research received higher ratings because it compared favorably to pervious experiences with journal articles.

Another interesting pattern that emerged was that the visitors of effective pages tended to be less knowledgeable prior to visiting PsySuccess (Figures 2-5). Less knowledgeable clinicians 
may have engaged more and consequently, learned more. This points to the utility self-guided learning tools. Clinicians tend to seek out what they need to know. This pattern was not observed for Persuasion-Decision. It may be that clinicians are generally motivated to increase their knowledge, but not motivated to change their attitudes and actions. If this is the case, self-guided learning tools may only be effective for the initial stage of Innovation-Decision.

Clinician engagement. A significant issue in this study was the low response rate. Despite efforts to create a wide-reaching intervention, only $2.2 \%$ of potential participants started and completed the entire study. This speaks to a significant challenge in engaging clinicians. Before the efficacy of a dissemination intervention can be evaluated, clinicians need to first be engaged. For this reason, engagement is proposed as an additional, initial stage of InnovationDecision.

While participants said they participated for reasons of convenience, non-participants and non-completers tended to not have the time or did not make the time to participate. Time, money, and other practical concerns have been identified as barriers to professional development previously (Cook, Biyanova, et al., 2009; Stewart et al., 2012). Researchers wanting to translate their findings need to design interventions that are quick and convenient.

In addition to participating because the intervention was convenient, most participants wanted to obtain $\mathrm{CE}$ credits. CE credit training programs generally provide one $\mathrm{CE}$ credit in exchange for one hour of learning. While participants were not required to spend any set amount of time on PsySuccess, the offer of six CE credits may have led clinicians to believe that they did not have the time to participate. In effect, our compensation may have served as a barrier to clinician engagement. Future dissemination interventions may consider breaking down CE credit training programs into shorter activities where clinicians can obtain a single CE credit. Future 
researchers need to assess the impact of wide-reaching, rapid dissemination interventions on these earlier stages of Innovation-Decision. Once sufficiently interested, clinicians may be more willing to invest the time necessary to advance towards long term implementation.

Previous research has identified other reasons for participating in continuing education. Clinicians in psychology have reported that continuing education tends to be too remedial to be helpful. When selecting training programs, they report choosing presenters or organizers that they are familiar with to ensure that the training will be useful (Stewart et al., 2012). Outside of psychotherapy, nurses have reported participating in continuing education to increase selfesteem, confidence, and opportunities for promotion (Murphy, Cross, \& McGuire, 2006). For teachers, motivators have been divided into personal, school, and system related. Personal motivators included career advancement, growth and achievement; school related included peer experiences as well as school policy and culture towards professional development; and systemwide motivators included professional development being compulsory (McMillan, McConnell, \& O’Sullivan, 2016). If clinicians in psychotherapy are similar to these other professionals, continuing education cannot just be quick and convenient: it must also contribute to a sense of competence and have career benefits; additionally, there should be systemic motivators. In Canada, systemic motivators in psychotherapy already exist: licencing bodies across the country require clinicians to obtain $\mathrm{CE}$ credits on a regular basis. Therefore, to improve engagement $\mathrm{CE}$ training programs should clearly advertise how they will promote individual clinician development. Clinics, hospitals, schools, and other employers of clinicians should also consider how they can implement policy or change the culture of their organization in a way which further supports continued professional development. This may mean providing financial support or 
time off to employees for continuing education. It may also mean demonstrating to employees a clear link between continuing education and career advancement.

Before implementing future dissemination interventions, researchers need to consider clinician engagement. Preliminary results indicate that convenience and rapidity should be prioritized; however, clinician growth, career opportunities and systemic motivators should also be considered. Once engaged, clinicians appear to be interested in research that is presented in a succinct and digestible format. Resources that are self-guided and combine both research and practical information may be especially useful for learning and anecdotal material may be more useful for persuasion and decision.

\section{Limitations and Future Directions}

This study developed an effective dissemination intervention with interesting implications for future knowledge translation projects. When considering the limitations, the most significant was the low response rate. Although online interventions can communicate messages on a large scale, our targeted sample was difficult to engage. Future researchers need to remember that time is a limited resource for clinicians and may be acting as a significant barrier to engagement. The impact of brief dissemination interventions on engagement and InnovationDecision should be explored.

The naturalistic nature of this study prevented an analysis where all independent variables could be tested together. Our analyses pointed to the kinds of strategies that may help move clinicians along the Innovation-Decision continuum. However, because the impact of each strategy was tested separately, it is possible that the impact of some of these strategies was overinflated. Future researchers should attempt to test multiple variables in a single analysis. 
Given the current state of the field, only the initial stages of the dissemination process were studied. To improve our understanding of Innovation-Decision in its entirety, future researchers will need to assess the impact of dissemination strategies on the later stages of the process.

Finally, our analysis examined dissemination at the level of the individual. Simple exposure to PM does not lead to improved outcomes: clinicians must be motivated to use the measures (de Jong et al., 2012). Individual buy-in is essential. While understanding dissemination at the level of the individual is necessary, it is not sufficient. Dissemination also occurs at the level of the organization, community, system, and policy (Tabak et al., 2012) and meaningful PM uptake will require dissemination operating at all levels. 
Figures and Tables

Table 1

Dissemination Strategies Used on PsySuccess

\begin{tabular}{ll}
\hline Strategy & Hypothesized Stage of Impact \\
\hline $\begin{array}{l}\text { Research } \\
\text { Efficacy research }\end{array}$ & Knowledge \\
$\begin{array}{l}\text { Systemated research (meta-analyses and } \\
\text { When and with whom? } \\
\text { (population/treatment specific research) }\end{array}$ & Knowledge \\
$\begin{array}{l}\text { How-to research (includes a specific } \\
\text { description of how PM was used) }\end{array}$ & Knowledge \\
News and blogs & Knowledge \\
PM theory & Knowledge \\
Practical Material & Knowledge \\
Cost & Knowledge \\
Technology & Knowledge \\
Time & Knowledge \\
Free trials & Knowledge \\
Case examples & Persuasion and Decision \\
Endorsements (the clinician experience) & Knowledge, Persuasion, Decision, \\
Why start using PM? & Implementation and Confirmation \\
& Knowledge, Persuasion, Decision, \\
Why continue using PM? & Implementation and Confirmation \\
Advice & Knowledge, Persuasion, Decision, \\
Training videos & Implementation and Confirmation \\
& Knowledge, Persuasion, Decision, \\
The client experience & Implementation and Confirmation \\
Manuals & Implementation and Confirmation \\
\hline
\end{tabular}


Table 2

Demographics Characteristics $(N=100)$

\begin{tabular}{|c|c|}
\hline & $n(\%)$ \\
\hline \multicolumn{2}{|l|}{ Gender } \\
\hline Male & $33(33 \%)$ \\
\hline Female & $67(67 \%)$ \\
\hline Undisclosed & $0(0 \%)$ \\
\hline Other & $0(0 \%)$ \\
\hline \multicolumn{2}{|l|}{ Ethnicity } \\
\hline Aboriginal & $1(1 \%)$ \\
\hline African/Caribbean & $0(0 \%)$ \\
\hline East Asian & $5(5 \%)$ \\
\hline South Asian & $6(6 \%)$ \\
\hline Southeast Asian & $1(1 \%)$ \\
\hline European & $75(75 \%)$ \\
\hline Latin American & $3(3 \%)$ \\
\hline Middle Eastern & $3(3 \%)$ \\
\hline Other & $5(5 \%)$ \\
\hline \multicolumn{2}{|l|}{ Education } \\
\hline MA & $14(14 \%)$ \\
\hline MSc & $4(4 \%)$ \\
\hline $\mathrm{PhD}$ & $65(65 \%)$ \\
\hline PsyD & $9(9 \%)$ \\
\hline MD & $0(0 \%)$ \\
\hline Ed.D & $1(1 \%)$ \\
\hline Other & $7(7 \%)$ \\
\hline \multicolumn{2}{|l|}{ Primary employment setting } \\
\hline Private practice & $69(69 \%)$ \\
\hline Hospital & $9(9 \%)$ \\
\hline Community clinic & $7(7 \%)$ \\
\hline School/college/university counselling centre & $12(12 \%)$ \\
\hline Other & $3(3 \%)$ \\
\hline \multicolumn{2}{|l|}{ Primary Theoretical Orientation } \\
\hline Cognitive Behavioral & $42(42 \%)$ \\
\hline Third-wave cognitive behavioral & $16(16 \%)$ \\
\hline Psychodynamic & $6(6 \%)$ \\
\hline Humanistic & $5(5 \%)$ \\
\hline Existential & $1(1 \%)$ \\
\hline Experiential & $2(2 \%)$ \\
\hline Systemic & $0(0 \%)$ \\
\hline Narrative & $0(0 \%)$ \\
\hline Interpersonal & $1(1 \%)$ \\
\hline Integrative & $24(24 \%)$ \\
\hline Other & $3(3 \%)$ \\
\hline
\end{tabular}


Table 3

Proportion of Participants Who Visited Each Page on Psy Success $(N=100)$

\begin{tabular}{ll}
\hline Page & $n(\%)$ \\
\hline Research & $76(76 \%)$ \\
Efficacy research & $61(61 \%)$ \\
Synthesized research (meta-analyses and systematic reviews) & $66(66 \%)$ \\
When and with whom? (population/treatment specific research) & $56(56 \%)$ \\
How-to research (includes a specific description of how PM was & \\
used) & $30(30 \%)$ \\
News and blogs & $69(69 \%)$ \\
Theory & \\
Practical material & $63(63 \%)$ \\
Cost & $55(55 \%)$ \\
Technology & $51(51 \%)$ \\
Time & $46(46 \%)$ \\
Free Trials & $42(42 \%)$ \\
Case examples & $60(60 \%)$ \\
Endorsements (the clinician experience) & $60(60 \%)$ \\
Why start using PM? & $42(42 \%)$ \\
Why continue using PM? & $51(51 \%)$ \\
Advice & $69(69 \%)$ \\
Training videos & $57(57 \%)$ \\
The client experience & $48(48 \%)$ \\
Manuals &
\end{tabular}

Table 4

Means and Standard Deviations Regarding Participants Level of Agreement with the Statements, "I learned a lot from the page titled __," "I was persuaded by the page titled__," and "My intention to use PM was positively impacted by the page titled

\begin{tabular}{lcccc}
\hline Page & $N$ & $\begin{array}{c}\text { Learned } \\
M(S D)\end{array}$ & $\begin{array}{c}\text { Persuaded } \\
M(S D)\end{array}$ & $\begin{array}{c}\text { Intent to use } \\
M(S D)\end{array}$ \\
\hline Research & & & & \\
$\quad$ Efficacy research & 76 & $4.21(.596)$ & $4.09(.657)$ & $4.04(.682)$ \\
$\quad \begin{array}{l}\text { Synthesized research (meta-analyses and } \\
\quad 61\end{array}$ & $4.26(.681)$ & $4.10(.651)$ & $4.03(.682)$ \\
$\quad$ systematic reviews) & 66 & $4.12(.755)$ & $3.74(.791)$ & $3.76(.745)$ \\
$\quad \begin{array}{l}\text { When and with whom? } \\
\quad \text { population/treatment specific research) }\end{array}$ & & & & \\
$\quad$ How-to research (includes a specific & 56 & $4.02(.726)$ & $3.71(.731)$ & $3.79(.825)$ \\
$\quad$ description of how PM was used) & & & & \\
$\begin{array}{l}\text { News and blogs } \\
\text { PM theory }\end{array}$ & 30 & $3.77(.858)$ & $3.73(.785)$ & $3.83(.834)$ \\
Practical material & 69 & $4.20(.632)$ & $3.93(.714)$ & $3.90(.731)$ \\
$\quad$ Cost & 63 & $3.87(.707)$ & $3.22(.832)$ & $3.16(.987)$ \\
$\quad$ Technology & 55 & $3.73(.706)$ & $3.42(.712)$ & $3.53(.742)$ \\
\hline
\end{tabular}




\begin{tabular}{lllll}
\hline Time & 51 & $3.86(.693)$ & $3.80(.693)$ & $3.82(.793)$ \\
$\quad$ Free trials & 46 & $3.63(.711)$ & $3.52(.836)$ & $3.72(.911)$ \\
Case examples & 42 & $3.93(.745)$ & $3.86(.783)$ & $3.83(.730)$ \\
Endorsements (the clinician experience) & & & & \\
$\quad$ Why start using PM? & 60 & $3.80(.732)$ & $3.70(.766)$ & $3.63(.736)$ \\
$\quad$ Why continue using PM? & 42 & $3.86(.718)$ & $3.81(.707)$ & $3.79(.682)$ \\
$\quad$ Advice & 51 & $3.73(.695)$ & $3.57(.671)$ & $3.47(.703)$ \\
Training videos & 69 & $3.78(.745)$ & $3.57(.717)$ & $3.58(.736)$ \\
The client experience & 57 & $4.04(.706)$ & $3.82(.735)$ & $3.81(.718)$ \\
Manuals & 48 & $3.69(.776)$ & $3.40(.736)$ & $3.52(.772)$ \\
\hline
\end{tabular}

Table 5

Mean Levels of Knowledge Before and After Visiting PsySuccess and Effect Sizes of Repeated Measures ANOVA Analysis.

\begin{tabular}{llll}
\hline \multicolumn{4}{c}{$M(S D)$ Prior to } \\
& \multicolumn{1}{c}{$M(S D)$ After Visiting } & $\eta^{2}$ \\
\hline $\begin{array}{l}\text { Visiting PsySuccess } \\
\text { research of the how-to }\end{array}$ & $3.29(.641)$ & $4.09(.436)$ & .133 \\
$\begin{array}{l}\text { Non-visitors of the } \\
\text { how-to research page }\end{array}$ & $3.66(.718)$ & $4.08(.471)$ & .133 \\
$\begin{array}{l}\text { Visitors of the cost } \\
\text { page }\end{array}$ & $3.30(.619)$ & $4.06(.425)$ & .110 \\
$\begin{array}{l}\text { Non-visitors of the } \\
\text { cost page }\end{array}$ & $3.73(.751)$ & $4.13(.467)$ & .110 \\
$\begin{array}{l}\text { Visitors of the } \\
\text { efficacy research } \\
\text { page }\end{array}$ & $3.35(.624)$ & $4.06(.404)$ & .094 \\
$\begin{array}{l}\text { Non-visitors of the } \\
\text { efficacy research } \\
\text { page }\end{array}$ & $3.92(.849)$ & $4.20(.588)$ & .094 \\
$\begin{array}{l}\text { Visitors of the } \\
\text { technology support } \\
\text { systems page }\end{array}$ & $3.33(.669)$ & $4.11(.395)$ & .091 \\
$\begin{array}{l}\text { Non-visitors of the } \\
\text { technology support } \\
\text { systems page }\end{array}$ & $3.40(.707)$ & $4.06(.493)$ & .091 \\
\hline
\end{tabular}

Table 6

Mean Levels of Persuasion and Decision Before and After Visiting PsySuccess and Effect Sizes of Repeated Measures ANOVA Analysis.

\begin{tabular}{ccc}
\hline$M(S D)$ Prior to & $M(S D)$ After Visiting \\
Visiting PsySuccess & PsySuccess & $\eta^{2}$ \\
\hline
\end{tabular}




\begin{tabular}{lccc}
\hline $\begin{array}{l}\text { Visitors of the why } \\
\text { start using PM? page }\end{array}$ & $4.01(.484)$ & $4.19(.513)$ & .124 \\
$\begin{array}{l}\text { Non-visitors of the } \\
\text { why start using PM? }\end{array}$ & $4.02(.467)$ & $3.99(.512)$ & .124 \\
page
\end{tabular}

Table 7

Proportion of Participants Endorsing the Different Reasons Which Contributed to Their Decision to Participate, Not Participate, or Not Complete Participation in PsySuccess

\begin{tabular}{|c|c|}
\hline Participants $(\mathrm{n}=19)$ & $n(\%)$ \\
\hline I was interested in the online format & $11(57.9 \%)$ \\
\hline I could participate when I wanted to & $14(73.7 \%)$ \\
\hline It was time efficient & $7(36.8 \%)$ \\
\hline $\begin{array}{l}\text { I was interested in the self-guided } \\
\text { nature of the program }\end{array}$ & $9(47.4 \%)$ \\
\hline $\begin{array}{l}\text { I was interested in the topic of Progress } \\
\text { Monitoring (PM) }\end{array}$ & $15(78.9 \%)$ \\
\hline I could go at my own speed & $10(52.6 \%)$ \\
\hline $\begin{array}{l}\text { I could choose what I wanted to learn } \\
\text { about }\end{array}$ & $7(36.8 \%)$ \\
\hline I could participate where I wanted to & $7(36.8 \%)$ \\
\hline I wanted to contribute to research & $5(26.3 \%)$ \\
\hline I wanted to obtain $\mathrm{CE}$ credits & $12(63.2 \%)$ \\
\hline $\begin{array}{l}\text { I could choose how much time I } \\
\text { dedicated to learning }\end{array}$ & $3(15.8 \%)$ \\
\hline \multicolumn{2}{|l|}{ Non-Participants $(\mathrm{n}=143)$} \\
\hline I did not have the time & $53(37.1 \%)$ \\
\hline $\begin{array}{l}\text { I was not aware that } \mathrm{CE} \text { credits were } \\
\text { being offered }\end{array}$ & $16(11.2 \%)$ \\
\hline $\begin{array}{l}\text { I am not interested in online learning } \\
\text { programs }\end{array}$ & $8(5.6 \%)$ \\
\hline $\begin{array}{l}\text { I was not aware that I was being invited } \\
\text { to participate in PsySuccess }\end{array}$ & $27(18.9 \%)$ \\
\hline $\begin{array}{l}\text { I prefer to learn at a live conference or } \\
\text { workshop }\end{array}$ & $13(9.1 \%)$ \\
\hline $\begin{array}{l}\text { I meant to participate but never got } \\
\text { around to starting }\end{array}$ & $37(25.9 \%)$ \\
\hline I am not interested in Progress & $10(7.0 \%)$ \\
\hline Monitoring (PM) & \\
\hline I prefer to learn with colleagues & $7(4.9 \%)$ \\
\hline I did not want to take a CE credit quiz & $2(1.4 \%)$ \\
\hline $\begin{array}{l}\text { I am not interested in obtaining CE } \\
\text { credits }\end{array}$ & $4(3.3 \%)$ \\
\hline
\end{tabular}


I am not interested in obtained CE credits conferred by the CPA

I am not interested in self-guided learning programs

Other
$3(2.8 \%)$

$1(0.7 \%)$

$35(24.5 \%)$

\begin{tabular}{ll}
\hline Non-Completers $(\mathrm{n}=19)$ & \\
\hline I forgot to finish & $11(21.1 \%)$ \\
I did not have the time & $3(15.8 \%)$ \\
I found the website difficult to navigate & $2(10.5 \%)$ \\
I was not given enough time to finish & 2 ( $)$ \\
I did not find the information credible & $1(5.3 \%)$ \\
There was too much information & $4(21.1 \%)$ \\
I wanted more practical information & $3(15.8 \%)$ \\
I did not find the information easy to & $3(15.8 \%)$ \\
understand & $3(15.8 \%)$ \\
I wanted more case examples & $1(5.3 \%)$ \\
I wanted more opportunities to try it out & \\
for free & $1(5.3 \%)$ \\
I did not find the information useful for & \\
relevant & $2(10.5 \%)$ \\
I wanted the opportunity to practice & \\
using the measures & $1(5.3 \%)$ \\
I did not like the self-guided nature of & \\
the website & $1(5.3 \%)$ \\
I wanted more videos & $1(5.3 \%)$ \\
I wanted full access to PM manuals & $1(5.3 \%)$ \\
Other &
\end{tabular}




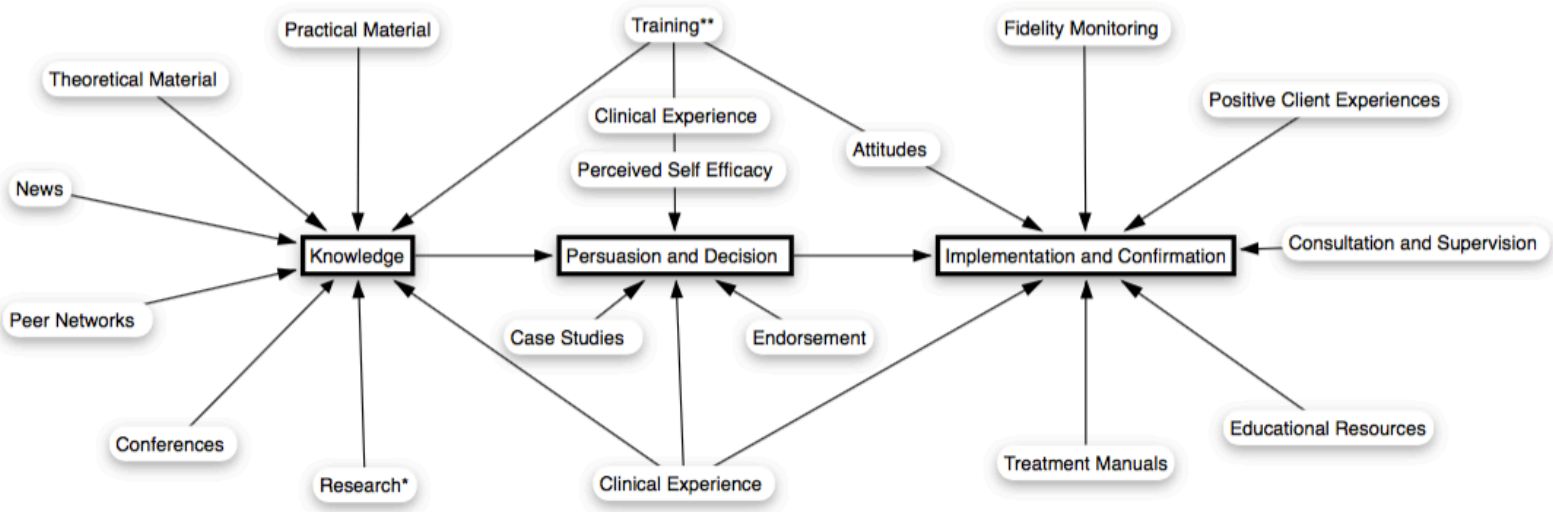

Figure 1. A proposal of how various strategies, facilitators, and processes may impact the dissemination of a psychotherapy innovation according to a review of the psychotherapy practice literature and Rogers' (2003) Diffusion of Innovations theory.

* Research that is conducted on clinically relevant populations and that demonstrates how the innovation was used, efficacy, and a replication of results may be especially useful.

** Training that is locally available or occurs online which focuses on application and skill, encourages reflection, and includes ongoing support may be especially effective.

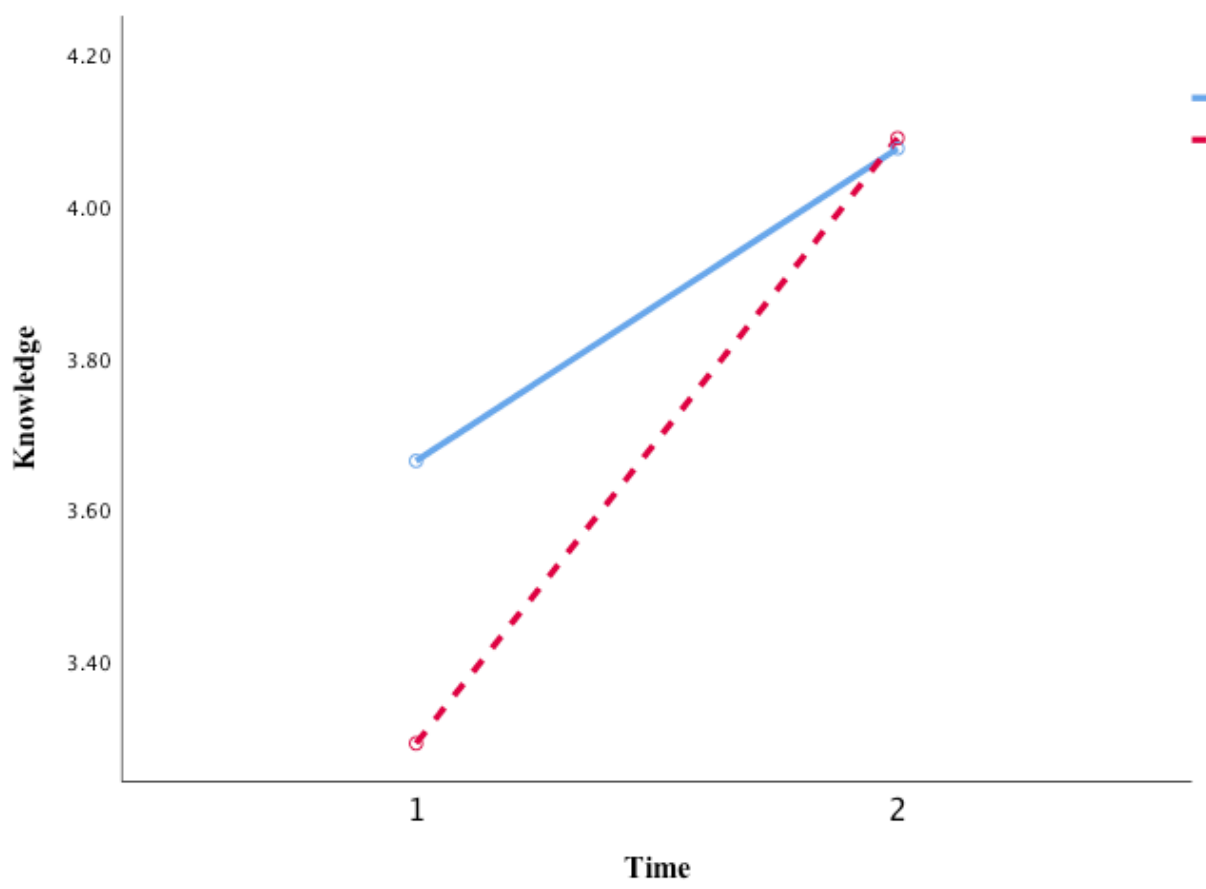

Figure 2. Change in Knowledge by those who visited and those who did not visit the how-to research page. 


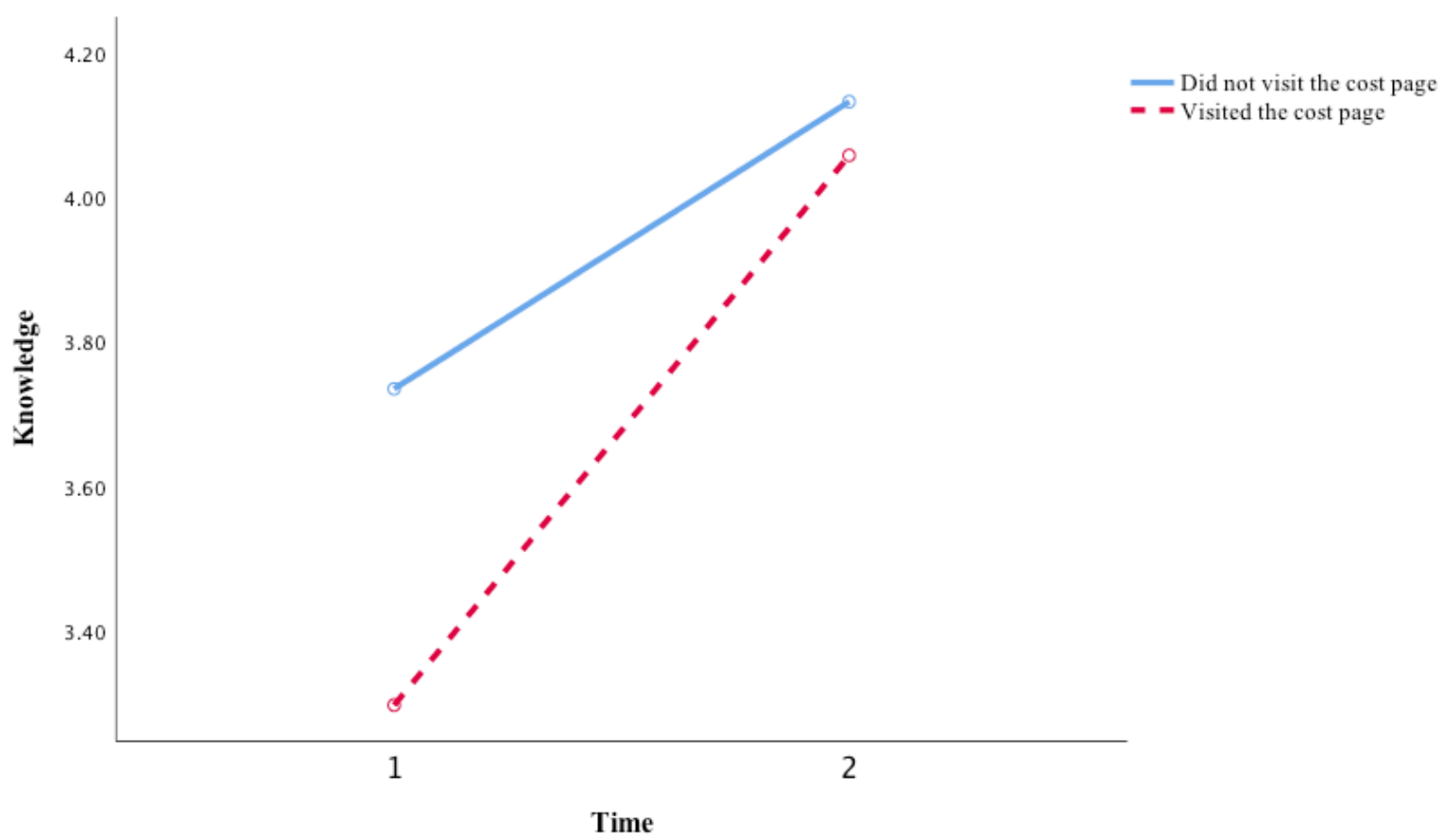

Figure 3. Change in Knowledge by those who visited and those who did not visit the cost page.

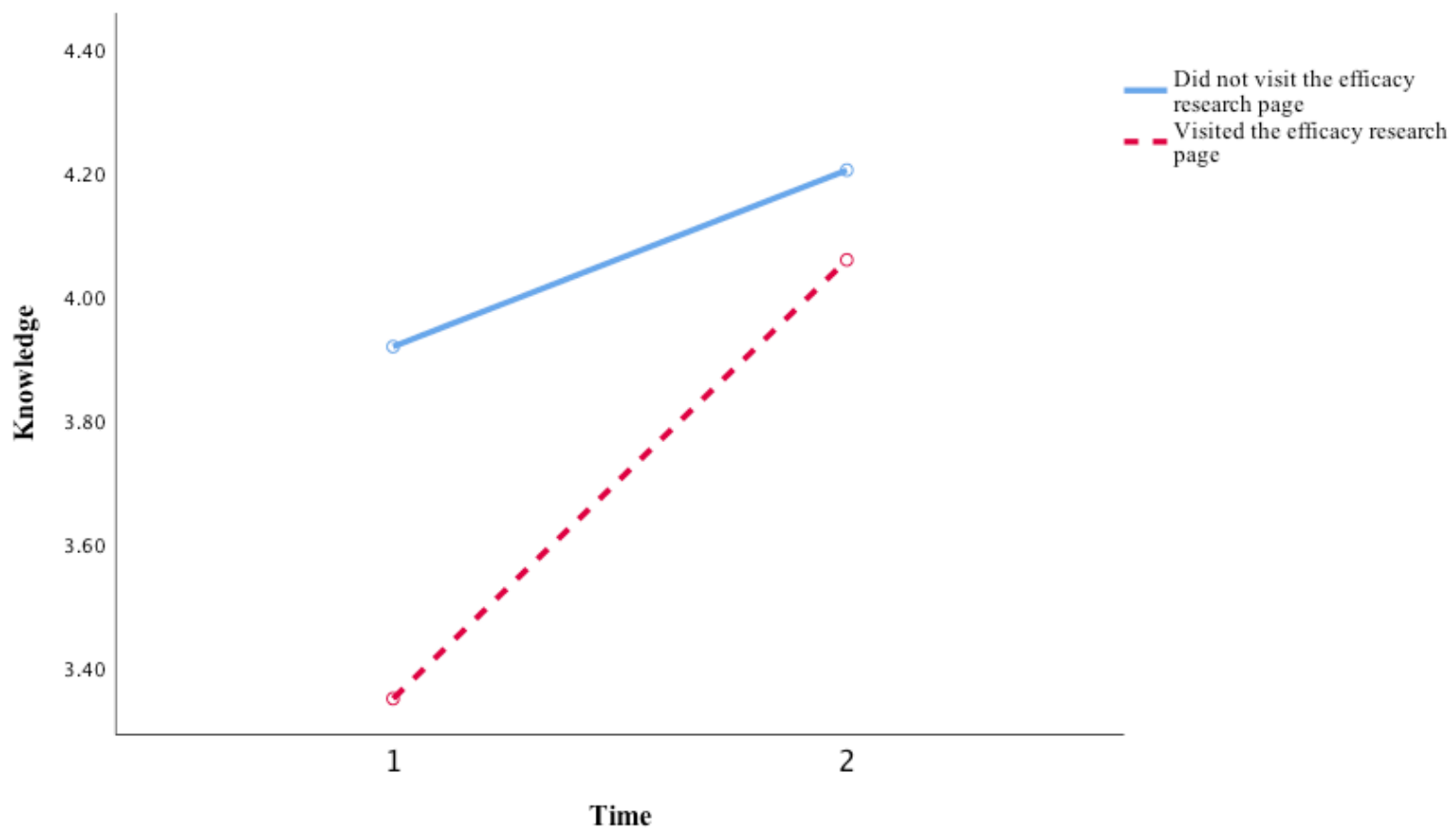

Figure 4. Change in Knowledge by those who visited and those who did not visit the efficacy research page. 


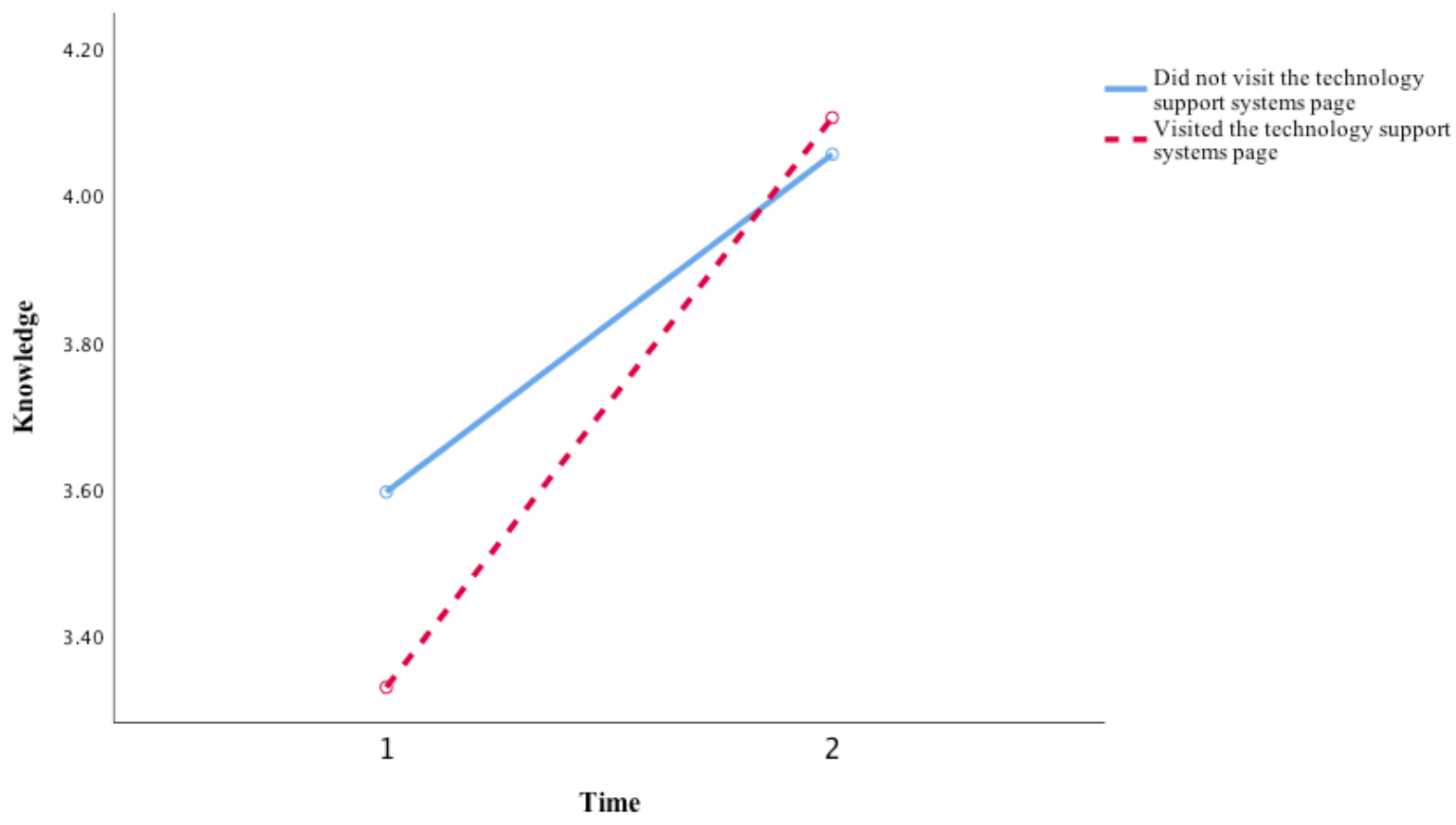

Figure 5. Change in Knowledge by those who visited and those who did not visit the technology support systems page.

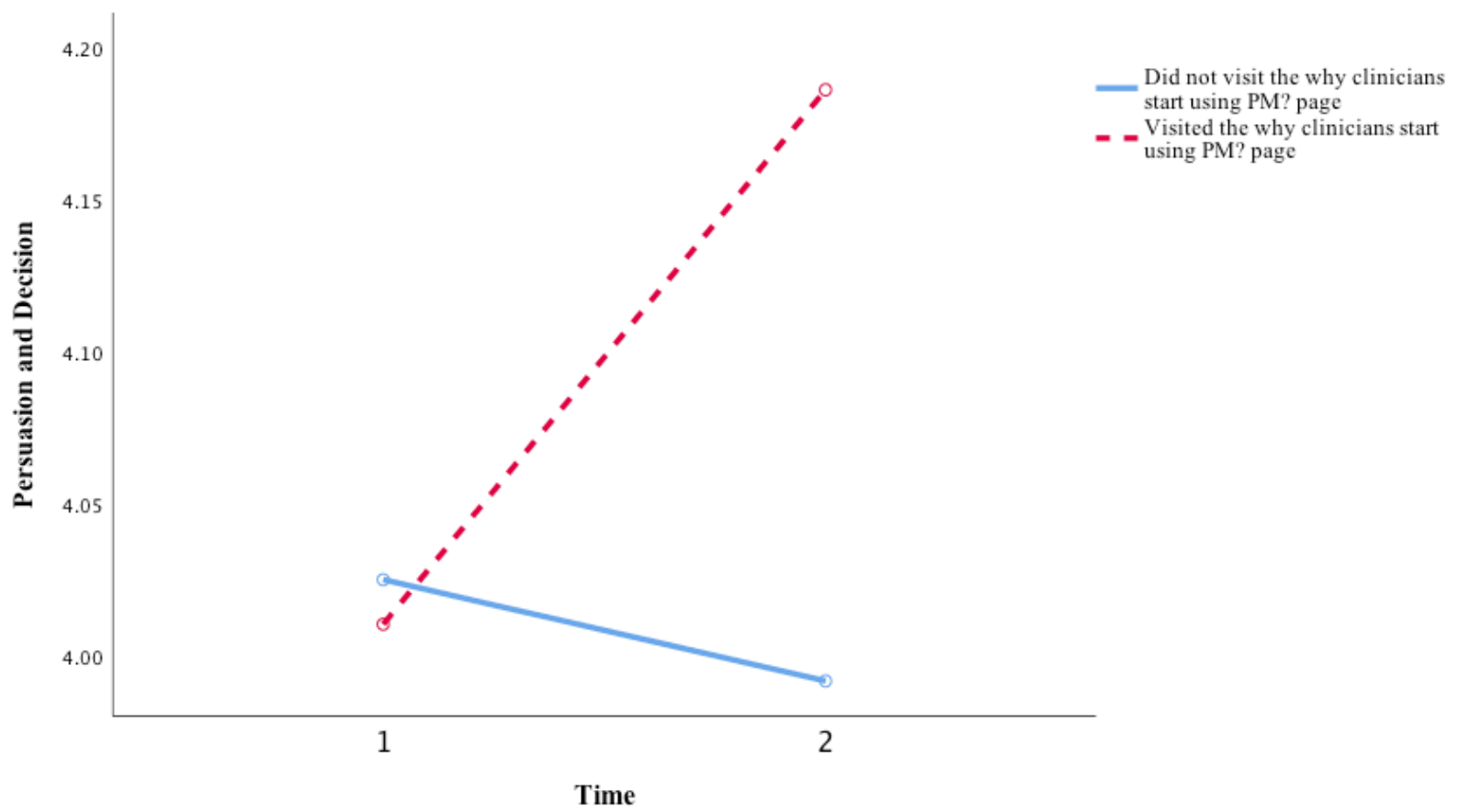

Figure 6. Change in Persuasion and Decision by those who visited and those who did not visit the why start using PM? page 
Appendix

Research Supported Strategies and Messages Used on PsySuccess

\section{Research}

Research providing detailed explanations of how PM was used

Efficacy research

Meta-analysis and systematic reviews

Efficacy research across treatment type and patient populations

News and blogs

Theoretical material
The measures are convenient

The measures can improve outcomes

The measures can improve outcomes

The measures can improve outcomes

The measures can help identify issues in therapy

The measures can improve outcomes

The measures facilitate conversations with clients

The measures can be very brief

The measures provide more data and a more objective picture of clients

The measures can improve clinician effectiveness

The measures can improve outcomes

The measures can help identify issues in therapy

The measures provide more data and a more objective picture of clients

The measures can improve clinician effectiveness

The measures can show clients their progress 
Practical material

Cost of measures

Time investment

Technical support systems

Access to free trials

\section{Training}

Online training videos

Live training opportunities

Access to PM manuals

Case examples

Endorsements (the clinician experience)
Some of the measures are free

The measures can be very brief

The measures can be combined with internetbased scoring programs that analyze the results

The measures can improve clinician effectiveness

The measures facilitate conversations with clients

The measures can help identify issues in therapy

The measure can help to guide treatment

The measures can be used for quality evaluation

The measures provide data to be used in practice

The measures help identify therapists' strengths and weaknesses

The measures allow clinicians to participate in research

The reasons clinicians start using the measures 
The reasons clinicians continue using the measures

Advice from PM users

Client experiences

The measures facilitate conversations with clients

The measures can show clients their progress

Clients have reported that therapists who use the measures seem more credible

Clients have reported that the measures provide them a voice in their own treatment

Clients have reported that the measures add structure and focus to treatment

Clients have reported that the measures enhance their self-awareness

Clients have reported that the measures are easy to understand

${ }^{\mathrm{a}}$ Content comprised of important facilitators to PM use as identified by Ionita (2016). 


\section{Thesis Discussion}

The research in this thesis aimed to answer three questions: (1) what are the means by which innovations are disseminated in psychotherapy? (2) how can we measure the impact of a dissemination intervention? and (3) what makes a dissemination intervention effective? In answering these questions, a dissemination intervention was designed, implemented, and evaluated. In effect, two stages of the KTA model's Action Cycle were initiated: (1) select, tailor, and implement an intervention and (2) monitor knowledge use. Thus, in addition to shedding light on the previously posed research questions, this thesis actively contributes to the KT of PM.

To determine the means by which innovations are disseminated in psychotherapy, a narrative review of the psychotherapy literature was conducted. The review was organized according to Rogers' (2003) five-stage model of dissemination and summarized in a psychotherapy-specific model of dissemination. Manuscript 1 contributes to a more nuanced theory of dissemination by indicating that it may be valuable to consider the stage of dissemination when determining how to best promote the uptake of an innovation.

To determine how to measure the impact of a dissemination intervention, a scale based on Rogers' (2003) theory was developed and validated. The stages of persuasion and decision were found to empirically overlap; that is, the decision to use a particular innovation was tightly linked to attitude. Manuscript 2 further refines dissemination theory in psychotherapy by suggesting that the strategies which are useful for influencing attitudes may also be useful for influencing decision-making and vice versa.

Finally, to determine what makes an intervention effective, a dissemination intervention was designed based on the findings of Manuscript 1 and evaluated using the scale developed in Manuscript 2. When questioned directly, clinicians perceived that the research and theory 
resources were most useful. The findings of the scale were more nuanced: research and practical material increased Knowledge and anecdotal endorsements increased Persuasion-Decision regarding PM. As hypothesized in Manuscript 1, particular strategies appear to impact the stages of dissemination differently. The findings of Manuscript 3 add weight to this idea that the stage of diffusion is important when developing dissemination interventions. Additionally, due to the low participation, engagement was proposed as a preliminary stage of Innovation-Decision. In this sense, Manuscript 3 enriches dissemination theory in psychotherapy by indicating that additional strategies should be implemented to facilitate clinician engagement.

Across the three manuscripts, a major theme that emerged was disconnection. Contradictory findings arose between the research and the literature as well as within the research. In the section that follows, four important instances of disconnection are described relating to (1) clinician time, (2) the utility of practical material, (3) how to best communicate scientific information, and (4) dissemination strategies deemed useful. Implications for the study and practice of dissemination are suggested.

The first disconnect relates to clinician time as a barrier to engagement. The impact of low clinician engagement was underestimated in this project and because of this, sample sizes in both Manuscripts 2 and 3 were low. The existence of effective dissemination tools is moot if we cannot convince clinicians to use them. While in this research and elsewhere, time is reported to be one of the most significant barriers to participating in continuing education (Cook, Biyanova, et al., 2009; Stedman et al., 2000), clinicians did not elect to participate in a time-efficient CE credit training program when it was offered. There appears to be a disconnect between what clinicians say they want and how they act. 
In general, $\mathrm{CE}$ credit workshops are expensive and provide one $\mathrm{CE}$ credit in exchange for one hour of learning. We offered six CE credits for free and participants could spend as much or as little time on PsySuccess as they needed to pass the quiz. They were able to use PsySuccess where they wanted and when they wanted. This could easily be less time-intensive than a daylong workshop. Given that only a small proportion indicated a preference for learning at a live conference or workshop (10.7\%) or with colleagues (5.8\%), it seems that our participant pool was poor at assessing opportunity costs. Non-participants may have assumed that a longer time investment was required due the high number of $\mathrm{CE}$ credits offered. In effect, our large compensation may have been a barrier to clinician engagement. To remedy this, future knowledge translation efforts should highlight the time and logistical benefits of their learning programs more clearly. For example, offering single CE credits may help to communicate the time benefits of shorter learning programs. Overall, more effective communication may help to guide clinicians in making decisions that are more aligned with their needs and constraints, improving clinician engagement and hence dissemination.

The second disconnect related to the utility of practical information. The literature has previously characterized practical material as useful for knowledge (Gyani et al., 2013; Stewart et al., 2012), persuasion (Borntrager et al., 2009; Cook, Schnurr, et al., 2009), implementation and confirmation of an innovation (Powell et al., 2013). For PM specifically, practical resources including manuals and free trials have been anticipated to be some of the most significant facilitators of uptake (Ionita, 2015). Users of PsySuccess however, reported that the manuals, free trials, and other practical material (i.e., information on the cost of the measures and technology support systems) were among the least useful resources. While the literature 
characterized practical material as useful, the participants in this research perceived that it was not.

It may be that practical material is more effective when it is paired with experience with the innovation, which was not possible with our intervention. Practical material can facilitate experience with the innovation (e.g., free trials) or provide information which may facilitate implementation (e.g., information cost, technology, and time investment). It may be through the associated experience that clinicians become more likely to adopt: clinical experience has been found to be a preferable source of learning (Stewart et al., 2012) that impacts decision making (Gyani et al., 2013; Stewart \& Chambless, 2007; Stewart et al., 2012) and maintenance of a new practice (Powell et al., 2013). If a clinician has access to a PM free trial but is not able to actually try-out the measure, the free trial is clearly not as useful. Practical material may be useful, but only in the extent to which it facilitates opportunities for experience.

According to the Innovation-Decision scale, however, both research (i.e., how-to research and efficacy research) and practical material (i.e., information on cost and technology support systems) had notable effects on Knowledge. When practical information is provided within a journal article, as is the case in how-to research, clinicians may be more motivated to learn about PM without the need for direct clinical experience. The how-to information may permit clinicians to envision themselves implementing the measures while the research findings may serve as a testament to their effectiveness. Additionally, there may be certain kinds of practical information that is particularly important to clinicians. Information on cost and how the measures can be integrated with technology appears to address important clinician questions (Ionita, 2015). Providing this kind of information may facilitate learning, regardless of whether the clinician obtains experience or not. Future dissemination interventions should find creative ways to 
provide practical material and subsequently facilitate clinical experience. If experience is not feasible, as was the case with PsySuccess, practical material in the form of how-to research may facilitate learning on its own. Additionally, certain kinds of information are especially pertinent to clinicians and it may be that this kind of practical material will also promote learning, regardless of experience.

The third disconnect relates to the communication of scientific information: there were inconsistencies in the dissemination strategies deemed useful in the literature and those deemed useful in the current research. Previous research has highlighted the strengths of anecdotal information (Borgida \& Nisbett, 1977; Cook, Schnurr, et al., 2009; Stewart \& Chambless, 2009) and the relative weaknesses of research (Borgida \& Nisbett, 1977; Stewart \& Chambless, 2009; Stewart et al., 2012) for dissemination. Users of PsySuccess, however, were less likely to use the anecdotal resources and they found these materials less useful. Conversely, the research pages were consistently perceived as top contributors to changes in knowledge, persuasion, and decision.

Previous researchers have suggested that it is the format of research articles that dissuades clinician interest, not the research itself (Pagoto et al., 2007; Stewart et al., 2012). The present research supports this idea. PsySuccess used infographics, a combination of simple text, images, and data visualization to present the most important findings of each study. In the fields of business and communication, consumers have reported finding infographics more effective than commercials, presentations, articles, and blogs when it comes to understanding and retaining information (Carter, Dehart, Gaskin, \& Golben, 2017). It is possible that while clinicians appreciate and respect research findings, they do not have the time or mental resources to stay up to date on the literature. Presenting research in a summary format which maximizes 
understandability and knowledge retention may be key to reducing the practice-research gap in psychology. Future studies might directly compare different ways of presenting research (e.g., public significance statements, infographics, short videos, etc.) in order to determine the formats which can best facilitate dissemination.

The final disconnect was between the perceptions of our participants and the findings of the Innovation-Decision scale. While anecdotal and practical material were identified as significant dissemination strategies by the Innovation-Decision scale, clinicians perceived otherwise. This contradiction may not be statistically significant, as analyses on the clinician perception data were only descriptive. However, it is worth considering that clinicians may lack of awareness of what impacts their learning, attitudes, and decision making. While both methods of inquiry utilized self-report, the Innovation-Decision scale is rooted in theory and has psychometric support. While self-assessments of knowledge are moderately correlated to cognitive learning, they are largely correlated to how a learner feels about a learning program (Sitzmann, Ely, Brown, \& Bauer, 2010). Thus, the perception that clinicians became more knowledgeable from PsySuccess may be more reflective a positive experience with the intervention. What this disconnect implies is that we may not be able to rely entirely on clinician self-report when it comes to studying dissemination. The dissemination in psychotherapy literature currently relies heavily on qualitative and survey data. Alternative study designs are required to validate the current state of the literature. While the present research takes the first steps, utilizing a theory-based scale to observe pre- and post-intervention impact, future research should consider higher quality study designs (e.g., randomized controlled trials) and a variety of outcome measures (e.g., measures of cognitive learning, implementation data, etc.) to determine the impact of dissemination strategies with more confidence. 


\section{Limitations}

The studies in this thesis have several limitations. The first limitation concerns generalizability. The strategies that are effective for PM dissemination will not necessarily be effective for other psychotherapy innovations. The strategies tested on PsySuccess were those that emerged in the psychotherapy practice literature. An implicit assumption of this kind of study design is that the strategies will have the same impact regardless of the innovation being disseminated. While this research has implications for other evidence-based innovations, generalizability cannot be assumed. The impact of each strategy on individual innovations should be empirically validated.

Small sample sizes were a limitation throughout the research. Participation was not high enough to have full confidence in the validation of the Innovation-Decision scale and in the evaluation of effective strategies on PsySucces. Future research is needed to explore how to engage clinicians so dissemination can be studied with more confidence.

Another limitation of this thesis was its reliance on the Innovation-Decision scale. The scale was developed in response to a lack of instruments for assessing dissemination that are rooted in theory (Martinez et al., 2014). Having framed Manuscript 1 in Rogers' (2003) Innovation-Decision process, we sought to develop a scale based on this model. However, other relevant scales were identified as potentially useful (e.g., the Evidence-Based Practice Attitudes Scale (EBPAS) (Aarons, 2004), the Monitoring and Feedback Attitudes Scale (MFA), and the Attitudes Toward Standardized Assessment Scales - Monitoring and Feedback (ASA-MFA) (Jensen-Doss et al., 2016)). These scales assess attitudes towards EBP or PM and could have been used to measure clinicians' change in attitudes towards PM before and after using PsySucces. These scales were rejected, however, to prioritize having a scale more representative 
of Rogers' (2003) theory; that is, a scale that could assess learning and decision making in addition to attitudes. In hindsight, using one or multiple of these scales as an adjunct may have been useful. While these scales and the Innovation-Decision scale do not cover the same domains, a thorough comparison of the psychometrics, pros, and cons of each measure may have permitted a more psychometrically sound assessment of PsySuccess or more confidence in our use of the Innovation-Decision scale.

Finally, all three studies were rooted in Rogers' (2003) Innovation-Decision process. While the purpose of this was to further implementation science by building on previous research and theory, it is possible that this theory does not hold entirely when it comes to dissemination in psychotherapy. While the research in this thesis begins to validate the Innovation-Decision process in psychotherapy, it is limited to the earlier stages. Understanding implementation and confirmation will be necessary to obtain a comprehensive picture of dissemination in psychotherapy.

\section{Final Conclusion and Summary}

This research directly disseminated PM in a novel way and developed several recommendations for closing the practice-research gap. Firstly, engagement needs to be considered a necessary and challenging component of dissemination. While clinicians have identified time as an important barrier to engagement, they do not appear to recognize how online learning programs may be especially time efficient. Developers of dissemination programs should explore and employ effective ways of communicating the benefits of online learning to clinicians.

Once engaged, particular dissemination strategies may be especially effective at different times. The stage of diffusion should be considered to specialize dissemination interventions, 
improving the efficiency of knowledge translation efforts. Toolkits are a kind of dissemination intervention which bundle together a variety of learning materials (Barac et al., 2014). They permit users to learn about the specific subjects they are interested in, in a format they choose. One way to consider the stage of dissemination may be to preface toolkits with an assessment instrument such as the Innovation-Decision scale. Once a clinician's "stage" has been identified, the tool can suggest or direct clinicians towards the resources that may be particularly useful for them at that moment in time. This may be particularly important at the stage of PersuasionDecision, as clinicians appear to be less motivated when it comes to changing their attitudes. While practical material is a frequently suggested strategy in the literature, coupling it with opportunities for experience or embedding it into research may be important for improving knowledge. If provided alone, practical material addressing issues particularly important to clinicians (e.g., cost, technology) may be more useful. Research is probably an effective dissemination tool when presented in a succinct and digestible format. Despite perceptions that it was less impactful, anecdotal information may be effective resource when it comes to improving clinician attitudes towards and intent to use PM. The disconnection between clinician perceptions and the findings of the Innovation-Decision scale may reflect a lack of clinician awareness regarding what impacts dissemination. It may also reflect a problem with self-report data. While this research enriches the psychotherapy dissemination literature with a broader range of evidence, alternative study designs could advance the state of field.

Overall, this thesis enhances the current understanding of dissemination in psychotherapy. The findings of this research can be used to bridge the practice-research gap and improve the overall efficacy of psychotherapy. 


\section{References}

Aarons, G. A. (2004). Mental health provider attitudes toward adoption of evidence-based practice: the Evidence-Based Practice Attitude Scale (EBPAS). Ment Health Serv Res, 6(2), 61-74. doi:10.1023/b:mhsr.0000024351.12294.65

Alicke, M. D. (1985). Global self-evaluation as determined by the desirability and controllability of trait adjectives. Journal of Personality and Social Psychology, 49(6), 1621-1630. doi:10.1037/0022-3514.49.6.1621

Alves, P. C., Sales, C. M., \& Ashworth, M. (2016). "It is not just about the alcohol": service users' views about individualised and standardised clinical assessment in a therapeutic community for alcohol dependence. Subst Abuse Treat Prev Policy, 11(1), 25. doi:10.1186/s13011-016-0070-5

Anker, M. G., Duncan, B. L., \& Sparks, J. A. (2009). Using client feedback to improve couple therapy outcomes: a randomized clinical trial in a naturalistic setting. $J$ Consult Clin Psychol, 77(4), 693-704. doi:10.1037/a0016062

Aoun, S., Pennebaker, D., \& Janca, A. (2002). Outcome measurement in rural mental health care: a field trial of rooming-in models. Aust J Rural Health, 10(6), 302-307. doi:10.1046/j.1440-1584.2002.00484.x

Baker, R., Camosso-Stefinovic, J., Gillies, C., Shaw, E. J., Cheater, F., Flottorp, S., \& Robertson, N. (2010). Tailored interventions to overcome identified barriers to change: effects on professional practice and health care outcomes. Cochrane Database Syst Rev(3), CD005470. doi:10.1002/14651858.CD005470.pub2 
Barac, R., Stein, S., Bruce, B., \& Barwick, M. (2014). Scoping review of toolkits as a knowledge translation strategy in health. BMC Med Inform Decis Mak, 14, 121. doi:10.1186/s12911014-0121-7

Beidas, R. S., Edmunds, J. M., Marcus, S. C., \& Kendall, P. C. (2012). Training and consultation to promote implementation of an empirically supported treatment: a randomized trial. Psychiatr Serv, 63(7), 660-665. doi:10.1176/appi.ps.201100401

Beidas, R. S., Koerner, K., Weingardt, K. R., \& Kendall, P. C. (2011). Training research: practical recommendations for maximum impact. Adm Policy Ment Health, 38(4), 223237. doi:10.1007/s10488-011-0338-Z

Bennett-Levy, J., \& Padesky, C. A. (2014). Use it or lose it: Post-workshop reflection ehnaces learning and utilization of CBT skills. Cognitive and Behavioral Practice, 21, 12-19. doi:https://doi.org/10.1016/j.cbpra.2013.05.001

Bergman, H., Kornør, H., Nikolakopoulou, A., Hanssen-Bauer, K., Soares-Weiser, K., Tollefsen, T. K., \& Bjørndal, A. (2018). Client feedback in psychological therapy for children and adolescents with mental health problems. Cochrane Database of Systematic Reviews(8).

Beutler, L. E., Williams, R. E., Wakefield, P. J., \& Entwistle, S. R. (1995). Bridging scientist and practitioner perspectives in clinical psychology. Am Psychol, 50(12), 984-994. doi:https://doi.org/10.1037/0003-066X.50.12.984

Bickman, L., Douglas, S. R., De Andrade, A. R., Tomlinson, M., Gleacher, A., Olin, S., \& Hoagwood, K. (2016). Implementing a Measurement Feedback System: A Tale of Two Sites. Adm Policy Ment Health, 43(3), 410-425. doi:10.1007/s10488-015-0647-8 
Bickman, L., Kelley, S. D., Breda, C., de Andrade, A. R., \& Riemer, M. (2011). Effects of routine feedback to clinicians on mental health outcomes of youths: results of a randomized trial. Psychiatr Serv, 62(12), 1423-1429. doi:10.1176/appi.ps.002052011

Borgida, E., \& Nisbett, R. E. (1977). The differential impact of abstract vs. concrete information on decisions. Journal of Applied Social Psychology, 7(3), 258-271.

Borntrager, C. F., Chorpita, B. F., Higa-McMillan, C., \& Weisz, J. R. (2009). Provider attitudes toward evidence-based practices: are the concerns with the evidence or with the manuals? Psychiatr Serv, 60(5), 677-681. doi:10.1176/appi.ps.60.5.677

Boswell, J. F. (2019). Monitoring processes and outcomes in routine clinical practice: A promising approach to plugging the holes of the practice-based evidence colander. Psychother Res, 1-14. doi:10.1080/10503307.2019.1686192

Brattland, H., Koksvik, J. M., Burkeland, O., Grawe, R. W., Klockner, C., Linaker, O. M., . . . Iversen, V. C. (2018). The effects of routine outcome monitoring (ROM) on therapy outcomes in the course of an implementation process: A randomized clinical trial. $J$ Couns Psychol, 65(5), 641-652. doi:10.1037/cou0000286

Brattland, H., Koksvik, J. M., Burkeland, O., Klockner, C. A., Lara-Cabrera, M. L., Miller, S. D., ... Iversen, V. C. (2019). Does the working alliance mediate the effect of routine outcome monitoring (ROM) and alliance feedback on psychotherapy outcomes? A secondary analysis from a randomized clinical trial. J Couns Psychol, 66(2), 234-246. doi: $10.1037 /$ cou0000320

Browne, M. W., \& Cudeck, R. (1993). Alternative ways of assessing model fit. Sage focus editions, 154, 136-136. doi:https://doi.org/10.1177/0049124192021002005 
Callaly, T., \& Hallebone, E. L. (2001). Introducing the routine use of outcomes measurement to mental health services. Aust Health Rev, 24(1), 43-50. Retrieved from https://www.ncbi.nlm.nih.gov/pubmed/11357741

Callaly, T., Hyland, M., Coombs, T., \& Trauer, T. (2006). Routine outcome measurement in public mental health: results of a clinician survey. Aust Health Rev, 30(2), 164-173. Retrieved from https://www.ncbi.nlm.nih.gov/pubmed/16646765

Carter, L., Dehart, M., Gaskin, J., \& Golben, L. (2017). The State of Infographics. In I. M.-C. Marketing (Ed.).

Castonguay, L. G., Boswell, J. F., Zack, S. E., Baker, S., Boutselis, M. A., Chiswick, N. R., . . Holtforth, M. G. (2010). Helpful and hindering events in psychotherapy: a practice research network study. Psychotherapy (Chic), 47(3), 327-344. doi:10.1037/a0021164

Castonguay, L. G., Pincus, A. L., \& McAleavey, A. A. (2015). Practice research network in a psychology training clinic: building an infrastructure to foster early attachment to the scientific-practitioner model. Psychother Res, 25(1), 52-66. doi:10.1080/10503307.2013.856045

Cohen, L. H., Sargent, M. M., \& Sechrest, L. B. (1986). Use of psychotherapy research by professional psychologists. Am Psychol, 41(2), 198-206. Retrieved from http://www.ncbi.nlm.nih.gov/pubmed/3963613

Connolly Gibbons, M. B., Kurtz, J. E., Thompson, D. L., Mack, R. A., Lee, J. K., Rothbard, A., . .. Crits-Christoph, P. (2015). The effectiveness of clinician feedback in the treatment of depression in the community mental health system. J Consult Clin Psychol, 83(4), 748759. doi: $10.1037 / \mathrm{a} 0039302$ 
Cook, J. M., Biyanova, T., \& Coyne, J. C. (2009). Barriers to adoption of new treatments: an internet study of practicing community psychotherapists. Adm Policy Ment Health, 36(2), 83-90. doi:10.1007/s10488-008-0198-3

Cook, J. M., Schnurr, P. P., Biyanova, T., \& Coyne, J. C. (2009). Apples don't fall far from the tree: influences on psychotherapists' adoption and sustained use of new therapies. Psychiatr Serv, 60(5), 671-676. doi:10.1176/appi.ps.60.5.671

Costello, A. B., \& Osborne, J. W. (2005). Best practices in exploratory factor analysis: Four recommendations for getting the most from your analysis. Practical Assessment, Research, \& Evaluation, 10(7). doi: https://doi.org/10.7275/jyj1-4868

Crits-Christoph, P., Ring-Kurtz, S., Hamilton, J. L., Lambert, M. J., Gallop, R., McClure, B., .. . Rotrosen, J. (2012). A preliminary study of the effects of individual patient-level feedback in outpatient substance abuse treatment programs. J Subst Abuse Treat, 42(3), 301-309. doi:10.1016/j.jsat.2011.09.003

Dattilio, F. M. (2006). Does the case study have a future in the psychiatric literature? International Journal of Psychiatry in Clinical Practice, 10(3), 195-203. doi: $10.1080 / 13651500600649895$

Davidsen, A. H., Poulsen, S., Lindschou, J., Winkel, P., Tróndarson, M. F., Waaddegaard, M., \& Lau, M. (2017). Feedback in group psychotherapy for eating disorders: A randomized clinical trial. J Consult Clin Psychol, 85(5), 484. doi:10.1037/ccp0000173

de Jong, K. (2016). Deriving Implementation Strategies for Outcome Monitoring Feedback from Theory, Research and Practice. Adm Policy Ment Health, 43(3), 292-296. doi:10.1007/s10488-014-0589-6 
de Jong, K., Van Sluis, P., Nugter, M. A., Heiser, W. J., \& Spinhoven, P. (2012). Understanding the differential impact of outcome monitoring: Therapist variables that moderate feedback effects in a randomized clinical trial. Psychotherapy Research, 22(4), 464-474. doi:10.1080/10503307.2012.673023

DeAngelis, T. (2010). Closing the gap between practice and research: Two efforts are addressing the reasons practitioners may not always use research findings. 41 .

Dimeff, L. A., Koerner, K., Woodcock, E. A., Beadnell, B., Brown, M. Z., Skutch, J. M., .. . Harned, M. S. (2009). Which training method works best? A randomized controlled trial comparing three methods of training clinicians in dialectical behavior therapy skills. Behav Res Ther, 47(11), 921-930. doi:10.1016/j.brat.2009.07.011

Douglas, S., Button, S., \& Casey, S. E. (2016). Implementing for Sustainability: Promoting Use of a Measurement Feedback System for Innovation and Quality Improvement. Adm Policy Ment Health, 43(3), 286-291. doi:10.1007/s10488-014-0607-8

Duncan, B. (2019). Better Outcomes Now. Retrieved from https://betteroutcomesnow.com/resources/

Duncan, B., Miller, S. D., Sparks, J. A., Claud, D., Reynolds, L., Brown, J., \& Johnson, L. D. (2003). The Session Rating Scale: Preliminary psychometric properties of a "working” alliance measure. Journal of brief Therapy, 3(1), 3-12.

Dyer, K., Hooke, G. R., \& Page, A. C. (2016). Effects of providing domain specific progress monitoring and feedback to therapists and patients on outcome. Psychother Res, 26(3), 297-306. doi:10.1080/10503307.2014.983207

Eccles, M. P., \& Mittman, B. S. (2006). Welcome to Implementation Science. Implementation Science, 1(1). 
Edbrooke-Childs, J., Wolpert, M., \& Deighton, J. (2016). Using Patient Reported Outcome Measures to Improve Service Effectiveness (UPROMISE): Training clinicians to Use Outcome Measures in Child Mental Health. Adm Policy Ment Health, 43(3), 302-308. doi:10.1007/s10488-014-0600-2

Finn, S. E., \& Tonsager, M. E. (1992). Therapeutic effects of providing MMPI-2 test feedback to college students awaiting therapy. Psychol Assess, 4(3), 278. doi:https://doi.org/10.1037/1040-3590.4.3.278

Fornells-Ambrojo, M., Johns, L., Onwumere, J., Garety, P., Milosh, C., Iredale, C., .. . Jolley, S. (2017). Experiences of outcome monitoring in service users with psychosis: Findings from an Improving Access to Psychological Therapies for people with Severe Mental Illness (IAPT-SMI) demonstration site. Br J Clin Psychol, 56(3), 253-272. doi:10.1111/bjc. 12136

Gleacher, A. A., Olin, S. S., Nadeem, E., Pollock, M., Ringle, V., Bickman, L., .. . Hoagwood, K. (2016). Implementing a Measurement Feedback System in Community Mental Health Clinics: A Case Study of Multilevel Barriers and Facilitators. Adm Policy Ment Health, 43(3), 426-440. doi:10.1007/s10488-015-0642-0

Goldberg, S. B., Rousmaniere, T., Miller, S. D., Whipple, J., Nielsen, S. L., Hoyt, W. T., \& Wampold, B. E. (2016). Do psychotherapists improve with time and experience? A longitudinal analysis of outcomes in a clinical setting. J Couns Psychol, 63(1), 1-11. doi:10.1037/cou0000131

Gondek, D., Edbrooke-Childs, J., Fink, E., Deighton, J., \& Wolpert, M. (2016). Feedback from Outcome Measures and Treatment Effectiveness, Treatment Efficiency, and 
Collaborative Practice: A Systematic Review. Adm Policy Ment Health, 43(3), 325-343. doi:10.1007/s 10488-015-0710-5

Goodman, J. D., McKay, J. R., \& DePhilippis, D. (2013). Progress Monitoring in mental health and addiction treatment: A means of improving care. Professional Psychology: Research and Practice, 44(4). doi:10.1037/a0032605

Graham, I. D., Logan, J., Harrison, M. B., Straus, S. E., Tetroe, J., Caswell, W., \& Robinson, N. (2006). Lost in knowledge translation: time for a map? J Contin Educ Health Prof, 26(1), 13-24. doi:10.1002/chp.47

Green, B. N., Johnson, C. D., \& Adams, A. (2006). Writing narrative literature reviews for peerreviewed journals: secrets of the trade. Journal of chiropractic medicine, 5(3), 101-117. doi: 10.1016/S0899-3467(07)60142-6

Gyani, A., Shafran, R., Rose, S., \& Lee, M. J. (2013). A Qualitative Investigation of Therapists' Attitudes towards Research: Horses for Courses? Behavioural Cognitive Psychotherapy, 43(4), 436-448. doi:10.1017/S1352465813001069

Hall, C. L., Moldavsky, M., Taylor, J., Sayal, K., Marriott, M., Batty, M. J., .. . Hollis, C. (2014). Implementation of routine outcome measurement in child and adolescent mental health services in the United Kingdom: a critical perspective. Eur Child Adolesc Psychiatry, 23(4), 239-242. doi:10.1007/s00787-013-0454-2

Hall, C. L., Taylor, J., Moldavsky, M., Marriott, M., Pass, S., Newell, K., . . Hollis, C. (2014). A qualitative process evaluation of electronic session-by-session outcome measurement in child and adolescent mental health services. BMC Psychiatry, 14, 113. doi:10.1186/1471-244X-14-113 
Hannan, C., Lambert, M. J., Harmon, C., Nielsen, S. L., Smart, D. W., Shimokawa, K., \& Sutton, S. W. (2005). A lab test and algorithms for identifying clients at risk for treatment failure. J Clin Psychol, 61(2), 155-163. doi:10.1002/jclp.20108

Hansen, N. B., Lambert, M. J., \& Forman, E. M. (2002). The psychotherapy dose-response effect and its implications for treatment delivery services. Clinical Psychology: Science and Practice. doi:10.1093/clipsy.9.3.329

Harmon, C., Lambert, M. J., Smart, D. W., Hawkins, E., Nielsen, S. L., Slade, K., \& Lutz, W. (2007). Enhancing outcome for potential treatment failures: Therapist-client feedback and clinical support tools. Psychotherapy Research, 17(4), 379-392. doi:10.1080/10503300600702331

Hatfield, D. R., \& Ogles, B. M. (2004). The use of outcome measures by psychologists in clinical practice. Professional Psychology: Research and Practice, 35, 485-491. doi:10.1037/0735-7028.35.5.485

Henderson, J. L., MacKay, S., \& Peterson-Badali, M. (2006). Closing the research-practice gap: factors affecting adoption and implementation of a children's mental health program. $J$ Clin Child Adolesc Psychol, 35(1), 2-12. doi:10.1207/s15374424jccp3501_1

Herschell, A. D., Kolko, D. J., Baumann, B. L., \& Davis, A. C. (2010). The role of therapist training in the implementation of psychosocial treatments: a review and critique with recommendations. Clin Psychol Rev, 30(4), 448-466. doi:10.1016/j.cpr.2010.02.005

Hu, L. t., \& Bentler, P. M. (1999). Cutoff criteria for fit indexes in covariance structure analysis: Conventional criteria versus new alternatives. Structural equation modeling: a multidisciplinary journal, 6(1), 1-55. doi:https://doi.org/10.1080/10705519909540118 
Hunsley, J., Elliott, K., \& Therrien, Z. (2014). The efficacy and effectiveness of psychological treatments for mood, anxiety, and related disorders. Canadian Psychology/Psychologie canadienne, 55(3), 161-176. doi:10.1037/a0036933

Hunsley, J., Ronson, A., \& Cohen, K. R. (2013). Professional psychology in Canada: A survey of demographic and practice characteristics. Professional Psychology: Research and Practice, 44(2), 118-126. doi:10.1037/a0029672

Ionita, G. (2015). Moving research into clinical practice: Usage of Progress Monitoring measures. Doctoral Dissertation. Educational and Counseling Psychology. McGill University.

Ionita, G., \& Fitzpatrick, M. (2014). Bringing science to clinical practice: A Canadian survey of psychologists practice and usage of progress monitoring measures. Canadian Psychology, 55(3), 187-196. doi:10.1037/a0037355

Ionita, G., Fitzpatrick, M., Tomaro, J., Chen, V. V., \& Overington, L. (2016). Challenges of using progress monitoring measures: Insights from practicing clinicians. $J$ Couns Psychol, 63(2), 173-182. doi:10.1037/cou0000122

Jensen-Doss, A., Haimes, E. M., Smith, A. M., Lyon, A. R., Lewis, C. C., Stanick, C. F., \& Hawley, K. M. (2016). Monitoring Treatment Progress and Providing Feedback is Viewed Favorably but Rarely Used in Practice. Adm Policy Ment Health. doi:10.1007/s10488-016-0763-0

Jones, D. J., Forehand, R., Cuellar, J., Parent, J., Honeycutt, A., Khavjou, O., . . Newey, G. A. (2014). Technology-enhanced program for child disruptive behavior disorders: development and pilot randomized control trial. J Clin Child Adolesc Psychol, 43(1), 88101. doi:10.1080/15374416.2013.822308 
Kahneman, D. (2013). Thinking fast and slow: Farrar, Straus and Giroux.

Kazdin, A. E. (2008). Evidence-based treatment and practice: new opportunities to bridge clinical research and practice, enhance the knowledge base, and improve patient care. American Psychologist, 63(3), 146-159. doi:10.1037/0003-066X.63.3.146

Kendrick, T., El-Gohary, M., Stuart, B., Gilbody, S., Churchill, R., Aiken, L., . . . de Jong, K. (2016). Routine use of patient reported outcome measures (PROMs) for improving treatment of common mental health disorders in adults. Cochrane Database of Systematic Reviews(7). doi: 10.1002/14651858.CD011119.pub2

Kilbride, M., Byrne, R., Price, J., Wood, L., Barratt, S., Welford, M., \& Morrison, A. P. (2013). Exploring service users' perceptions of cognitive behavioural therapy for psychosis: a user led study. Behav Cogn Psychother, 41(1), 89-102. doi:10.1017/S1352465812000495

Knaup, C., Koesters, M., Schoefer, D., Becker, T., \& Puschner, B. (2009). Effect of feedback of treatment outcome in specialist mental healthcare: meta-analysis. The British Journal of Psychiatry, 195(1), 15-22. doi: 10.1192/bjp.bp.108.053967

Knoll, M., \& Fitzpatrick, M. (in press). Dissemination of evidence-based practices in psychotherapy. Canadian Psychology.

Knoll, M., Fitzpatrick, M., \& Konishi, C. (2018). Closing the practice-research gap: Development of the Innovation-Decision scale. Manuscript submitted for publication.

Knoll, M., Ionita, G., Tomaro, J., Chen, V., \& Fitzpatrick, M. (2016). Progress Monitoring measures: The interaction of clinician initial motivation and maintenance issues. Psychology, 7(3). doi:http://dx.doi.org/10.4236/psych.2016.73046

Knowledge Translation. (July 28, 2016). Retrieved from http://www.cihr-irsc.gc.ca/e/29418.html 
Knowledge translation and commercialization. (2016). Retrieved from http://www.cihrirsc.gc.ca/e/29418.html

Kopta, M., Owen, J., \& Budge, S. (2015). Measuring psychotherapy outcomes with the Behavioral Health Measure-20: Efficient and comprehensive. Psychotherapy (Chic), 52(4), 442-448. doi:10.1037/pst0000035

Krägeloh, C. U., Czuba, K. J., Billington, D. R., Kersten, P., \& Siegert, R. J. (2015). Using feedback from patient-reported outcome measures in mental health services: a scoping study and typology. Psychiatric Services, 66(3), 224-241. doi:10.1176/appi.ps.201400141

Kruger, J., \& Dunning, D. (1999). Unskilled and unaware of it: How difficulties in recognizing one's own incompetence lead to inflated self-assessments. Journal of Personality and Social Psychology, 77(6), 1121-1134. doi:10.1037/0022-3514.77.6.1121

Lambert, M. J., Harmon, C., Slade, K., Whipple, J. L., \& Hawkins, E. J. (2005). Providing feedback to psychotherapists on their patients' progress clinical results and practice suggestions. J Clin Psychol, 61(165-174). doi:10.1002/jclp.20113

Lambert, M. J., \& Harmon, K. L. (2018). The merits of implementing routine outcome monitoring in clinical practice. Clinical psychology Science and Practice, 25. doi:10.1111/cpsp.12268

Lambert, M. J., \& Ogles, B. M. (2004). The efficacy and effectiveness of psychotherapy. New York, NY: Wiley.

Lambert, M. J., \& Shimokawa, K. (2011). Collecting client feedback. Psychotherapy (Chic), 48(1), 72-79. doi:10.1037/a0022238 
Lambert, M. J., Whipple, J. L., \& Kleinstauber, M. (2018). Collecting and delivering progress feedback: A meta-analysis of routine outcome monitoring. Psychotherapy (Chic), 55(4), 520-537. doi:10.1037/pst0000167

Lambert, M. J., Whipple, J. L., \& Kleinstäuber, M. (2018). Collecting and delivering progress feedback: A meta-analysis of routine outcome monitoring. Psychotherapy (Chic), 55(4), 520-537. doi:10.1037/pst0000167

Lambert, M. J., Whipple, J. L., Smart, D. W., Vermeersch, D. A., Nielsen, S. L., \& Hawkins, E. J. (2001). The effects of providing therapists with feedback on patient progress during psychotherapy: Are outcomes enhanced? Psychotherapy Research, 11, 153-166. doi:10.1080/713663852

Larson, M. J., Amodeo, M., Storti, S. A., Steketee, G., Blitzman, G., \& Smith, L. (2009). A novel CBT Web course for the substance abuse workforce: community counselors' perceptions. Subst Abus, 30(1), 26-39. doi:10.1080/08897070802611741

Lerner, J. S., Li, Y., Valdesolo, P., \& Kassam, K. S. (2015). Emotion and decision making. Annu Rev Psychol, 66, 799-823. doi:10.1146/annurev-psych-010213-115043

Lewis, C. C., Boyd, M., Puspitasari, A., Navarro, E., Howard, J., Kassab, H., . . Douglas, S. (2019). Implementing Measurement-Based Care in Behavioral Health: A Review. JAMA psychiatry, 76(3), 324-335. doi:10.1001/jamapsychiatry.2018.3329

Loewenstein, G. F., Weber, E. U., Hsee, C. K., \& Welch, N. (2001). Risk as feelings. Psychol Bull, 127(2), 267-286. doi:10.1037/0033-2909.127.2.267

Macdonald, J., \& Mellor-Clark, J. (2015). Correcting psychotherapists' blindsidedness: Formal feedback as a means of overcoming the natural limitations of therapists. Clin Psychol Psychother, 22(3), 249-257. doi:10.1002/cpp.1887 
Martinez, R. G., Lewis, C. C., \& Weiner, B. J. (2014). Instrumentation issues in implementation science. Implement Sci, 9, 118. doi:10.1186/s13012-014-0118-8

McDonough, M., \& Marks, I. M. (2002). Teaching medical students exposure therapy for phobia/panic - randomized, controlled comparison of face-to-face tutorial in small groups vs. solo computer instruction. Med Educ, 36(5), 412-417. Retrieved from http://www.ncbi.nlm.nih.gov/pubmed/12028390

McMillan, D. J., McConnell, B., \& O’Sullivan, H. (2016). Continuing professional development-why bother? Perceptions and motivations of teachers in Ireland. Professional development in education, 42(1), 150-167. doi:https://doi.org/10.1080/19415257.2014.952044

Morrow-Bradley, C., \& Elliott, R. (1986). Utilization of psychotherapy research by practicing psychotherapists. Am Psychol, 41(2), 188-197. Retrieved from http://www.ncbi.nlm.nih.gov/pubmed/3963612

Mours, J. M., Campbell, K. A., \& Peterson, M. (2009). Training in the use of psychotherapy outcome assessment measures at psychology internship sites. Training and Education in Professional Psychology, 3(3), 169-176. doi:10.1037/a0016135

Mundfrom, D. J., Shaw, D. G., \& Ke, T. L. (2005). Minimum sample size recommendations for conducting factor analyses. International Journal of Testing, 5(2), 159-168. doi:https://doi.org/10.1207/s15327574ijt0502_ 4

Murphy, C., Cross, C., \& McGuire, D. (2006). The motivation of nurses to participate in continuing professional education in Ireland. Journal of European Industrial Training, 30(5), 365-384. doi:https://doi.org/10.1108/03090590610677926 
Nelson, T. D., \& Steele, R. G. (2007). Predictors of practitioner self-reported use of evidencebased practices: practitioner training, clinical setting, and attitudes toward research. $A d m$ Policy Ment Health, 34(4), 319-330. doi:10.1007/s10488-006-0111-x

Newnham, E. A., Hooke, G. R., \& Page, A. C. (2010). Progress monitoring and feedback in psychiatric care reduces depressive symptoms. J Affect Disord, 127(1-3), 139-146. doi:10.1016/j.jad.2010.05.003

Nissen-Lie, H. A., Havik, O. E., Hoglend, P. A., Monsen, J. T., \& Ronnestad, M. H. (2013). The contribution of the quality of therapists' personal lives to the development of the working alliance. J Couns Psychol, 60(4), 483-495. doi:10.1037/a0033643

Nissen-Lie, H. A., Ronnestad, M. H., Hoglend, P. A., Havik, O. E., Solbakken, O. A., Stiles, T. C., \& Monsen, J. T. (2017). Love Yourself as a Person, Doubt Yourself as a Therapist? Clin Psychol Psychother, 24(1), 48-60. doi:10.1002/cpp.1977

Nunnally, J. C. (1994). Psychometric theory 3E: Tata McGraw-Hill Education.

Omer, S., Golden, E., \& Priebe, S. (2016). Exploring the Mechanisms of a Patient-Centred Assessment with a Solution Focused Approach (DIALOG+) in the Community Treatment of Patients with Psychosis: A Process Evaluation within a Cluster-Randomised Controlled Trial. PLoS One, 11(2), e0148415. doi:10.1371/journal.pone.0148415

Osborne, J. W., Costello, A. B., \& Kellow, J. T. (2008). Best practices in exploratory factor analysis. In Best practices in quantitative methods (pp. 86-99).

Overington, L., Fitzpatrick, M., Hunsley, J., \& Drapeau, M. (2016). Perspectives of internship training directors on the use of progress monitoring measures. Canadian Psychology, 57(2), 120-129. doi:10.1037/cap0000051 
Pagoto, S. L., Spring, B., Coups, E. J., Mulvaney, S., Coutu, M. F., \& Ozakinci, G. (2007). Barriers and facilitators of evidence-based practice perceived by behavioral science health professionals. J Clin Psychol, 63(7), 695-705. doi:10.1002/jclp.20376

Perry, T., Barkham, M., \& Evans, C. (2013). The CORE-OM and CORE-OM (SV) in secure settings: A template analysis of the experiences of male pratients and their staff. Journal of Forensic Practice, 15(1), 32-43. doi:10.1108/14636641311299068

Persons, J. B., Koerner, K., Eidelman, P., Thomas, C., \& Liu, H. (2016). Increasing psychotherapists' adoption and implementation of the evidence-based practice of progress monitoring. Behav Res Ther, 76, 24-31. doi:10.1016/j.brat.2015.11.004

Pett, M. A., Lackey, N. R., \& Sullivan, J. J. (2003). Making sense of factor analysis: The use of factor analysis for instrument development in health care research: Sage.

Powell, B. J., Hausmann-Stabile, C., \& McMillen, J. C. (2013). Mental health clinicians' experiences of implementing evidence-based treatments. J Evid Based Soc Work, 10(5), 396-409. doi:10.1080/15433714.2012.664062

Practice, A. P. A. P. T. F. o. E.-B. (2006). Evidence-based practice in psychology. Am Psychol, 61(4), 271-285. doi:10.1037/0003-066X.61.4.271

Practice guidelines for providers of psychological services. (2001). Retrieved from https://cpa.ca/cpasite/UserFiles/Documents/publications/Practice\%20Guidelines2001(2). pdf

Puspitasari, A., Kanter, J. W., Murphy, J., Crowe, A., \& Koerner, K. (2013). Developing an online, modular, active learning training program for behavioral activation. Psychotherapy (Chic), 50(2), 256-265. doi:10.1037/a0030058 
Rabin, B., Cameron, W. C., Henton, M., Tabak, R., Mitchell, S., Brownson, R., \& Glasgow, R. (2016). Dissemination and implementation modes in health research and practice. Retrieved from https://dissemination-implementation.org/

Rakovshik, S. G., McManus, F., Westbrook, D., Kholmogorova, A. B., Garanian, N. G., Zvereva, N. V., \& Ougrin, D. (2013). Randomized trial comparing Internet-based training in cognitive behavioural therapy theory, assessment and formulation to delayed-training control. Behav Res Ther, 51(6), 231-239. doi:10.1016/j.brat.2013.01.009

Raubenheimer, J. (2004). An item selection procedure to maximise scale reliability and validity. SA Journal of Industrial Psychology, 30(59-64). doi:10.4102/sajip.v30i4.168

Reese, R. J., Norsworthy, L. A., \& Rowlands, S. R. (2009). Does a continuous feedback system improve psychotherapy outcome? Psychotherapy (Chic), 46(4), 418-431. doi:10.1037/a0017901

Reese, R. J., Toland, M. D., Slone, N. C., \& Norsworthy, L. A. (2010). Effect of client feedback on couple psychotherapy outcomes. Psychotherapy (Chic), 47(4), 616-630. doi:10.1037/a0021182

Reese, R. J., Usher, E. L., Bowman, D. C., Norsworthy, L. A., Halstead, J. L., Rowlands, S. R., \& Chisholm, A. S. (2009). Using client feedback in psychotherapy training: An analysis of its influence of supervision and counselor self-efficacy. Training and Education in Professional Psychology, 3(3), 157-168. doi:http://psycnet.apa.org/doi/10.1037/a0015673

Riemer, M., Rosof-Williams, J., \& Bickman, L. (2005). Theories related to changing clinician practice. Child and Adolescent Psychiatric Clinics, 14(2), 241-254. doi: 10.1016/j.chc.2004.05.002

Rogers, E. M. (2003). Diffusion of Innovations (5 ed.). New York: Free Press. 
Sapyta, J., Riemer, M., \& Bickman, L. (2005). Feedback to clinicians: theory, research, and practice. J Clin Psychol, 61(2), 145-153. doi:10.1002/jclp.20107

Schreiber, J. B., Amaury, N., Stage, F. S., Barlow, E. A., \& King, J. (2006). Reporting structural equasion modeling and confirmatory factor analysis: A review. The journal of Educational Research, 99(6), 323-338. doi:10.3200/ JOER.99.6.323-338

Schuman, D. L., Slone, N. C., Reese, R. J., \& Duncan, B. (2015). Efficacy of client feedback in group psychotherapy with soldiers referred for substance abuse treatment. Psychother Res, 25(4), 396-407. doi:10.1080/10503307.2014.900875

Shimokawa, K., Lambert, M. J., \& Smart, D. W. (2010). Enhancing treatment outcome of patients at risk of treatment failure: meta-analytic and mega-analytic review of a psychotherapy quality assurance system. J Consult Clin Psychol, 78(3), 298-311. doi:10.1037/a0019247

Simon, W., Lambert, M. J., Busath, G., Vazquez, A., Berkeljon, A., Hyer, K., . . Berrett, M. (2013). Effects of providing patient progress feedback and clinical support tools to psychotherapists in an inpatient eating disorders treatment program: a randomized controlled study. Psychother Res, 23(3), 287-300. doi:10.1080/10503307.2013.787497

Simons, A. D., Padesky, C. A., Montemarano, J., Lewis, C. C., Murakami, J., Lamb, K., .. . Beck, A. T. (2010). Training and dissemination of cognitive behavior therapy for depression in adults: a preliminary examination of therapist competence and client outcomes. J Consult Clin Psychol, 78(5), 751-756. doi:10.1037/a0020569

Sitzmann, T., Ely, K., Brown, K. G., \& Bauer, K. N. (2010). Self-assessment of knowledge: A cognitive learning or affective measure? Academy of Management Learning \& Education, 9(2), 169-191. doi:https://doi.org/10.5465/amle.9.2.zqr169 
Slone, N. C., Reese, R. J., Mathews-Duvall, S., \& Kodet, J. (2015). Evaluating the efficacy of client feedback in group psychotherapy. Group Dynamics: Theory, Research, and Practice, 19(2), 122-136. doi:http://dx.doi.org/10.1037/gdn0000026

Solstad, S. M., Castonguay, L. G., \& Moltu, C. (2017). Patients' experiences with routine outcome monitoring and clinical feedback systems: A systematic review and synthesis of qualitative empirical literature. Psychother Res, 1-14.

doi:10.1080/10503307.2017.1326645

Stedman, T., Yellowlees, P., Drake, S., Chant, D., Clarke, R., \& Chapple, B. (2000). The perceived utility of six selected measures of consumer outcomes proposed for routine use in Australian mental health services. Aust N Z J Psychiatry, 34(5), 842-849. doi:10.1080/j.1440-1614.2000.00803.x

Steinfeld, B., Franklin, A., Mercer, B., Fraynt, R., \& Simon, G. (2016). Progress Monitoring in an Integrated Health Care System: Tracking Behavioral Health Vital Signs. Adm Policy Ment Health, 43(3), 369-378. doi:10.1007/s10488-015-0648-7

Stewart, R. E., \& Chambless, D. L. (2007). Does psychotherapy research inform treatment decisions in private practice? J Clin Psychol, 63(3), 267-281. doi:10.1002/jclp.20347

Stewart, R. E., \& Chambless, D. L. (2009). Interesting practitioners in training in empirically supported treatments: research reviews versus case studies. J Clin Psychol, 66(1), 73-95. doi:10.1002/jclp.20630

Stewart, R. E., Stirman, S. W., \& Chambless, D. L. (2012). A Qualitative Investigation of Practicing Psychologists' Attitudes Toward Research-Informed Practice: Implications for Dissemination Strategies. Prof Psychol Res Pr, 43(2), 100-109. doi:10.1037/a0025694 
Sundet, R. (2014). Patient-focused research supported practices in an intensive family therapy unit. Journal of Family Therapy, 36, 195-216. doi:https://doi.org/10.1111/j.1467$\underline{6427.2012 .00613 . x}$

Swarm Jr, W. B. (1983). Self-verification: Bringing social reality into harmony with the self. Social psychological perspectives on the self, 2, 33-66.

Tabachnick, B. G., Fidell, L. S., \& Ullman, J. B. (2007). Using multivariate statistics (Vol. 5): Pearson Boston, MA.

Tabak, R. G., Khoong, E. C., Chambers, D., \& Brownson, R. C. (2012). Bridging research and practice: Models for dissemination and implementation research. American Journal of Preventative Medicine, 43(3), 337-350. doi:https://doi.org/10.1016/j.amepre.2012.05.024

Tam, H., \& Ronan, K. (2017). The application of a feedback-informed approach in psychological service with youth: Systematic review and meta-analysis. Clin Psychol Rev, 55, 41-55. doi: 10.1016/j.cpr.2017.04.005

Tasca, G. A., Bonli, R., Hunsley, J., Angus, L., Drapeau, M., Fitzpatrick, M., \& Knoll, M. (2019). Outcome and progress monitoring in psychotherapy: Report of a Canadian Psychological Association task force. Canadian Psychology, 60(3), 165-177. doi:https://doi.org/10.1037/cap0000181

Thompson, B. (2004). Exploratory and confirmatory factor analysis: Understanding concepts and applications: American Psychological Association.

Trauer, T., Pedwell, G., \& Gill, L. (2009). The effect of guidance in the use of routine outcome measures in clinical meetings. Aust Health Rev, 33(1), 144-151. Retrieved from https://www.ncbi.nlm.nih.gov/pubmed/19203344 
Tversky, A., \& Kahneman, D. (1971). Belief in the law of small numbers. Psychological Bulletin, 6, 105-110.

Tzur Bitan, D., Zilcha-Mano, S., Ganor, O., Biran, L., \& Bloch, Y. (2018). Routine measurement and feedback in support groups for parents of children with autistic spectrum disorder. Psychotherapy (Chic), 55(2), 191-195. doi:10.1037/pst0000140

Unsworth, G., Cowie, H., \& Green, A. (2012). Therapists' and clients' perceptions of routine outcome measurement in the NHS: A qualitative study. Counselling and Psychotherapy Research, 12(1), 71-80. doi:https://doi.org/10.1080/14733145.2011.565125

Walfish, S., McAlister, B., O'Donnell, P., \& Lambert, M. J. (2012). An investigation of selfassessment bias in mental health providers. Psychol Rep, 110(2), 639-644. doi:10.2466/02.07.17.PR0.110.2.639-644

Wampold, B. E., \& Imel, Z. E. (2001). The Great Psychotherapy Debate: Models, Methods, and Findings. New York, United States: Tayloy \& Francis Inc.

Whipple, J. L., Lambert, M. J., Vermeersch, D. A., Smart, D. W., Nielsen, S. L., \& Hawkins, E. J. (2003). Improving the effects of psychotherapy: The use of early identification of treatment and problem-solving strategies in routine practice. J Couns Psychol, 50, 59-68. doi:10.1037/0022-0167.50.1.59

Willis, A., Deane, F. P., \& Coombs, T. (2009). Improving clinicians' attitudes toward providing feedback on routine outcome assessments. Int J Ment Health Nurs, 18(3), 211-215. doi:10.1111/j.1447-0349.2009.00596.x

Wolpert, M., Curtis-Tyler, K., \& Edbrooke-Childs, J. (2014). A qualitative exploration of patient and clinicians views on patient reported outcome measures in child mental health and diabetes services. Adm Policy Ment Health, 43, 309-315. doi:10.1007/s10488-014-0586-9 
Yong, A. G., \& Pearce, S. (2013). A beginner's guide to factor analysis: Focusing on exploratory factor analysis. Tutorials in Quantitative Methods for Psychology, 8(2), 79-94. doi:10.20982/tqmp.09.2.p079 